University of Rhode Island

DigitalCommons@URI

Open Access Dissertations

1974

\title{
Acute Grief in Adulthood: Toward a Cognitive Model of Normal and Pathological Mourning
}

Allen G. Schor

University of Rhode Island

Follow this and additional works at: https://digitalcommons.uri.edu/oa_diss

\section{Recommended Citation}

Schor, Allen G., "Acute Grief in Adulthood: Toward a Cognitive Model of Normal and Pathological Mourning" (1974). Open Access Dissertations. Paper 1112.

https://digitalcommons.uri.edu/oa_diss/1112

This Dissertation is brought to you for free and open access by DigitalCommons@URI. It has been accepted for inclusion in Open Access Dissertations by an authorized administrator of DigitalCommons@URI. For more information, please contact digitalcommons-group@uri.edu. 


\section{$B_{F 575}$ \\ G 7 \\ 536}

ACUTE GRIEF IN ADULTHOOD, TOWARD A COGNITIVE MODEL OE NORMAL AND PATHOLOGICAL

MOURNING

BY

ALLEN G. SCHOR

A DISSERTATION SUBMITTED IN PARTIAL FURFILLMENT OF THE REQUIREMENTS FOR THE DEGREEE OF DOCTOR OF PHILOSOPHY

IN

PSYCHOLOGY

UNIVERSITY OF RHODE ISLAND

1974 


\section{ABSTRACT}

The 'cognitive model' In this treatise is proposed as an original method of understanding, describing and explaining the acute gxief process and outcome. The model suggests that the primary impact of a sudden death event is upon the survivor's conceptual frame-of-reference. This differs from the traditional psychoanalytic view of mourning which emphasizes the emotional impact as being forencst. Man's typical functioning is assumed to be dependent on the cognitive dimensions or categories by which he comprehends those events which he encounters. These dimensions are postulated as forming a cognitive structural matrix, in which dimensions relating to significant others are central or core elements. The development of such a matrix is believed to result from increased differentiation, organization and integration of the dimensions during growth. This process tends to increase the individual's adaptiveness and effectiveness and, therefore, increases his survival potential.

When the sudden death of a significant other occurs, the matrix is postulated as being traumatically dismpted, since a core dimenston has been unexpectedly damaged by the 1oss. This distuption creates a state of cognitive inadequacy and initiates a process of cognitive regression to less refined and less adequate methods of understanding events. The regression is analyzed in the dissertation, along four principle criteria processes, (a) disjunction (the separation of cognition from affect and conation); (b) modtfication-absorption 
(the openness to change of the dimersions): (c) dilationconstriction (the variations of cogntclve activicy from matrix exparsion to matrix compression, respectively) and (d) subjectivicy-objentivity (the extent to which understanding is channelled through self-reference).

Using changes in these cognitive developmental processes. the influence of cognitive dismption (following a sudien death event) upon cognitive, somatic, affective and behavioral functioning is discussed. The symptomolopy of acute grief that occurs in these spheres is reviewed, and then is described in terms of being postulated derivatives of cognitive dismption. The general syiptom categories discussed include: (a) cogritive confusion, cognitive defenses (deniai, distortion and depersonalization) and pre-occupation with the deceaseds (b) somatic symptoms in respiratory, circulatury, digestive, musculo-skeletal and neurological systems, as well as overall morbidity and mortality effects; (c) affective fear and anxiety, anger and hostility, guilt, depression, and(d) behaviorally, interpersonal changes, activity level changes and searching.

Finally, majo: determinants of healthy versus pathological grief outcome are reviewed, and their effects upon bereavement are explained from the perspective of the cognitive model. Inis is done with particular regard to the determinant's insluence upon cognitive discuption, and the meaning attribution by the survivor to the death event. The determanant factors examined 
Include (a) mode of deach, such as anclcipated death, sudden death, suicide, accident and Sudden Infant Dearh Syndrome; (b) the relationship of survivor to the deceased, such as spouse or parent of the deceased, and(c) characteristics of the survivor, such as age and sex. 
In memorium:

SHERY ADELMAN

August 9, 1958 - December 2, 1973

My niece, who enriched the Iives

of others for 15 years. Not long

enough. We wanted so much more time. 


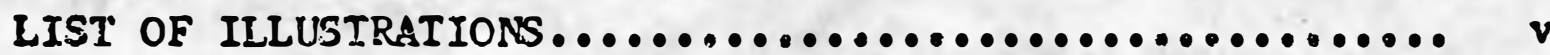

LIST OF TABLES $\ldots \ldots \ldots \ldots \ldots \ldots \ldots \ldots \ldots \ldots \ldots \ldots \ldots \ldots \ldots \ldots \ldots \ldots \ldots \ldots \ldots$ vi

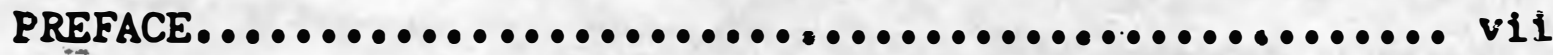

I. INTRODUCTION............................

II. TOWARD A COGNITIVE MODEL OF GRIEF.............. 6

A. The Basic Cognitive Framework................ 6

1. Functional Value of Cognitive Framework... 6

2. Validation............................ 7

3. Invalidation........................ 9

4. Multi-Dimensional Structure........... 10

B. Development of the Cognitive Matrix........... 14

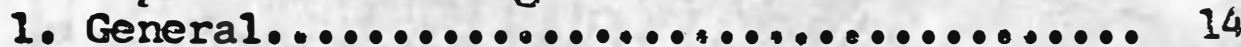

2. Survival and Adavtation............... IS

3. Actively Cognizing Events.............. 17

4. Stages of Cognitive Development.......... 18

C. Assessment Criteria for Cognitive

Development and Functioning...........

1. Individual Differences..................

2. Cognition. Affection and Conation..........

3. Dis junction .........................

4. Adaptations Absorption - Modification.....

5. Dilation - Constriction .................

6. Subjectivity - Objectivity..............

D. The Importance of Core Relationships .........

1. General ...........................

2. Survival and Adaptivity ................

3. Primacy ............................

4. Quantitative Centrality ................

5. Self Identity .......................

E. Sudden Death as a Dis ruptor of a Core

Cognitive Dimension ..................

1. Steady State ........................

2. Confrontative Cognitive Challenge .........

3. Destructive Cognitive Challenge ...........

4. Suddenness ...........................

5. Death ...........................

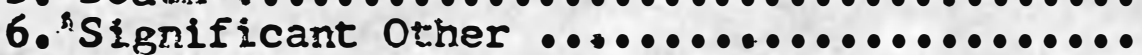

F. The Influence of Cognitive Disruption

on Symptomology ....................

1. Introduction ........................

2. Effect in Cognitive Sphere ..............

a. Cognitive kegression ..............

b. Dis junetion ......................

c. Absorption - Modification ............

d. Dilation - Constriction .............

e. Sub jectivity - Objectivity .........

f. Other Cognitive Changes ............ 
3. Effect in Somatic Spisere ............... 64

4. Effect in hiectivo Sphere ...n........ 67

a. Dis junction ..................... 69

b. Redefinition of Tems $\ldots \ldots \ldots \ldots \ldots \ldots \ldots$ ii

c. Physlological Axozisa1 ............ 75

5. Effect in Behavioral Sphere $\ldots \ldots \ldots \ldots \ldots \ldots \ldots .77$

a. Activity Levels .................. 78

b. Searching $\ldots \ldots \ldots \ldots \ldots \ldots \ldots \ldots \ldots \ldots \ldots$........... 80

6. Concludine Note .................... 80

III. NORMAL AND PATHOLOGICAL SNMPTOMOLOGY OF GRIEF ..... 82

A. Introduction ......................... 82

B. Cognitive Symptomology .................. 85

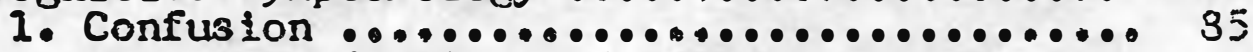

a. Introduction and Literature Review... 85

b. Cognitive Model Explanation

for Normal Confusion ............ 90

c. Cognitive Model Explanation

for Pathological Confusion........ 91

2. Cognitive Defenses .................. 92

a. Denial ............................... 94

1. Introduction and Iiterature

Review.................. 94

11. Cognitive Model Exmlanation

for Normal Denial............ 97

111. Cognitive Model Explanation

for Pathological Lenial ...... 98

b. Distortion..................... 99

1. Introduction and Literature

Review ................. 99

11. Cognitive Model Explanation

for Normal Distortion ....... 103

iii. Cognitive Model Explanation

for Pathological pistortion.: 104

c. Depersonalization ................ 105

1. Introduction anci Literature

Review ............... 105

1i. Cognitive Model Explanation for Normal Depersonalization.. 107

iil. Cognitive Model Explanacion for Pathological

Depersonalization ........... 108

3. Pre-occupation with the Deceased .......... 110

a. Introduction and Literature Review... 110

b. Cognitive Model Explanation

for Normal Pre-occupation

tolth the Deceased.................. 1if

c. Cognitive Model Explanation for

Pathological Pre-occupation

with the Deceased .............. 116 


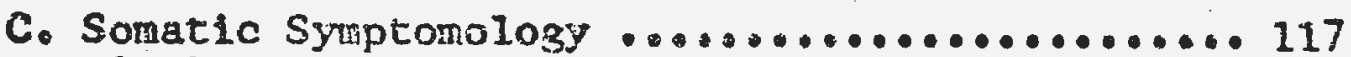

1. Introduction ...................... 117

2. Resplratory Symptons ................. 123

3. Circlatory Sympeoss .................. 125

4. Digestive and Gastro-Intestinal symptoms.. 127

5. Musculo-Skeletal Symptoms ............ 129

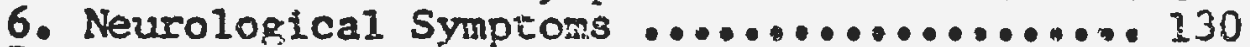

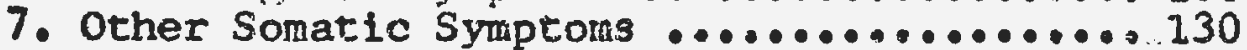

8. General Morbldity and Mortality of

the Bereaved ...................... 133

D. Affective Symptomology ................... 135

1. General Explanation for Cognitive

Bas is of Affective Symptoms ......... 135

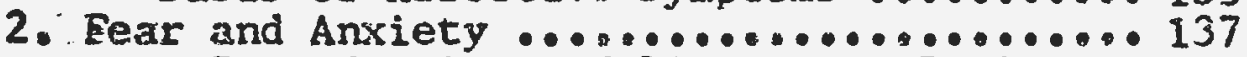

a. Introduction and Literatrue Review... 137

b. Cognitive Model Explanation ......... 138

3. Anger and Hostility ................. 140 a. Introduction and Literature Review... 140

b. Cognitive Model Explanation......... 143

4. Gullt ........................... 144

a. Introduction and Literature Review... 144

b. Cognitive Model Explanation ......... 146

5. Depression ....................... 147

a. Introduction and Literature Review... 147

b. Beck's Cognitive Explanation of

Depression .................... 148

1. Introduction .............. 148

11. Cognitive Content Areas

in Depression ............ 149

111. Thinking Errors in

Depression ................ 150

iv. Formal Characteristics of

Depressive Cognitions........ 153

v. Cognition as the Determinant

of Depressive Mood ......... 154

vi. The Primary Triad of

Depression

E. Behavioral Symptomology................. 162

1. General Explanation for Cognitive

Basis of Behavioral Symptoms ........ 162

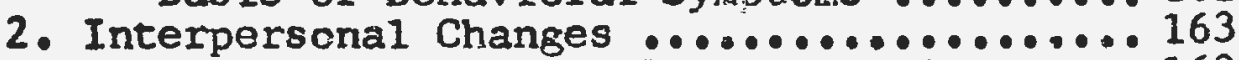

a. Introduction and Literature Review... 163

b. Cognitive Model Explanation ......... 164

3. Activity Levels ..................... I66

a. Introduction and Literature Review... 166

b. Cognitive Model Explanation......... 167

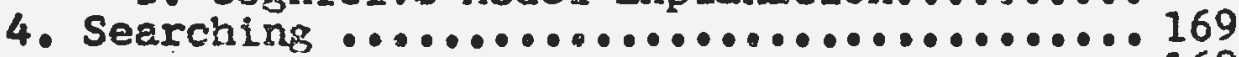

a. Inticodustion and Literature Review... 169

b. Cognitive Model Explanation......... 170

IV. DETERMINANTS OF THE COURSE OF BEREAVEMENT ....... 173

A. Introduction ......................... 173 
B. Mode of Death ........................ 176

1. Anticipated Deatin .................. 176

a. Introduction and ilterature Review... 176

b. Cognitive Model Explsnatjon for Effects of Anticipated Death........ 180

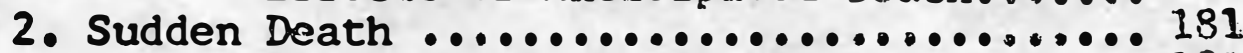

a. Introduction ard iiterature Review... 181

b. Cognitive Model Explanation for Effects of Sudden Deatin .......... 185

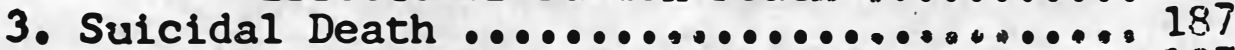

a. Introduction and Literature Review... 187

b. Cognitive Model Explanation for

Effects of Suicidal Deatin.......... 193

4. Accidental Death .................... 197

a. Introduction and Literature Review... 197

b. Cognitive Model Explanation for Effects of Accidental Death.......200

5. Sudden Infant Death Syndrome .......... 202

a. Introduction and Literature Review... 202

b. Cognitive Model Explanation for Effects of Sudden Infant Death ..... 204

6. Notes on Other Nodes of Death ........... 206

C. Relationship of the Survivor to the Leceased.. 207

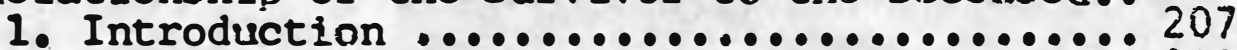

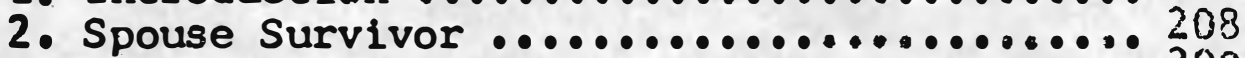

a. Introduction and Literature Review... 208

b. Cognitive Model Explanation for Effects of a Spouse Survivor....... 210

3. Parent Survivor .................... 212

a. Introduction and Literature Review... 212

b. Cognitive Model Explanation for Effects of a Parent Survivor....... 213

4. Brief Notes on Other Relationships....... 216 a. Adult Survivor of . Parental

Death....................... 216

b. Child Survivor of Parental

Death ....................... 217

c. Sibling Grief .................. 219

d. General ........................ 220

D. Characteristics of the Survivor ........... 221

1. Age ............................ 221

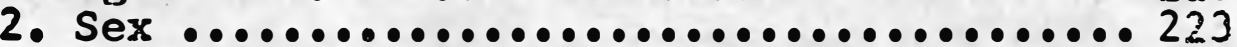

3. Other Characteristics ................ 226

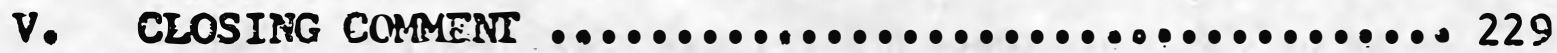

BIBLIOGRAPHY 


\section{LIST OF ILLUSTRATIOIS}

1. Summary Chart of the Basic Cognitive Framewcrk ......... 13

2. Summary Chart of the Development of the Copnitive

Matrix .................................. 21

3. Summary Chart for the Assessment Criteria of Connitive

Development and Functioning...................... 33

4. Sumnary Chart of Bases for the Inportance of Core

Relationships ............................... 42

5. Summary Chart of the Effect of Sudden Death as a

Disruptor of Cognitive Functioning .............. 48

6. Summary Chart of the Bases for the Effects of the

Sudden Death of a Significant Other................ 51

7. Sumary Chart of the Ef fect of Sudden Death upon

the Cognitive Sphere............................. 58

8. Sumary Chart of the Effect of Sudden Death upon

the Somatic Sphere............................ 68

9. Summary Chart of the Effect of Sudden Death upon

the Affective Sphere.......................... 72

10. Sumary Chart of the Ef fect of Sudden Death upon

the Behavioral sphere.......................... 79

11. Summary Chart of Symptom Sections to be Presented

in Part III................................ 86

12. Summary Chart of Cognitive Confusion ............... 93

13. Summary Chart of Cognitive Defenses................... 100

14. Summary Chart of Cognitive Pre-occupation with the

Deceased.................................... 118

15. Summary Chart of Bases for Somatic Symptomolozy.......... 124

16. Summary Chart of Affective Symptoms of Anxiety.

Anger and Guilt............................. 141

17. Summary Chart of Beck's Primary Iriad of Depression...... 159

18. Summary Chart of Behavioral Symptoms ................ 172

19. Summary Chart of the General Effect of Determinants

upon Grief Dutcome............................. 177

20. Summary Chart of Effect upon Grief Outcome of

Anticipated Death and of Sudden Death ............. 182 


\section{LIST OF TAELES}

1. Summary of the Assessment Criteria ox Cognitive Developinent and Cosnltive Functiontrg............... 34

2. Th1nking Errors in Depression....................... 151 


\section{PEEFACE}

Man's physical, cognitive and enotional relationship with death has changed considerably during the past generation (Choron, 1964; Fulton, 1965; Feifel, 1959). There are, undoubtedly, multiple determinants for these changes, They include longer life spans, organ and tissue transplantations, vicarious involvement with death through a decade-long war, the increased possibilities of death on the nation's highways or in nuclear holocaust, and the confrontation of death by newly revived and popularized phil o osophies and belief systems such as existentialism, snysticism and witchcraft.

Nonetheless, these confrontations with death as a concept provide some distance between the individual and the abstraction. Psychologists, however, have becone increasingly interested in studyine $\operatorname{man}^{\circ} s$ behavior when the individual is in more direct contact with his own imminent death as a result of aging (Kastenbaum \& Eisenberg, 1972), terminal 11lness (Brim et al, 1970, Hinton, 1967, Kubler-Ross, 1969) or suicidal behavior (Farberow, 1972, Resnik, 1969). In addition to the considerable investigative efforts and output on pre-death behavior, there has also been a renewed interest in the post-death behavior of bereaved survivors (e.g.,Kutscher, 1969, Parkes, 1972). This seems motivated, in part, by recent clinical emphases in family therapy (e.8.,Howel1s, 1971), orisis intervention (Parad, 1965) and the aforementioned trend toward studying death related 
behavior when it is a concrete reality rather than when it is abstract, distant and hypothetical.

This dissertation will add to the understanding of the post-death behavior of the bereaved by providing a novel conceptual model of acute grief in adulthood. By developing this 'Cognitive' model of mourning. I propose to offer a more concise and relevant framework than now exists for the explanation and treatment of acute grief. The literature on bereavement will be reviewed with regard to the symptomology of grief and the determinants of a normal versus patholcgical course of mourning. In order to demonstrate the applicability of the cognitive model, these symptoms and determinants will be accounted for by this original cognitive perspective. In order to give the reader a useful expectation of what follows, a summary of the plan of the dissertation is presented here. After a brief Introduction (PartI), the cognitive model of acute grief is developed (Part II). The latter begins with an overall description of man's general cognitive functioning, followed by a developmental analysis of those processes postulated as important for attaining an adult level of cognitive functioning. The processes proposed are (a) disjunction, (b) absorption and modification, (c) dilation and constriction, and (d) objectivity - subjectivity. These will be defined and exemplified in the text, and then applied to bereavement.

Turning to the structure of the hypothetical cognitive frame-of-reference, a rationale is offered for the central 
importance of intimate interpersonal relationships, on the basis of their. survival and adaptivity value, their long developmental history, and their quantitative centrality regarding other conceptual dimensions. The unique qualities of a sudden death event as a disruptor of cognitive functioning and stability is then provided.

Part II concludes with an explanation of the influence of cognitive disruption, subsequent to a sudden death, upon the four major spheres in which grief symptoms are manifested. These are the cognitive, somatic, affective and behavioral spheres.

Part III is a review of the relevant literature of mourning, with particular regard to the symptomology that occurs within these major spheres of functioning. Each symptom group is further described according to the terminology and concepts derived from the cognitive model previously detailed.

Part IV offers a literature review of those principle determinants which appear to influence a healthy versus a pathological outcome of grief. These determinant factors are analyzed uncier the general categories of (a) Mode of Death, (b) Relationship of Survivor to the Deceased, and (c) Characteristics of the survivor. In addition, there is proposed for each factor, a cognitive model explanation for its positive or negative influence upon the grief process. 
A doctcral dissertation is, in itself, a major endeavor. However, my perspective on this 'last hurdle' is that it really stands as a culminating linkage for a 5-year process which required much support, guidance and stimulation from many people. I wish to acknowedgle a few of them specifically.

Dr. James Prochaska has accompanted me through the five years as my major professor ... through courses, clinical cases, coraprehensive exans, a master's thesis, an abortive and a completed doctoral dissertation. My committee, Drs. Larry Grebstein, Albert Lott and Richard Travisano, have likewlse advised and supported the at critical points. I an indebted to each of them.

Along the way, various other faculty members have extended thenselves to me personally and intellectually, helping me to grow in both these dimensions. I must especially thank Dr. Alan Wllloughby, my clinical mentor, who never stopped reminding me that psyches live in a body, and the body, in turn, lives in an enviromental context..... and that the person must be viewed in this totality. I have learned wuch at his stide. I shall return to him often for counsel. Though my peers have always been a source of stimulation and ideas, particular acknowledgement must be directed toward two colleagues. Herb Wax was an initial and continuing catalyst for my thiniling about man. He helped me to cohese a philasophy and world view, both congruent with my own 
values and functional in understanding the individual from his own existential stance. Ira Silvezman has been my consistent supporter and critic, co-planner for the future and co-Monday-morning-quarterback of the past, reality tester, Idea reflector, indignation sharer. We have learned to trust each other. I believe it is very difficult to survive Graduate School without a rellable friend. Ira has been my friend. When I embarked on this road, my parents embraced the decision and comitted themselves to its achievement. The road could not have been traveled at all without their sustained involvement. They have been unflinching. At each plateau, they've expressed their pride in me. At this juncture, I want them to know how proud I am of them. Dana and $\mathrm{KIm}$, my daughters, have literally grown up with my schooling, always understanding, concerned and caring about me and what I was trylng to accomplish. They've given me foy, warmth, insight and peace as they have grown. I have needed these gifts to make it thru.

In talking about the Ph.D., I'm frequently questloned on my usage of "we", when the 1lstener expects the pronoun "I". My usage is neither error, nor manuveur, but rather a genuine (and for me, a very automatic) expression of the partnership which exists between my wife, Carole, and myself. She has been my prinary resource in all ways. We've spent five years together in this task. We've laughed, cried, fought, loved, been foyously exhilirated and profoundly disappointed. We have spent endless days and exhausting nights talking, sharing, reflecting, deciding, somerimes fust siteing and not knowing what to do. My 
woran has given me much coffee, much effort and much sacrifice for my poals. We are very much in love. 


\section{INTRODUCTION}

Traditionally, the obseryation of grier has been made frea a rather well-defined perspective based on a psychoanalytic model of man (Freud, 1917). This model and its modern variations (e.g., Bowlby, 1960, Pollack, 1961) have had considerable influence on the understanding, explanation and amelioration of bereavement. Since this pervasive psychodynamic understanding of grief is founded on challengeable assumptions about the nature of man's functioning. it is possible to pose an alternate set of assumptions and to deduce an alternative understanding of the bereavement phenomenon. Such a purpose is the primary thrust of this dissertation.

It is not antention to initiate a cosfrontation with psycheanalytic notions - on simply a new battleground, grief - although the learning theorists (e.8., Salter, 1963) and others have shown how enticing this is to do. Rather, my intention is to develop a medel for the understanding of grief which provides a more cogent and cemprehensible explanation of this experience than has been provided by the traditional psychoanalytic paradigm. Whether my model is 'better' than the older one is left, as it must be, to the evaluative criteria of the reader. However, it can be confidently stated that my notions are, in fact, considerably different from the psychoanalytic description and, therefore, provide a distinct and optional framework for viewing bereavement.

I de Intend to suppert the vlability of my model 


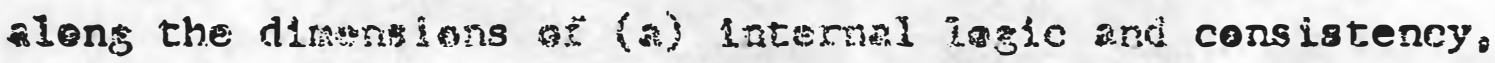
(b) Its oxtermat cogsnoy, (a) j.ts degcriptive power for

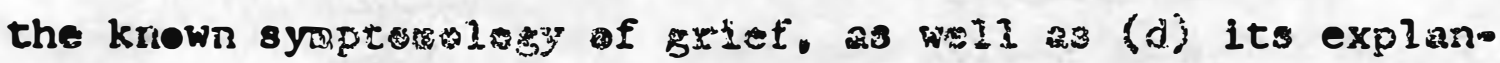
atory power for the inportant deterwinant factors influencing grief outcone.

Following a brief descziption below of the general traditional notions absut grief, the emphas is in the bal. ance of this treatise will be upen the building of ny own model, rather tinan the presentation of a point-by-point comparison. The basis psycheanalytic assumptions about man are available throughout the literature (e.g., Cameron, 1963, Feniche1, 1945) and wa't be repeated here. The description below is a fair and reasonable summary of the grief phenomenon from the psychoanalytic viewpoint. However, ny own bias should be stated at this point and can be put Forth succinctly. I disagree, respectfully, but firmly, with a deterministic philosophy about the nature of man. As a consequence, my choice of assumptions are different and, therefore, my explanation and conclisions are different. I do not intend to diligently argue against the psychoanalytic model of grief. I perceive my major responsibility here as one of presenting and establishing the rationale and support for a new paradign of mourning, without necessarily attempting to unseat the old representative. The purpose of presenting the traditional bereavement description to which J'll nok turn is one of simple fuxtaposition, not competition. This will be followed by the main body of the work aimed at progressing toward an original nodel of 


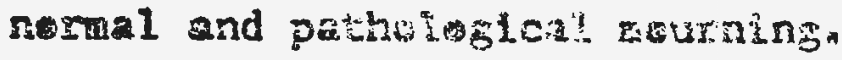

Histerically, srief and awroning hive been essentialy viewed as acute depresstve reactions to an interpersonal 10s9. With occasienal extension of the term to Include other ferms of loss, such 23 job, status or 11rabs (Buss, 1966, Parkes, 1972). The explanation of why such 2 iess should result in this type of reaction has generally been framed in affective terms. The paradigm is one of emotional-bonding. The individual is described as having been emotionally bound to the deceased ('cathected') because the latter had fulfilied a variety of emotional and practical needs of the mourner. The loss is censtrued to be representative and reminiscent of other periods in the person's developtaental history during which the security of need gratification was, for some reason. absent. As a result of the, perhaps uncanscious, reminiscent experience plus the current episode of need frustration and security less, the mourner is postulated as experiencing over whelming and primitive (i.e., historical) anxiety which approaches panic and forbedes doom. Thus, the rupture of $a$ highly intense, energized emotional bonding (based on need gratifleation) yields a highly intense, energized emotional set of symptems ... anxiety and despair. Other affective symptons are alse included in the dominant pertrait of the mourning syndrome. Anger is explained as the emotional respense to being abandened by the loved one, 2 rage expressed toward the deceased for having arbitrarily severed a nutual bond. Gullt is explained elther as a reaction to the experlenced, yet unacceptable, rage toward the deceased or as regret 
for net meeting the natd wis the decessol.

The emphas ls througheut this paradigra is upen the enstional ties to the deceased, often postulated as parailel to the enotional ties of the infant/child to its parents (Bowlby, 1961,1963). The lose is that of emotional gratificatien, a breaking of an affective link with a significant, security producing, need fulfilling other person. The symptoms of grief are, therefore, viewed as primarily affective or at least affectively derived. It is a model which focuses on the dependence of one individual in relation to another along the emotional dimension, and it is presumed to be based on his prototypic emotional relationships of earlier years.

As an alternative perspective, I will put forth 2 model of mourning which focuses on the cognitive, rather than the emotional, integrity of the individual. In its explanation of the grief process, my model leans heavily upon the importance of the individual's conceptual framework, rather than his need-fulfilling emotional-bonding to another. The emphasis is upon the structural conceptualization of the person's world, from his peint of view. For this reasen, I've chosen te term my paradigm a 'cognitive model' of acute grief. Cognitive is defined here as referring to the conceptual meanings and categeries which the individual applies to events (persons, places, things, eccurrences) that he encounters and which permit him to organize his experiences inte some comprehensible form.

Although my cognitive model shares some basic presuppositions with cognitive theories and orientations that 
have been applind to other payohelogicat phenowena, it is net my intent to intwgrate tise extant literature of cognitive psychology or oognitlve tixeary. My purpose is to demantrate the worthwhite application of this particular perspective to an event, actte grief, which has not yet been explained from this viewpolnt. This is not a superfluous re-application of a standard model to skmply another area. Rather, the cognitive model of acute grief will be presented as a more comprehensive and moxe comprehensible explanation of this experience than are ther paradigms which have been previousiy applied to mourning. It is ray general prenise that the cognitive meaning and effect of sudden death is more relevant to the survivor's experience than is the emotional lmpact of this traumatic event. 


\section{TONARO COGNTIVE MODSP OF GRTSF}

The sudien death of a significant other person precipitates a variety of cognitive, scmatic, affective and behavieral changes in the bereaved. The content and extent of these changes will be detailed at length in Part III of this dissercation. However, in order to recognize and understand that the bereavement experience is actually a unique, atypical condition for the individual, it is first necessary to postlilate the person's normal, routine functioning. In addition, this postulation of routine functioning serves as a useful vehicle for explaining my assumptions, perspectives and concepts concerning the cognitive nature of man. A. The Basic Cognitive Framework

1. Functional Value of Cognitive Framework

A basic assumption of the model is that the individual funtions within a self-developed framework of meanings and interpretations of his world, similar to kelly's (1953) theory -f "personal constructs". It is a framework which the person strives to maintain lest it deteriorate and cause his cogni * zance of his life to become meaningless and chaotic. Yet it is also a framework which he attempts to gradually expand and extend in order to secure greater predictive control over eyents which he encounters and events which influence his goal attaiment (Kelly, 1963). Thus, man is basicaliy postulated 2 being motivated (a) to make sense out of interactions with his enviroment, (b) to minimize ambiguity and uncertaintys (c) to be able to entertain experiences within his scope of understanding; and (d) to sufficicariy grasp 
the meaning and relevance of werts $\mathrm{s}$ a as to betcer predict, and thereby centrol, the outcome of his decisions and actions. To acconplish these ends, the individual builds and refines during his developrent (as discussed in the next chapter) a systen or method for comprenending the events that inevitably impinge upon him. In effect, he learns to cope with iffe's contingencies by develeping a personalized method of conceptuallzing, interpreting and applying meaning to events (Bruner, 1957, Harvey et 21, 1961; Kelly, 1963, Miller et al, 1960, Piaget, 1961, Shapiro, 1965, Shneidman, 1970).

since this cognitive system of construing events is postulated as the foundation for the individual's interaction with the world, it is therefore essential that the framework be protected, or at the least, maintained. If it is not maintalned, then the alternative is confusion, an inability to understand what is going on around him, a sequence of chaotic Interactions with the environment for which there is no conceptual resource for adequate coping. This hypothesized need to maintain and protect one's cegnitive perspective of the world is partially supported by the "cogritive consistency" theorists in the field of attitude change (e.g., Abelson \& Rosenberg, 1960; Festinger, 1964; Heider, 1958; Newcomb, 1943; Osgood \& Tarneribaun, 1955).

\section{Validation}

In erder to achieve this maintenance of his cognitive framework, man exerts considerable effort at obtaining validation and supfort for the particular way in which he construes events. He does this by subjecting his interpretations to 
tests, in order to learn whether his frawework satisfactorily explains his expertences. This form of cognicive syatem validation has been discussed at length by Relly (1963). Validation is said to occur when the prediction based on the system is confirmed by the experiential outcome. For example, people who talk softly are conceptualized as cooperative and friendly. Therefore, encounters with soft-spoken persons are expected and predicted to be cooperative and friendly meetings.

Validation is a form of subjective hypothesis testing in the individual's day-to-day activities which permits hias to confirm and thereby maintain his cognitive frameworik. This confirmation, in turn, keeps him in stable equilibrium with the world of events that he routinely encounters, since he then possesses an appropriate framework for understanding these events (e.8., understanding and expecting that as a person's voice rises, he predictabiy becomes less cooperative and friendly). His particular conceptual stance has been re-affirmed, his cognitive structure proven useful and accurate. The individual can then use that understanding of his environwent to (a) choose between a variety of optional actions that may lead him closer to his valued goals (e.g.. attempt to increase the frequency of his interactions with soft-spoken, and therefore cooperative, persons); or (b) he can use the understanding to increase his predictive probabilities regarding future events ( 8.80 , be able to assess the likelihood of eventual cooperation of anether person by the volume of $h$ is conversation); or (c) he can use it to confirm and be reassured regarding those personal meanings which he has assigned to 
aspects of his own life (e.s. viewing himsth as cooperative and friendly since he, too, is soft-spoken). In other words, in addition to ruifiliing the basic need of understanding one's world and avoling confusion in relation to it, the validated cognttive framework serves functional purposes: (2) of aiding goal attainment, (b) of increasing the likelihood that expectation will match actuality, and (c) of providing meaningfulness to one's 1ife.

3. Invalidarion

When one's cognitive framework is not validated by reality (i.e., the prediction is not confirmed), then the individual must either reject or accept this incongruity (Festinger, 1964; Kel1y, 1963; Rogers, 1951). For example, the individual interacts with someone who speaks softly, but who is neither cooperative, nor friendly. He may either accept or reject this invalidation of his cognitive system's prediction.

If he chooses rejection, then he may either distort or deny the actual outcome of his prediction (Rogers, 1951). Distortion invelves the fitting of the event into his preconceived notions, even though it does not really match (e.g., by rationalizing that the unfriendly person's soft voice was due to a sore threat or the fact they were in a public place). Or the distortion may take the extreme form of a denial, denial that the particular event even occurred or denial that his framework's validation is in any way affected by the outcome. such $2 s$ by disielieving the lack of cooperation.

If the individual chooses to accept the incongruence 
between predlction and autcome, then hy must experience an adjustment or modifleacion of his cognttive system in order to accommodate the urispected outcone (Festingser, 1964, Kelly, 1963; Rogers, 1951). In the latter case, the framework is changed rather than the experi ence distorted or dented. For example, by delineating cooperation and friendliness, such that soft spoken persons are expected to be cooperative and/or friendly, but not necessarily both. Such change in one's cenceptual system is the basis for cognitive development, growth and expansion.

Whether there is experiential distortion or cognitive modification appears to be 2 function of the amount of structural change required of the system by the event; and a function of the tolerance to change that the framework possesses at a particular time, beyond which there's risk of breakdown (Mehrebian, 1968). If soft spoken others were expected to be not only cooperative and friendly, but also affectionate, compassionate, intelligent and attentive, then invalidation would involve readjustment of more cognitive dimensions. If the individual could only cope with 4 simultaneous cognitive matrix modifications, then the situational demand for 6 sinultaneous changes would overload the person's abilities. Since the cognitive framework's self-maintenance is pesed as a basic motive, any significant threat to the integrity of the system will probably be protected against. The threat may take the form of an environmental interaction that demands multiple, simultaneous adjustments which are beyond the change-tolerance linits of the system (e.g., arrival 
in a new counery with a differenc culsure); or it may take the form of a sirguiar, but overwhelming event which requires major framework overhaul in order to be accommodated (e.g., sudden death of a significant other). These types of threats may result in gradual and prolonged readjustment or protective distortion/denial or (if there's insufficient protection) cognitive system breakdown. The consequences of such a breakdown are detailed later.

4. Multi-Dimensional Structure

Leaving the interaction and validation ideas for awhile and turning to the cognitive framework itself, it appears that a single, or even several, dimensions of such a cognitive system would be relatively insufficient for dealing with the complexities of living. Living involves interaction with more than soft spoken persons. The multiple and varied events that dally confront the individual, each of which must be perceived, comprehended, interpreted and given meaning, results in an overall demand for a complex, rather than simple, set of cognitive dimensions (Kelly, 1963). It is postulated that one's set of cognitive dimensions is, in fact, a complex matrix and that it is never complete or finite. It is always subject to expansion and growth, either by the addition of new dimensions or the refinement of old ones. This notion of a multi-dimensional cognitive matrix is dertved from the earlier assumption concerning the individual's need to maintain and protect his frame of reference. The expansion of his cognitive matrix has an adaptive and an anti-threat function because it allows the individual to interact with a greater number of environmental 
phensmena (e.g., thos who speak seftly and harshly and moderately), since he"s grerating fres a broader conceptua 1 base. The refinement iso neduces the probability of encountering an event for winton he has novadequate conceptual dimension (e.g., assessment of technical skill rather chan coeperation).

In the more advanced or expanded forms of cognitive framework as they normally exist in the adult, it can be assumed that the system of viewing the world is multidimensional and rather intricate, aptly termed a 'matrix'. It is proposed as an interweven and integrated matrix of conceptual dimensions which provide the framework or frareof-reference for making some organized and comprehensible sense out of complicated interactions with the world. The individual's cognitive matrix forms the basis for the person's perceptual and interpretive stance vis-a-vis the environment. It is the structural array of conceptual dimensions upon which events impinge.

In the adult, it is assumed that the components of this structural array are refined and conprised of erganized sets and subsets (Dabrowski, 1964; Piaget, 1960; Werner, 1957), This delineation permits the individual to perceive the world in a selective, sophisticated fashion, rather than indiscriminately in a crude, global manner. It also allows him to give differential interpretation and meaning to events, rather than forcing experiences linto brad and relatively meaningless categeries.

The ideas presented thus far are summarized in Figure 1. 


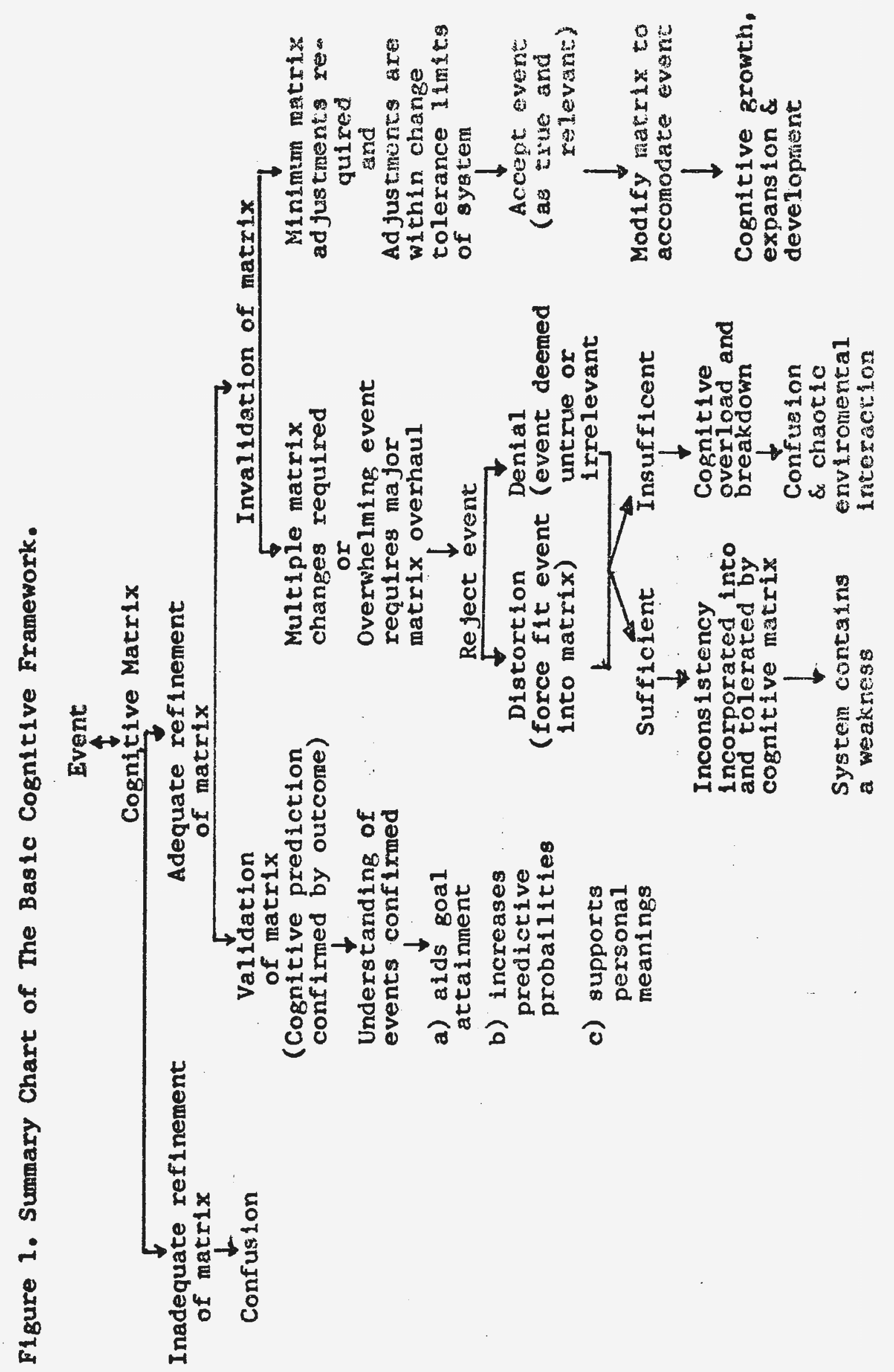


B. Develoment of the Connity ve Mugin

1. General

This developmental chapter is aimed at offering an ontogenetic foundation for my position of adult man being basically motivated by and affected in the cognitive sphere. My intent is to postulate some developmental processes that would explain how the individual attains the state of aduit cognitive functioning discussed in the preceding pages.

I also intend to use the processes of the developmental sequence as tools for the description and explanation of certain aspects of acute grief. In other words, the survivor's experlence of and symptomology conseguent to a sudden death event, can be partially explained and waterstood by using terminology of and reference to the more general rules of cognitive system development. For example, there are some similarities (e.g., temporary confusion; readjustrent) between the cognitive artermath of a sudisn death and that of other epigenetic crises, such as initial schooling, puberty and marriage (Cumming \& Cumming, 1962, Dabrowski, 1964). By a general discussion of how life's encounters are experienced and adjusted to, it is possible to articulate some elements of a basic pactern of development which can then be applied to the acute grief phenomenon.

The particular mixture of ideas presented in this section is my own, althougì I have leaned heavily upon and am Indebted to several theorlsts for provlding key ingredients for my brew (Dabrowsk1, 1964 , Mehrabian, 1968; Piaget, 1960, Herner, 1957). 


\section{Survival and Adaptation}

It is assumed that a basic function of living organisms is survival, and that continued survival is necessarily contingent on the organism's ability to adapt to its environment. Such adaptation is interactional in nature, since it involves mutual, though not always equal, effects on both organism and the environs. For example, the intake and digestion of food involves changes upon the nutrient itself and the body chemistry of the organism. The converse is not necessarily true, since some interactions may not result in the organism's survival potential being enhanced (e.g.. poisoned food). These would not be considered adaptive. Nonetheless, overall adaptation activities for survival purposes is seen as a primary function of living organisms, including man. The necessity to adapt in order to survive is also postulated as an energizer for the developmental drive, since developmental progress (as defined below) increases the organism's adaptive options and possibilities, thereby increasing its survival potential.

Development, by definition (Random House Dictionary of the English Language, Unabridged Edition) means "to bring to a more advanced or effective state; to cause to grow, elaborate or expand in detail, to cause to go through the process of natural evolution from a previous lower ... to a later and more complex stage, to undergo differentiation in ontogeny ..." . Werner (1957a) has applied this definition to the natural development of man, namely that "... wherever development occurs, it proceeds from a state of relative globality and 
lack of differentiation to a state of increasing differentiation, articulation and hierarchal integration".

These notions are borrowed from biology where phylogenetically and ontogenically more advanced states are more highly differentiated and, as a corollary, more organized. They are also typically more adaptive because they enable the organism to successfully cope with more complex stimuli (Dabrowski, 1964). The psychological equivalents of this blological metaphor (e.g., of cells, tissues, organs and systems) are postulated to be the cognitive units, categories, conceptual dimensions and systems which make up the overall cognitive framework of man. These units have been referred to by other theorists as schemas (Piaget, 1960), constructs (Kelly, 1963), perceptual sets (Bruner, 1957), plans and strategies (Miller et al, 1960) and concepts (Harvey et al, 1961). They are the cognitive, rather than blological, mechanisms by which the individual knows about, interacts with, adapts to and survives in his world.

The developmental progress of this cognitive sphere has important adaptation and survival function since it enables the Individual to interact with increasingly complex environmental impingements (Dabrowski, 1964), as well as enhancing his predictive and controlling abilities in relation to external events (Kelly, 1963). The manner of this cognitive developmental progress from the global undifferentiated state of the neonate to the complex, multi-dimensional state of the adult is relatively straightforward. It involves continual differentiation and delineation such that the cognitive 
components become more detalled and become integrated at a more advanced level of hierarchal organization (Dabrowski, 1964, Piaget, 1960, Werner, 1957). The payoff for cognitive development is the continued improvement of the individual's ability to make better sense out of the disorganized stimuli input coincidental to living. It also provides concomitant survival advantages in the control or management of his experlences and his environmental interactions.

3. Actively Cognizing Events

Implicit in this description is the assumption that man takes a highly active role in the construing of his world, that he is not simply the passive recipient and reactor to external stimuli. He structures the incoming experiences and stimulations according to the cognitive dimensions which are available to him (for example, see Bruner, 1957). This active construing of events is partially necessitated by the disorganized way in which the environment impinges on a person and the functional benefits of making sense out of the chaos. The greater the refinement or development of the cognitive dimensions, the more effectively and efficiently can the individual organize the data, exert influence over its effect on him, and modify his inceractions to maximize his gain, growth and survival.

Since the individual can actively construe or structure events only within the limits of his cognitive framework, it is important to explore the processes by which those limits are broadened. Based on the discussion thus far, it is assumed that matrix expansion is an adaptive and desirable change. This change can occur through greater separation/ 
differentiation of components $(e .80$ : delineating softspoken males froin soft-spoken females); or through more eloquent organization of sub-ordinate and super-ordinate dimensions ( $e_{.} .$, organizing the concepts so that cooperation is more important than and subsumes friendiness), or through more refined and intricate integration/interrelation of cognitive categories (e.g., cooperation and friendship are delineated and related to business and social interactions, respectively). Conversely, constriction of one's cognitive system, or inertia, when environmental demands require expansion, may be cors idered either nonadaptive or mal-adaptive.

4. Stages of Cognitive Development

Considering the actual process of cognitive development, both Werner (1.957) and Piaget (1960) suggest that the neonate's cognitive dimensions are relatively few in number and globally undifferentiated. Quite probably, there is not even a clear distinction between environmentally and selfgenerated stimuli (Piaget, 1960; Herner, 1957). Sensations are experienced without categorization. As he develops, there is gradual delineation of elements in the infant's cognitive sphere as crude distinctions emerge, such as between self and not-self. Further growth results in still additional refinements so that persons, things or occurrences which were initially experienced as non-distinct sensations soon begin to form particular sensation patterns. These become familiar sensate categories and may be considered distinct "percepts". 
The progress of the infant's cognitive development from the experiencing of global sensations to the experiencing of sets of sensations as distinct percepts has been explored at length by Werner (1957) and particularly Plaget (1960). The latter has adopted the aforementioned definition of development in his description of the forward movement from primitive cognition (i.e., global sensations) through percept formation (i.e., grouped and distinctive sensations) to the more advanced cognitive stage of concept formation. According to Plaget (1960), the ontogeny of cognition involves the advancement through increasingly differentiated, organized and adaptively efficient stages which he terms sensorimotor, perceptual and conceptual.

The adaptive value of this progressive advancement into the conceptual stage of functioning is that abstract conceptualization frees the individual from being bound to the immediate presence of sensory stimulation for utilization of his cognitive categories. Sensorimotor dimensions require the presence of the objects being cognized; perceptual dimensions require direct sensory stimulation; however, conceptual categories can operate without such direct contact with or stimulation by the particular object. The object, person or event being considered can be 're-presented' to the individual by a conceptual, rather than tangible, replication. Either an image of the object is generated (e.g., mentally picturing one's spouse), or the salient features of the object (i.e., the conceptual dimension criteria by which it is categorized) are abstractly defined (e.8., spouse's 
affection, calmness, likes and dislikes, ideas), Interaction with the environment is no longer contingent upon the requirement of actually acting upon or manipulating direct and concrete stimulations.

Furthermore, representation permits the individual to deal with events which are hypothetical, condicional and possibile, rather than only the concrete givens of actual1ty. This cognitive ability to inquire into the realm of 'if' results in a significant adaptive gain, for it opens the arena of future prediction to the individual. It provides the tools for weighing outcome probabilities for certain future (non-concrete) actions and thereby improves both predictive and controlling capabilities.

These developmental notions are summarized in Figure 2. C. Assessment Criteria for Cognitive Development and Functiontng After a brief narrative regarding (1) individual differences and (2) cognition, conation and affection, I will describe four proposed criteria of cognitive functioning which I've termed (3) disjunction, (4) absorption modification, (5) constriction-dilation, and (6) objectivitysubjectivity. I believe these are the principle developmental dimensions along which regression occurs during acute grief. They are the basic concepts that I will use later to describe and explain the symptoms and determinants of the mourning process.

1. Individual Differences

These notions about cognitive development convey some important implications concerning the state of the cognitive 
TET วuتวOd

IEATAIn $4^{8} T H$

$\uparrow$

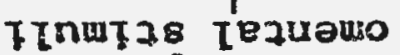

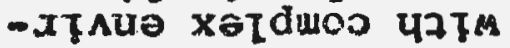
- Desazut [n]ssaoons

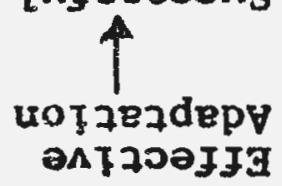

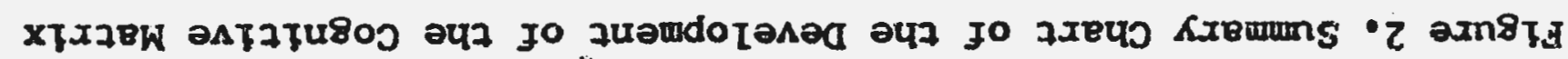


framework of the adult, especlally regarding differences between individuals. It is reasonable that the numerous developmental experiences of different individuals will result in various idiosyncratic conceptual categories that are distinctive for each person. Differentiation may break the event into novel components, organization may take a variety of structural forms, and integration of elements may be based on person-specific cognitive relationships. By adulthood, people are likely to have available some similar cognitive categories, as well as their own unique dimensions for construing events and coping with life. Those shared cognitions are exemplified by the comprehension of simple physical events (e.8., a chair) in which the common cultural influence is the main factor affecting the individual's understanding. The idiosyncratic constructions of events typically involve those interactions which are complex and ambiguous; that is, in which there are no significant cultural anchors for understanding the phenomenon (e.g., many interpersonal relationships and interactions). It is in these ambiguous situations that the individual is likely to exert a more pronounced, active and personalized effort in the cognitive structuring of his experience (Mehrabian, 1968).

2. Cognition, Affection and Conation

There are also probable differences, both between people and within the same individual, as a function of the particular content area under consideration. During development, not only are content areas delineated from one another (e.g., global cognition "other people" is differentlated 
into derivative dimensions "male" and female" other people), but within each content area itself, there is further intraseparation into cognitive, conative and affective elements. The latter distinctions are common ways of describing a person's relationship with others, objects and events in his world. Cognition, as already mentioned, refers to the manner in which the individual comprehends or knows his world (e.g., recognizes a woman by her figure), conation refers to the person's desire or wish (or lack of it) for objects/others (e.8., desiring to touch a woman's hand), and affection refers to the person's positive and negative feelings or emotions toward elements in his world (e.g., experiencing pleasure at touching her hand). Analagous to the general differentiation process described above, within a given content area, these three modes of relating to the environment progress from a merged state (e.g., recognition, desire and pleasure experienced simultaneously at sighting a woman) to a defined triadic state (as exemplified above). Originally, there is a lack of differentiation of cognition from conation and affection. With ontogenetic advance, there's increased independence between one's cognitive, conative and affective relationship to events (Mehrabian, 1968).

Thus, in infancy, comprehension of an object is strongly influenced by the infant's desire and feelings toward that object. In adulthood, assuming normal development, comprehension of an object according to available cognitive dimensions (e.g., blue car) can be accomplished without regard to one's like or dislike (affection) for the item or the 
desire for/rejection of the item (conation). There is undoubtedly between-inaividual variance regarding the degree of separation of cognition, conation and affection in relation to objects. Some people are emotionally aroused by a news article. Others are not. There is also withinIndividual variance depending on the particular content area. For every individual, there are most probably given content areas where the merging of thoughts, feelings and desires is very strong and minimally differentiated.

3. Dis junction

These ideas yield some criteria for assessing the degree of cognitive development in the individual. The yield also includes terminology and approaches for describing some general types of cognitive styles or frameworks (i.e., typical stances which people assume in their interaction with the world). For example, we may consider the separation of cognition from conation and affection as a process of "dis junction". This concept is similar to Freud's (1917) notion of isolation and to Plaget's (1960) description of dis-engagement.

By definition, greater disjunction (or separation) of these modes of relating to events is indicative of a higher level of developmental growth, resulting in more successful adaptation and an increased survival potential. The individual who has disfoined a variety of content areas is hypothetically better able to cope with 1ife, such as the businessman whose decisions are based on information (i.e., cognitions) about his clients rather than his emotional feelings (i.e.. 
affections) toward them.

By postulating degree-of-disjunction as a continuum, it is passible to compare the ontogenetic growth between individuals on this criterion. Some individuals are emotionally aroused by many different events. Others are aroused by relatively few encounters. It is also possible to assess which cognitive categories within an individual are more susceptible (due to a low degree of dis junction) to conative and affective influence, such as categories involving interpersonal relationships. Furthermore, this criterion permits a description of the particular person in terms of disjunction, which portray his degree of cognitive independence from the bias of his feelings and desires. For example, a person can be depicted as highly dis junctive (i.e., emotionally unbiased) regarding the contents of his automobile driving experience, but minimally dis junctive (i.e., emotionally involved) regarding nis girlfriend. Or an overall description can be evoked, for example, by the "highmoderate dis junctive person who is generally able to construe and interact with events (e.g., business decisions) irrespective of his desires or emotions in relation to the events. Production of such a 'disjunction scale' is beyond the scope of this writing, but may be a relevant empirical follow-up. My purpose here is simply to provide a few cognitive developmental criteria which can be used and understood by the reader later when the consequences of sudden death are detailed in cognitive terms. The notion of dis junction is one such criterion. 


\section{Adaptation Absorption-Modification}

Another criterion dimension derives from the nature of adaptation. As noted earlier regarding food intake, adaptation is always a mutual interaction between the individual and his environnent in whicn each has some effect on the other. The balance of these effects can be analyzed from the standpoint of the individual. (see Flavell, 1963). As he interacts with in milieu, the person typically strikes some compromise between total absorption of the event into his pre-existing cognitive framework without any substantial change to the framework (as in the paranold's incorporation of information into his delusional system), or total modification of the relevent framework structures so as to accommodate the event without changing the event at all (as in the highly suggestible state of a deep hypnotic trance). Such total or pure absorption and modification is highly improbable. However, these extremes may be considered as the anchoring ends of a continuum of relative absorption versus modification, similar to Piaget's (1960) assimilation/ accommodation, respectively; and with some parallel between modification and Cameron's (1938) term of overinclusiveness. Since adaptation, by definition, is a function with mitual effects, absorption and modification must be viewed as simultaneous occurrences during any particular interaction. They are conceptually, but not actually, separable.

An alternate way to characterize this same criterion refers to the openness-to-change of an individual. A person who is 'highly absorptive' tends to be relatively closed to 
cognitive changes influenced by his worldly encounters. His cognitive framework is stiffened or 'rigid' against Invasion from non-fitting stimul1, which are either rejected outright as untrue or ixrelevant to hira (i.e., denied); or the stimuli are forced to fit by grossly distorting them. There is no readiness to or capability of dealing with novel information except by processing it according to the dimensions of the existing matrix, even If those dimensions are inappropriate. Cognitive growth is stifled because cognition and behavior is dominated by repeated and unchanging reapplication of old concepts, inappropriate dimensions and anachronistic patterns of comprehension. This is perhaps exemplified in its extreme by the paranoid individual who force fits reality information into his delusional concept system by distorting some or all aspects of the data. Those which cannot be distorted In this way are simply rejected (denied).

On the other hand, the person who functions at the 'highly modifying' extreme of the continuum is overly opento-change. His cognitive structure is too 'lablle', too highly susceptible and responsive to environmental influence with regard to how he construes an event. He is likely to form and then re-form cognitive dimensions that are unstable, with loose and Iimited intra-structural associations. In the extreme, the non-paranold schizophrenic demonstrates this looseness of associations and inability to focus his attention on selected environmental stimuil. He is overly accessible to the varied suggestions and impingements of 
his surroundings.

In effect, the highly modifiable individual has a shifting and fraglle cognitive framework, which is as nonadaptive as the stiff and brittle framework of the highly absorptive person. As such, both extremes of closedness/ openness of the cognitive system to environmental influence are representative of relatively low levels of cognitive growth, both having 1 imited adaptive effectiveness.

On this criterion, a more functional position from which to comprehend events, persons and objects is one of relative equilibrium. In that instance, the individual is able to absorb salient and relevant aspects of the encounter without distorting them, by modifying those available and applicable cognitive dimensions. He can make these changes while maintaining his basic cognitive stability and sense of continuity. Novel experiences are dealt with 'flexibly' by construing them according to existing structural dimenslons (absorption), while simultaneously allowing moderate changes (modification) of some dimensions to accommodate non-fitting aspects of the event. For example, a person may meet a homosexual for the first time. He is able to deal with many aspects of the interaction with existing dimensions (absorption), including the knowledge that this person has sexual desires. However, his previous 'sexual partner preference' dimension regarding others may be modified (via differentiation) to include heterosexual and homosexual preferences.

Adaptive cognitive functioning is, therefore, a 
concurrent ark? proportionate balarce between absorption and modicication. It results in ezfective construing of events, as well as stimulating further cognitive development in response to the event's moderate demand for cognitive change. The growth can occur from a new differentiation. of concepts or from a reorgarization of some concepts or from the formation of new integration links of cognitive units.

5. Bilation $=$ Constriction

A third criterion for assessing and describing the developmental stage of the cognitive framework is suggested by Kelly (1963). He refers to the axis of dilation-constriction upon which an individual may move in response to demands for expansion or cohesion, respectively, of his cognitive frame-of-reierence,

At their extremes, dilation is similar to a manic's flight of ideas, while constriction is similar to an obsessive's narrowing of his attention to a single theme. Dilation/constriction are cognitive activities, not behavioral ones, though there may well be concurrent and similar behavioral activity (e.g., aimless agitation and compulsivity, respectively). Dilation/constriction are related to modification/absorption, but are not synonomous with these concepts. Dilation/constriction refer to the matrix boundaries as a whole, the number and scope of the dimensions. Modification/ absorption refer to the readjustment potential or openness to change of the individual dimensions within the matrix.

When a person broadens his area of concern or attention 
In order to make better sense out of the onrush of events, this expansive movement is referred to as dilation of the cognitive matrix. It involves an intentioned searching for new categories which will aid the person in comprehending or explaining an encounter (e.g., meeting a man dressed in woman's clothing, the cognizer searches for conceptual understanding by adding dimensions of actor, practical joker and transvestite to his cognitive matrix). The activity is not a prioriadaptive, for it may take the form of indiscriminate, non-productive searching for new cognitive dimensions (e.g., manicy thinking). Planned, consistent and specific goal directed dilation tends to be more effective, more adaptive and more developmentally mature than is disorganized, inconsistent and random dilation.

Constriction involves cognitive activity in the opposite direction; that is, an effort to consolidate one's cognitive framework, to shrink the dimensions and conceptual limits to a more manageable size. The effort is toward protecting one's framework by compression, by narrowing the cognitive boundaries. Instead of having separate cognitive dimensions for comprehending men by their hair color, the dimensions are reduced to men with hair and bald men. When this is extreme, the pattern of constriction can lead to a very limited focus cognitive structure (e.g., obsessive concern with the presence of hair, without concepts for dealing with other aspects of men's appearance). However, constriction can be quice adaptive when the end result is a matrix that is more refined and articulated, for example, when. 
irrelevant or poorly differentiated units have been consolidated into more meaningful cognitive dimensions.

Extremes of cognitive dilation and constriction activity are considered non-adaptive because they tend to be either too distended ( $e_{.}$, , as occurs with psychedelic drugs) or too restrictive (e.g., obsessive rumination). And rapid, violent oscillation between dilation and constriction is similarly non-adaptive because it creates cognitive confusion and represents a lack of stability in the cognitive structure. Note that this criterion assesses and describes the individual in cognitive motion (i.e., dilating or constricting his view of the world), rather than addressing his state of dis junction or the tendency of his cognitive dimensions to be absorptive or modifiable.

6. Subjectivity-Objectivity

A final measure of cognitive development to be discussed here focuses on the criterion of subjectivity-objectivity. The individual who is subjectively biased in his construing of experiences tends to conceptualize events only as they relate to him. For instance, he hears an advertisement for the latest model car and cognitively relates this to his spouse's auto death. A neighbor's pet dies and he is reminded of his own loss. All cognitive mediation is channelled through self, although the differentiation between self and not-self dimensions may actually be available. This is, at Its extreme, a very undeveloped cognitive state, since the person fails to exercise a very fundamental distinction. Such individuals are often described as 'self-centered' or 
in its pathological form, as having 'ideas of reference'.

In contrast, a higher level of functioning includes differentiations of the environment along dimensions external to self-reference. These are termed objective, since they involve cognitive categories which are independent of the cognizer's direct relationship to the particular object, person or event being dealt with (e.g., being able to assess the advantages of that new model car without relating it to the auto accident). The individual understands the experience along non-self dimensions. The greater the number of objective categories available to the individual through the course of development, the better he is able to assess, predict and control his experiences without being biased by an inappropriate self-reference. His functioning is more effective, more adaptive and more mature than his subjective counterpart.

As discussed more completely in later sections and Parts III and IV, I believe that the symptoms of acute grief are understandable as regressive changes along one or more of these four dimensions. A summary of these criteria is given in Figure 3 , and in Tabie 1.

D. The Importance of Core Relationships

1. General

Thus far, I have theorized about the overall cognitive matrix, its general nature and functioning, as well as some of its developmental background. This matrix of dimensions, meanings and conceptual categories that the individual uses to construe his environment is postulated to be a differentiated, 
Figure 3. Suminary Chart for the Assessment Criteria of Cognitive Developient and Functioning.

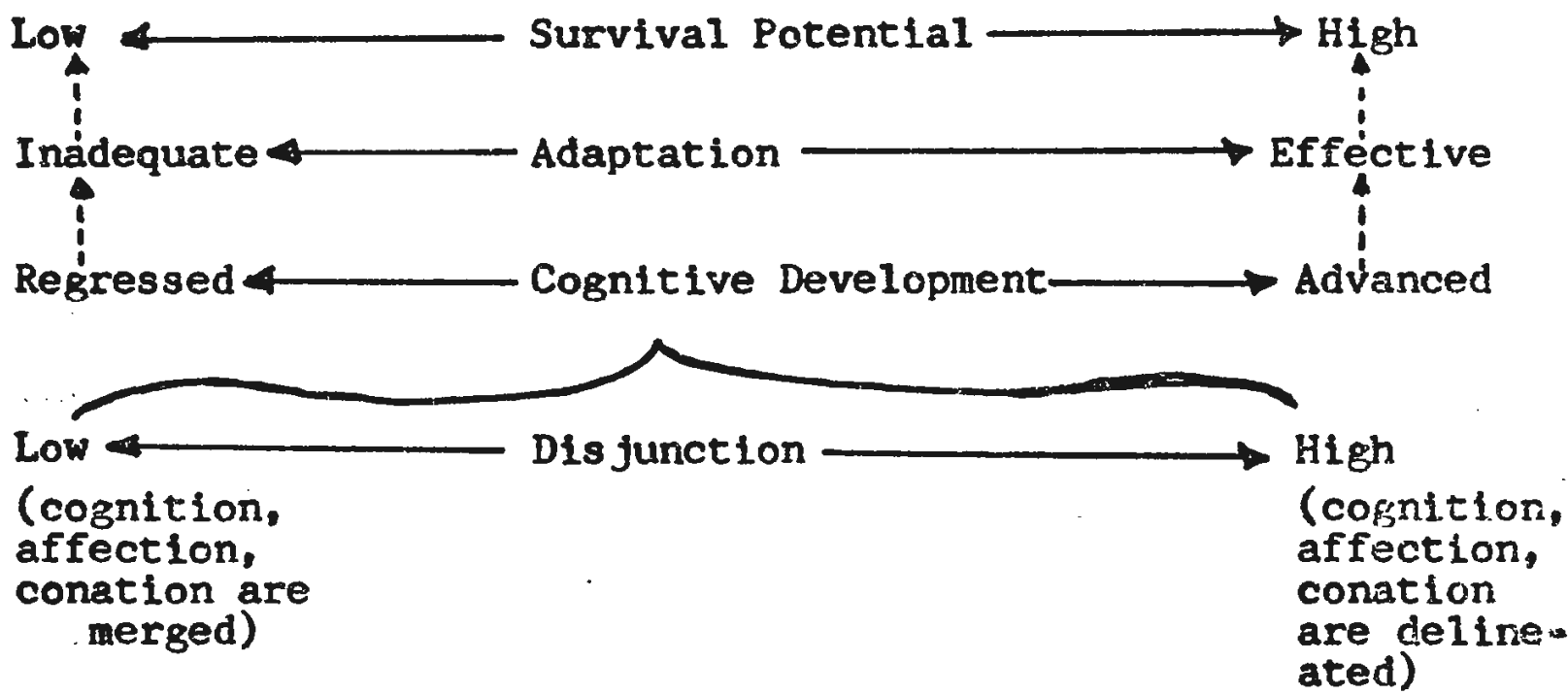

Extreme

Absorption .:

(rigid)

or

Extreme

Modification

(1abile)

Extreme

Dilation

(expansion of matrix)

or

Extreme

Constriction

(compression

of matrix)

or

Rapid Oscillation
Adaptation

Cognitive Activity

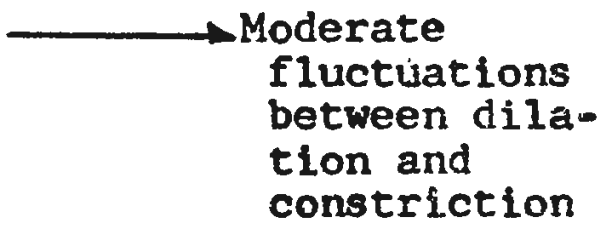

Equilibrium

with moder-

ate absorp-

tion and modification (flexible)

Overly

Self-reference

Subjective 
2

8

是

.

8



堀

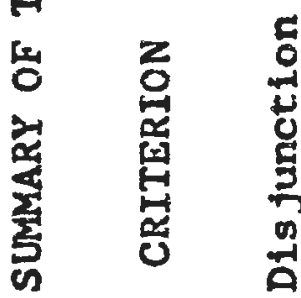

잉

造
곤

- 万ิ 겅

का में ज्य

खर क्षे की

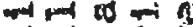

80

类

0 는

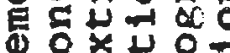

$4=200$

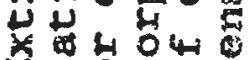

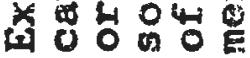

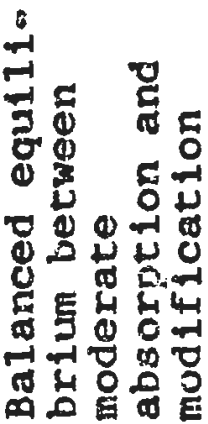

里

点慪

D $5 \mathrm{~N}$ or

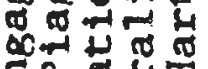

Cथ ต

0.

क 05

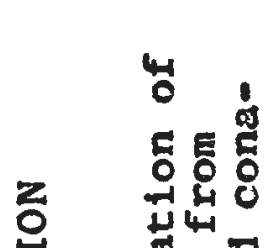

点 总医

2 of

近

牙

兘羊㟧

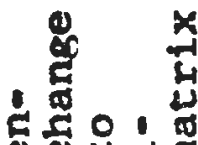

ㄷํㅇํำ

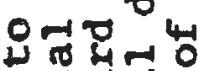

$4 \pi$

为

婂

द $>-1$

운돈

Q

ठ굘
10

3 문

40 is

동

ㄷํㅇำ

네

(느음

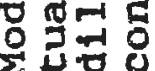

出

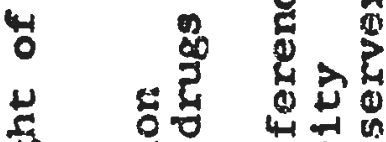

- 0 造

ज为证

40 क

(⿻) 000

$4-140 \%$ तो

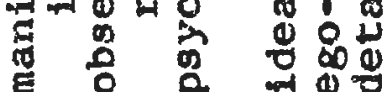

oc

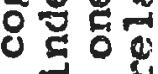

운 4

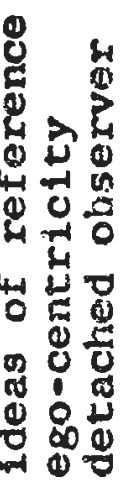

我占

0 崖势 
integrated and organized structure. It is upon these structural aspects of man's cognitive frame-cf-reference that I will now focus attention.

The actual impingement of stimuli is highly variable and a function of a person's circumstance and situation. Therefore, survival or other forms of goal-directed behavior require some selectivity of comprehension, mediation and action choices. A completely chaotic and cognitively un-differentiated position vis-a-vis the complex impinging stimuli forecloses the possibility of selective and effective response. Therefore, adaptivity (i.e., effective interaction with the environment) implies and necessitates an underlying organization of relative coherence.

'Organization'itself refers to the existence, within a totality, of super-ordinate and sub-ordinate dimensions, and to the inter-relationships between these dimensions. Therefore, a person's cognitive framework is postulated as being hierarchically ordered, with certain dimensions having a greater centrality or importance than do others with regard to the integrity of the cognitive structure as a whole.

Since my analysis of acute grief presumes that the death of a significant other is centrally traumatic to the cognitive matrix, it is necessary for me to establish that these relationships are, in fact, of core importance. I believe that the principle criteria for deducing which dimensions hold core positions in the matrix are (a) their relevance to adaptation and survival, (b) their primacy or developmental sigrificance, and (c) their quantitative 
centrality; i.e., the number of other structural dimensions interrelated with the component under consideration.

2. Survival and Adaptivity

With regard to the first criterion, it is reasonabie to assume that the cognitive dimensions relating to the individual's survival functioning (and hence its adaptive functioning) are amongst those of central importance, since self-maintenance is given as the basic energizing force of man. It follows that the viability of these select structural dimensions will have a major influerce on the individual's environmental interaction and adaptive effectiveness. In other words, those aspects of the cognitive frame-of-reference which are functionally useful for the individual in selfmaintenance and in attainment of valued goals (e.g., assessing another's cooperation) are super-ordinate to those dimensions which are less utilitarian (e.g., assessing another's hair color).

Although there are rare exceptions, man is basically a social being, interdependently involved with others for reasons of self-maintenance, self-satisfaction and goal attainment. While the degree and intensity of such involvement and dependency vary widely, it is usually granted that our survival is largely a function of our interaction with other peopie ... a few of whom take on a greater significance than others. The content of our adaptation, i.e., our interaction with the enviroment, is primarily other people. Typically this includes a select group of people (such as family and friends) with whom we interact frequently around 
most major and many minor issues, As a result of this form of adaptation-interaction, cur functional relationships with these significant others are of considerable importance in day-to-day coping and self-maintenance. Therefore, the cognitive dimensions assoclated with these relationships become relevant to effective survival; hence, they evolve as central or core components of the full cognitive matrix.

\section{Primacy}

Primacy refers to the developmental history of a particular cognitive component. Those structural dimen8lons which appear early in the developmental sequence (e.g., self-others) are more likely to be highly differentiated in the adult because of the longer temporal opportunity for delineation. For similar reasons of greater temporal opportunity, there is a higher probability that these earlier dimensions are substantially integrated into the matrix. Furthermore, since by definition, differentiation involves the separation of a larger whole into component parts, those cognitive dimensions from which many others are derived (i.e., those delineated early in development) are likely to have a multiplicity of bonds and linkages throughout the matrix. For example, the dimension of 'others' may be separated into males and females, then further differentlated into friendly and unfriendly males/females, then friendly males who are trustworthy or untrustworthy, etc. Trustworthiness may then be linked to the concept of honesty which is connected to cooperation and so on. Finally, during infancy and childhood early dimensions, 
being relatively few in numer, carry a greater developmental burden or proportion of the individual's comprehension of events he encounters. Though this burden 13 diffused as the structure expands with growth, the historical association between primacy dimensions and the early and adaptively rewarding reductions of impinging stimuli chaos are likely to make these dimensions more important to the individual. For example, in infancy, the interaction with other people may be understood only via the dimension of 'others'. Since males and females are merged, as are friendly and unfriendly males, into this global 'others' category, there can be potentially confusing and inconsistent interaction with other people whe sometimes are male, sometimes female, sometimes friendly, etc. As differentiation occurs, the early and derived dimensions (male/female, friendliness) allow some reduction of the inconsistency and confusion, and are therefore of early and sustained importance to the cognizer.

Many theorists, from Freud to Rogers, have noted the importance of other people in the very early and emergent development of the infant and child. Indeed, the primacy of differentiation between seif and others have been expounded upon at length (e.g., Sullivan, 1953) as a major developmental indicatur of growth. Because of the limited self-sufficiency capabiitites of the infant and young child, human dependency on others for basic sustenance continues for a prolonged post-natal period. In other words, the individual has an early, initial need for others which occurs 
at the very beginning of one's developmental history, and results in early differentiation of the world into 'me' and 'not-me'. The 'not-me' category is largely comprised of other people. This initial (primacy) distinction between oneself and surrounding others, forms the basis for later delineations of different aspects of oneself, and for future discriminations between different others. In other words, the conceptual dimensions by which we know aspects of ourselves, and by which we know distinctions between other people, can be viewed as having their origins in these early, primacy differentiations of 'me'/'not-me'. Therefore, an individual's relationship with significant others is propased as having a long developmental history and, thereby, meeting the primacy criterion as a core cognitive dimension.

\section{Quantitative Centrality}

'Quantitative centrality' refers to the number of other structural axes which are, in some direct way, related to the dimension under consideration. The direct connection is an important qualification, because the individual's cognitive framework is postulated as a structurally integrated totality. Thus, there are interconnections of varying steps or degrees between any two particular components. Figuratively, it is possible to move, stepwise, from cre corner of the matrix to the opposite corner. However. the reference here is to the more direct inter-relationships of certain dimensions to many others ... much like the axle of a spoked wheel which is directly linked to many poincs on 
the clrcumference. Such quantitatively central cognitive dimenstans can be portrayed as conceptual categories about which lles a heavily ciustered constellation of other. related conceptual categories. Thus, these central dimensions serve as anchoring points for a multiplicity of other matrix components which are individually and collectively used by the person in the comprehending of his world. Each of an individual's relationships with others (e.g., marital, friendship, occupational) are not the same in terms of their numerical 1inkages to additional components of mis cognitive matrix. Some of these relationships (e.g., warital, parental) are directly involved with a greater number of cognitive dimensions than are others (e.8., occupational, recreational). Those relationship dimensians which are bound to a larger proportion of daily events are likely to have a proportionately larger influence on the individual's overall cognitive functioning, since they will be called upon more frequently. Usually, the relatloriships that fall in this grouping involve intimate family mbers. Their lives and one's own tend to be quantitatively more inter-related than do the lives of people Eurther out on the periphery of one's life-space. The quantitative centrality of a spouse, parent or child is viewed as greater than that of vendor, employer or even most friends. The cognitive dimensions concerning these more significant others are directly affillated with many other structural components with which the individual construes and relates to his world. 


\section{Self Identity}

In addition to meeting the three criteria of a core dimension, I believe that relationships with significant others are essential keystones to an individual's selfidentity. All the various cognitive dimensions that are concerned with the relation of oneself to others, objects and events in his environment are seen, in their totality, as forming an individual's self-identity. The answer to "Who am I?" cannot emerge in a vacuum, but takes relevance from its context. Identity, therefore, is viewed by me as arising from the composite of dimensions dealing with relationships between the individual and the elements in his context. These provide his understanding of himself in relation to his world, thereby grounding him, stabilizing him within the context of his own life circumstances. However, all such relationships are not equally significant. As core dimensions, I believe the relationships the person has with significant others, are central to all other identity relationships, as well.

Based on these ideas, as summarized in Figure 4, I have concluded that a person's relationship with significant others in his life, typically immediate family members, forms a core and basic dimension of his cognitive matrix.

E. Sudden Death as a Disruptor of a Core Cognitive Dimension 1. Steady State

Typically, the individual is in a relatively steady 
Figure 4. Summary Chart of Bases for the Inportance of Core Relatfonsinips

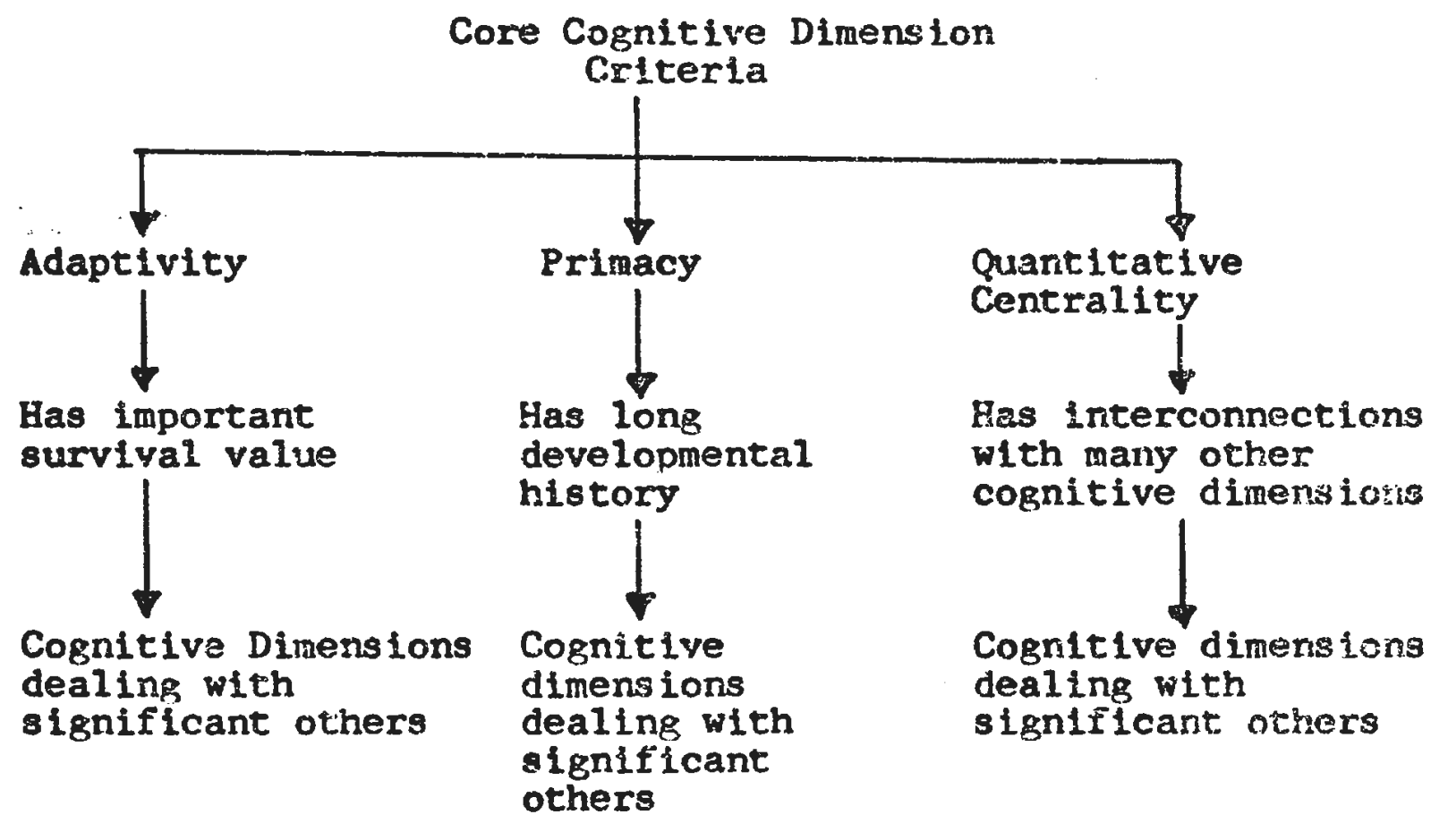


cognitive state, experiencing gradual expansion of his cognitive framework during his daily encounters, through increased differentiation, re-organization and re-integration. The adult is assumed to possess a moderately efficient and sufficient construct matrix for adaptively interacting with the environment of which he is a part. His conceptual categories, the tools of his comprehension, ordinarily suffice to give him scme understanding of events, allow him to attribute his own meaning to his experiences and provide the machinery for processing the data for decision making and action choices. The day-to-day, moment-to-moment encounters which demand cognitive response are usually met competently and routinely by application of the battery of structural dimensions available to the person. In this way, he is able to maintain his equilibrium and stability in the world, able to predict certain consequences to his behavior; and able to control the variety of chaotic environmental impingements so as to understand them in some coherent, organized fashion. He is thereby able to increase his probabilities for goal-achieving decisions.

Whenever a moderately novel event is encountered for which his cognitive structure is less than proficient (such as how to adaress a man attired in woman's clothing), the individual can (a) distort the experience to make it fit the pre-existing structure (e.g., address the person as he or she, and thereby disregard the incongruence), (b) deny/ reject the experi ence altogether (e.g., ignore the person), (c) construe and respond to the event with the conceptual 
tools he has available (i.e., ineffectively. respond by fumbling "he", "she", "it"), or (d) he can attempt to modify his cognitive matrix somewhat to meet the moderate confrontation. The latter tact might involve some further differentiation of an already existing dimension (e.g., from men globally to men who wear men's and those who wear women's clothing); or it might involve a new combination of constructs, a reorganization (e.g., associating women's clothing with both sexes rather than linked only to women): or it may involve the addition of some wholly novel dimension which is then incorporated and integrated into the framework $(e . g .$, adding the concepts of transvestite or of bisexuality or of unisex clothing). Note, the individual's cognitive structure is not intended, even ideally, to be able to accommodate all stimuli, but rather only intended to be able to adaptively comprehend those events which it has or is likely to engage. Hence, the normal, steady-state of man's cognitive functioning is a mild mixture of coping with routine and adjusting to novelty.

However, some events are undoubtedly more confronting of one's cognitive capabilities than are others. They are more than moderately novel experiences. Rather, they are highly challenging events which demand a considerable degree of cognitive adjustment for their competent comprehension. These phenomena (e.g., puberty, marriage, retirement) present the individual with a major cognitive challenge.

2. Confronting Cognitive Challenge

A critical distinction which the reader must make is 
between the form of cognitive challenge which is confrontative as opposed to a challenge which is destructive.

The confrontative cognitive challenge can be exemplified by a shift in the individual's cultural surroundings, i.e., culture shock. He finds himself faced with numerous new expertences for which he has no conceptual categories. His cognitive matrix has not developed an appropriate set of dimensions with which to adapt to the new environs, and he is confronted with events that he either can't make sense out of (because of his lack of applicable concepts); or about which he makes serious errors (because of his application of old concepts to a new and different situation). Adaptive functioning is reduced since his effective control and prediction of interaction is now seriously limited. Culture shock manifests itself within the individuai as massive cognitive overload which requires, after an initial period of confusion and disorganization, a period of rapid realignment and re-categorization of one's conceptual dimensions. The individual must, in order to effectively and appropriately cope with his new cultural context, make some important and major changes in the structural framework with which he understands the world.

It is toward this type of 'confrontative' cognitive challenge by sudden overload that Toffler (1970) has addressed himself to in Future Shock, where the individual is described as being repeatedly challenged by the rapid rate of change within his own culture. The resultant confusion. frustration, anxiety, depression and somatic 
synptorology detailed by forfler seens a function of both the overload demand itself and the wearing down effect of its repetitiveness. Nonethaless, survival is dependent on the individual's ability to control the chaotic, novel and chamging stimuli toward a rate of input which allows more gradual readjustment of his construing matrix. If this end can be accomplished, then a confronting cognitive challenge can become an impetus for cognitive growth. In this case, a growth spurt occurs because the individual has, in a relatively short period of time, considerably modified his overall framework. It is this positive outcome which is usually reierred to when "crisis theorists" (e.g." Caplan, 1964) speak of the important role played by certain life crises in providing the developmental process with an Impetus toward growth ... It is my contention that a sudden death crises poses a cognitive challenge of a very different order.

\section{Destructive Cognitive Challenge}

The confrontative/overload challenge demonstrates the inadequacy of the existing cognitive system when simultaneously Eaced with a large array of novel experiences. It forces rapid expansion and modification as the solution. However, the sudden death of a significant other involves the destruction of a core dimension, not merely its overload or confrontation. I have described in the previous section, the keystone properties of those cognitive dimensions which deal with significart other people, their importance in adaptive functioning, tiseir lengthy developmental history 
and their quantitative centrality. The loss of one of these core relationship axes challenges the very structural integrity of the survivor's conceptual matrix. It is my belief that sudden death represents such a loss and results in considerable danger to the mourner's continued functioning.

This is significantly different from a culture shock experience. With culture shock, the individual's cognitive structure remains intact, though its effectiveness is reduced because of the inadequate capabilities regarding the new stimuli. However, the sudden death of an important person in one's life results not merely in an assault on an existing framework, but rather represents a traumatic destructive impact with the concomitant elimination of a vital component of the framework itself.

This destruction is rapidly followed by an onrusin of events and experiences, not necessarily novel ones, upon a seriously damaged cognitive matrix ... a matrix whose effectiveness is substantialiy reduced because of the sudden absence of a core dimension, rather than the presence of novel stimuli.

Figure 5 represents a summary of the above notions. 4. Suddenness

It is necessary to underscore the extreme nature of the three components that make up the particular phenomenon under review here, namely the (a) sudden, (b) death, (c) of a significant other person. When any event occurs unexpectedly there is no opportunity to prepare or pre-adapt to the change. The lack of anticipation forces the person 
Figure 5. Summary Chart of the Effert of Sudden Death as a Dieruptor of Cognttive Eunctioning

Steady state of cognitive functioning with routine adaptive interaction with events

Moderately novel event encountered 1

deny/reject

experience

distore event

to make it $f i t$ pre-existing

matrix

construe/respond ineffectively

with availabie

conceptual

dimensions

$\rightarrow$ moderate modification of matrix

to accomodate event without distorting it

Further dimension

differentiation

Further

dimension

reorganization

Further

integration of

wholly new

dimensions
Highly challenging event encountered
Nove1 events

Confrontative

(e, g, culture

shock)

Cognitive overload and moderate inadequacy

Mild confusion (if appropriate dimenslons are lacking) and/or

Error(if old, inappropriate dimensions are applied)<smiles>C1CCCC1</smiles>

Cognitive expansion and

Cognitive modification<smiles>[AlH][V]</smiles>

Destructive

(e.R., death of a significant other)

Elimination of core dimension<smiles>[3H][Te]</smiles>

Cognitive inadequacy and insufficlency regarding routine events

Routine events are overloading<smiles>C[13CH]</smiles>

Symptom manifestation 
to face the event pith shocking onset. Suddenness leaves trauma in its wake, for the demand to cope with major change had not been predicted and is, therefore, unplanned and dis ruptive. Ongoing interactions of living continue while the individual is still stunned by the event. This compounds the confusion of his construing mechanism. The cognitive matrix, almed specifically at the control and prediction of events, is faced with its very antithesis ... an unpredicted, unpredictable challenge of maximum import.

5. Death

Death, as the event in focus, has special features, irrespective of the suddenness of onset. While avoiding the many philosophical expositions on the phenomenon of death, it is reasonably assumed that it is a mysterious and awesome contemplation for most people. The way one conceptualizes death, as an abstraction, will certainly have some influence on the impact of having to face the loss through death of someone important. However, for purposes of this section, the significance of the death event lies in its concrete consequences, rather than its abstract relevance. The death of another person represents an irreversible termination of the relationship. The severance is permanent and unchangeable, without rational hope of re-couping the loss or for bringing closure to unfinished aspects of the relationship or for correcting prior errors. Though memories may sustain, death, in effect, destroys a cognitive dimension along with the linkages that bound other dimensions to it. The matrix now contains a void, the size of which is a 
function of whose death occurred.

\section{Significant Other}

The importance of cognitive structures involving significant other people in one's life has already been detailed and postulated as core cognitive dimensions. This means that the relationship is pervasively linked to many other elements in the matrix, forming a major constellation of conceptual categories and axes by which the individual understands himself, his environment and his interactions. The loss of such a core dimension leaves a void of sizeable parameters and leaves the individual without a large functional portion of his previous cognitive framework, though he must still encounter and interact with the routine events of daily life.

Thus, the sudden death of a significant other (see Figure 6) is viewed as a traumatic and unexpected event which results in irreversible damage to an individual's cognitive frame-of-reference, rendering a large and core segment of that matrix, along with its associated linkages, vacant and inoperable.

Consequently, when a central construct is abruptly and irretrievably severed (i.e., by a sudden death event) the individual is ro longer confronting, understanding and dealing with his world from his standard position. Instead, he is forced into a state of emergency (1.e., acute grief), for his usual key resources for interaction are no longer available to him. Furthermore, his cognitive matrix and its internal structure face a massive insufficiency; 
Figure 6. Symary Char of the Bases for the iffects of the Suduen Death of a Significart other

Sudden............Death.......... of a Signiflcant Other
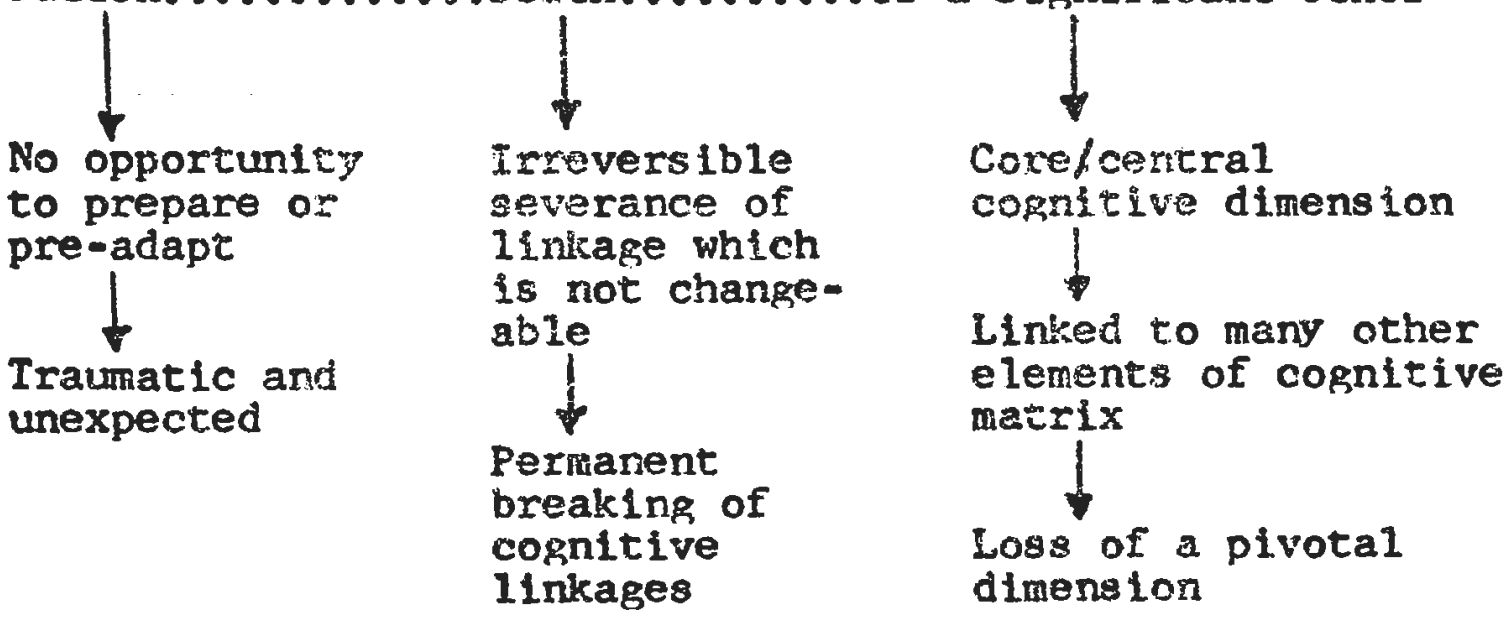
since a pivotal element ant 1 indige (1.e., a significant. other) is destroyed. The individual is in a personal crisis and finds himself unsuccessfuliy sncountering events which were previously routine. They are now overloading. This experlential inadequacy state with regard to cognitive functioning leads to confusion, disorganization, stress and a host of acute grief symptoms.

F. The Influence of Cognitive Disruption on Symptomology 1. Introduction

The acutely bereaved has suffered a dramatic rupture of his organized method of construing events. Therefore, he is likely to - and, in fact, does - deal with subsequent encounters in somewhat different ways than he had in the past. More importantly, he is likely to undergo a variety of experiences which are atypical for him, but which are relatively common sequelae for the survivor of a sudden death phenomenon. These experiences are, in the composite, termed 'the acute grief process' and include changes in all major spheres of functioning ... cognitive, somatic, affective and behavioral. This chapter will offer some theoretical notions that attempt to bridge the cognitive-disruptive state previously described and the multi-sphere symptomology of acute grief to be detailed in Part III.

The premise for a cognitive model of acute grief rests on the notions that the principle consequences of a sudden death event upon the survivors are cognitive in nature; and that symptomology in non-cognitive spheres is derived from or secondary to the initial cognitive impact and disruption. 
Having presented the foregoing cognitive model for man's functioning, it is now incumbert upon me to apply that paradigm to the grief process in order to determine its descriptive and explanatory power for that phenomenon. I shall do this, not only wi.th regard to the cognitive dysfunctions of bereavement, but for the multiple-sphere dysfunctions which constitute the whole grief process.

The sections in Part III will describe in greater detail the specific symptoms of mourning and relate them to their cognitive origins. Here, the aim is to provide a more general connection between cognitive disruption (with its resultant cognitive inadequacy) and the somatic, affective and behavloral spheres. In other words, this chapter's goal is to explain how cognitive disruption influences physiology, emotionality and activity, in general; while later chapters will focus on the effects upon specific symptoms of acute grief.

2. Effect in Cognitive Sphere:

(a) Cognitive Regression

Cognitive disruption (i.e., destruction/elimination of a core cognitive dimension, as occurs with the death of a significant other) yields as a necessary corollary, cognitive inadequacy. As already mentioned, this inadequacy differs from that which is caused by the overload of large numbers of novel stimuli, though both situations deal with the persons reduced effectiveness in coping with the world and events. Cognitive inadequacy resulting from a sudien death leaves the individual without the cognitive categories 
previously available for cealire with any of the routine, day-to-day encounters of living (e.g., decisions typically shared by spouses concerning parenting, employment choices, vacation plans, love-making, etc.). What was once routine is suddenly novel and overloading (e.g., preparing correct quantity of food for dinner for 3 people rather than 4), because of the damage to the structural components (e.g.. cognitive dimensions relating the deceased child to how much he eats) that were previously used for making sense out of prior, routine events (e.8., preparing dinner for four).

Thus, cognitive inadequacy is a function of neither person nor environment alone, but rather dependent on the interaction between the individual with his particular cognitive matrix (in this case, a matrix that lacks a core dimension) and the context with its particular cognitive demands (e.g., preparation for dinner). When a person, like the acutely bereaved, lacks the refined and sophisticated matrix for meeting certain contextual demands of adaptive coping, he must respond in a less refined, less sophisticated, more crude and more disorganized manner. Rather than making an advanced developinental response (e.g., preparing a properly distributed meal for four family members), he must fall back on less advanced methods of understanding his world (e.g., a buffet, with too much or ton little food); methods which are not dependent on the damaged core dimensions or its linkages. Such a movement backwards to a less refined, delineated, organized and 
integrated framework of eognitive functioning is cermed "cognitive regression".

Regression is not pervasive throughout the individual's cognitive matrix, since his cognitive inadequacy is defined only in relation to the contextual demands at hand, and these may be limited to particular areas of functioning (e.g., family interaction, but not work). However, it has been noted that a core dimension is an important keystone to the entire structure and has, therefore, at least some Influence throughout nost of the matrix. It can be assumed that cognitive regression for the acutely bereaved is most extreme in those areas directly relating to the deceased (i.e.. dally activities and decisions usually shared), with decreasing effects on those peripheral zones that are more distant from the damaged core (e.g., the car needs a tuneup). Since a central dimension has been involved in the event of a sudden death, the cognitive framework as a whole may be viewed as being under strain, though the outer ripples of the event's aftermath are less violent than those closer to the core.

Thus, the death of a significant other damages and disrupts a core cognitive dimension with which the person coped with events, construed experiences and understood himself in relation to his world. This disruption creates a state of great cognitive inadequacy and insufficiency, (i.e.. reduced coping ability), especially when the person must respond to events which are related directly or 


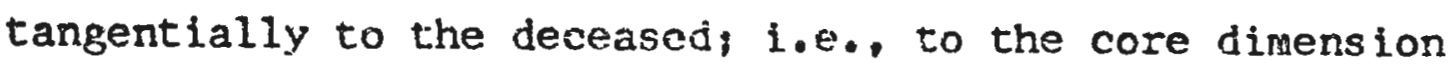
that's been disrupted. Adaptation and survival denands, however, force the individual to attempt some form of effective construing of events. This, in order to obtain at least miniaal need gratification from the environment and to avoid the chaotic state of a completely disorganized interaction with the world. This regressive, fall-back level of cognitive functioning to which the person retreats is relatively less developed than that existing prior to the cognitive disruption, when the cognitive framew rk had been intact and undanaged. However, it allows at least some protection from complete cognitive breakdown.

The regressive reversal of cognitive functioning to earlier levels can be described in terms of those criteria which were used earlier in the analysis of the developmental process of cognitive growth, namely, (a) disjunction, (b) absorption-modification, (c) dilation-constriction, and (d) subjectivity-objectivity. I contend that the survivor of a sudden death experiences regression along each of these criterion parameters. And in addition, that he experiences significant effects upon the overall differentiation, organization and integration of his entire cognitive structure. Adaptive efficiency, general ability to adequately understand and cope with interactions, and predicting/controlling capabilities are similarly affected. Finally, as a major by-product of reduced cognitive effectiveness, the bereaved experiences considerable cognitive overload. These consequences of sudden death upon the acute 
grief syndrome will be discussed on the following pages (see Figure 7).

(b) Disjunction

Disjunction was defined as the separation of the cognitive, conative and affective modes of relating to objects within a particular content area (see page). As part of the regressive process subsequent to a sudden death, there is a major reversal of disjunctiveness, especially in those areas of the cognitive matrix which deal with the deceased. Desire and emotionality merge with cognition in these content areas and severely interfere with the ability to give rational thought to the deceased. There evolves a mixture of intense feelings, strong desirability and cognition of the deceased. There is, in other words, reduced differentiation within this content area, such that the mourner's knowledge about the lost person is highly contaminated by whether he wants/rejects, likes/ dislikes the dead person. In particular, affect and cognition merge. For example, prior to his wife's death, a bereaved husband may be able to discuss her career goals in factual and informative terms without becoming emotionally aroused. After the death, he experiences such a conversation as distressing because of his intense desire for her presence mixed with profound feelings of emotional turmoil. There is, post-death, considerably less disjunction between the cognitive, conative and affective modes of relating to his wife's career plans ... a result of cognitive regression (see Figure 7). 
迠

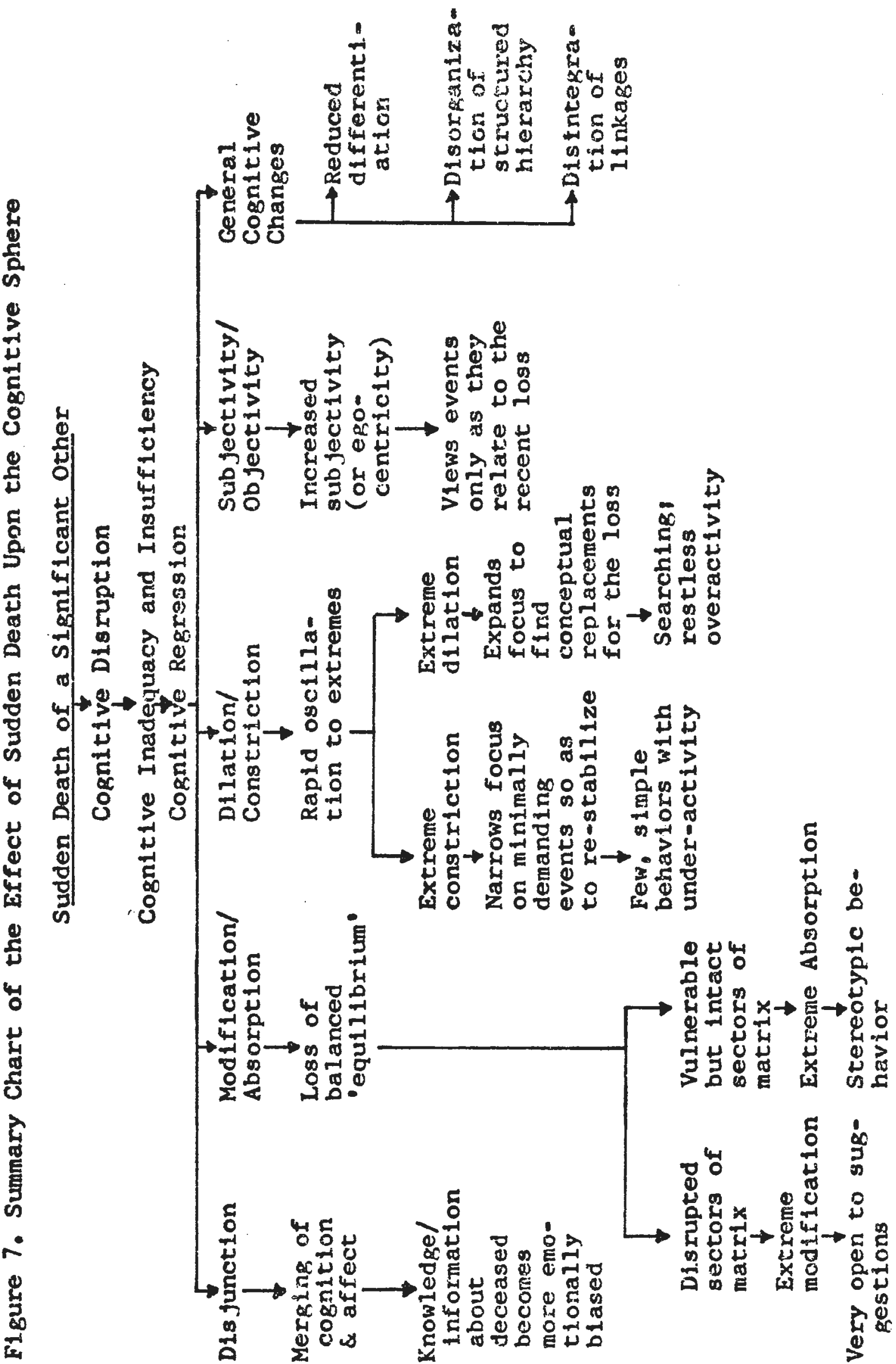




\section{(c) Absorption-Modification}

Sudden death leaves the mourner at a great disadvantage in some spheres of his cognitive matrix (e.g.. decisions about raising the children), and at lower risk in other, less directly involved areas (e.g., decisions at work about business transactions). Conceptual dimensions relating to the deceased are no longer available; while other dimensions are made vulnerable due to the general loss of structural integrity attendant to core construct damage. The protective reaction which ensues in the vulnerable, but intact, dimensions is one of increased absorption or rigidity (e.g., fob behavior becomes stereotypic and rigidified). Since there is massive change and modification necessary in the disrupted sector of the framework (i.e., dimensions surrounding the deceased), the other non-disrupted sectors (i.e., those areas of one's life, such as work or school, which are less directly involved with the deceased) compensate by lowering their flexibility to change, i.e., by greater absorption. The bereaved distorts and otherwise assimilates events into these more peripheral cognitive dimensions, without the usual flexibllity of compromising some structural aspect in order to make a better fitting of event to matrix. For example, at work the acutely bereaved becomes more dogmatic in his decisions and more routine or mechanical in his behavior. In other words, a balance between event and cognitive adjustment (i.e.. equilibrium) does not occur because there is such a large cognitive adjustment demand being made in those other dimensions relating to the death. If 
further adjustments are made in peripheral dimensions (e.g., change of job at same time as death occurred), then the entire, unstable structure may possibly collapse into chaos. Therefore, the bereaved tends toward extreme rigidity in his non-disrupted zones; he has lost so much functioning effectiveness in the core areas that he stiffly holds on to what remains intact.

In contrast, an acutely bereaved individual is very susceptible to modification of his cognitive matrix, in response to environmental encounters, in those areas which are somehow associated with the death or the deceased. In these areas there is a void that requires filling, and the mourner is open to considerable influence from impinging events (e.g., other people's comments). To this extent in these disrupted core cognitive dimensions and sectors the person is highly modifiable, labile and suggestible. He is very open to suggestion and makes futile efforts at repairing the cognitive damage with any of the varied inputs that present themselves.

It is this modifiability that crisis interveners focus upon when they offer help to the acutely bereaved. Certain sectors of the individual's cognitive matrix are especially open to change during this critical period. A trained intervener can provide appropriate new methods for construing events which will reinforce the structure and lead toward substitutive dimension formation, both these goals aimed at restoring cognitive framework integrity. For example, 
by suggesting activities that will lead to the formation of new relationships, such as joining Parents-WithoutPartners.

Thus, a sudden death results in movement by the individual away from cognitive equilibrium and flexibility, and toward extreme absorption/rigidity in the peripheral areas with converse extrene modification/lability in those sectors linked to the death and the deceased (see Figure 7).

(d) Dilation-Constriction

Another regressive change in cognitive functioning involves the continuum of dilation and constriction. Acute grief results in rapid fluctuations between these cognitive activity poles, along with parallel shifting in behavioral activity levels. The mourner may first narrow or constrict his focus onto environmental interactions which make only minimal cognitive demands (e.g., spending the day in deciding what to cook for dinner). Constriction is usually aimed at re-grouping one's cognitive structure in order to reassert some measure of stability. Then he may shift to uncoordinated expansion of cognitive efforts in order to find conceptual replacements for the dis rupted components of his matrix (e.8., trying to figure out the 'real' cause of death, such as how an obvious suicide can be explained as an accident). Dilation has as its primary purpose, the searching for substitute concepts or ways of understanding events, thereby replacing the loss and refilling the void. This oscillation between a narrowing and an expanding cognitive framework also manifests itself in the behavioral 
activity leveis of the nouner. He nay limit himself to a relatively few, simple behaviors and general underactivity ( $e . g .$, just sitting in the bedroom, eating), then engage in non-goal directed behavior which seems to only serve to keep him busy $\left(e_{.} g_{\bullet}\right.$, takes up a variety of new hobbies simultaneously). This latter activity, when focused on death, is related to the 'searching' phase of the grief process in which the mourner seeks out events and objects related to the deceased in order to somehow re-capture the stability of the past. Both extremes of dilation and constriction tend to be futile and represent lowered functioning capabilities since they are less than adaptive modes of interacting with the environment (see Figure 7).

(e) Subjectivity-Objectivity

The acute grief following sudden death appears to result in the mourner's attention being focused on himself as the center of events. Concern for one's own cognitive stability forces the person's interpretation of events to be based on how they affect and relate to him. He has difficulty dealing with non-personally related phenomena, and tends to distort the objective world by construing it as either irrelevant or subjectively overly relevant to him (e.g., he relates the death of a neighbor's cat to his own loss). There is an over-riding ege-centricity which does not permit the more accurate perspectives of his previous objectivity to surface. This limits the individual's ability to adaptively interact with environnental events. Acute grief subjectifies the mourner, restricting his concern 
to his own disability and distress, and their manifestations. There is a generalized centering upon the world of self, particularly upon the part of self that has been damaged by the death (e.g., woman's self perception as widow rather than as wife). Thus, on this parameter as we11, acute grief involves a regression to less functional adaptation (see Figure 7).

(f) Other Cognitive Changes

Along with these changes in developmental measures, there are general alterations of the bereaved's cognitive framework. He tends to construe interactions in more global terms, i.e., there is reduced differentiation. Selective comprehension (e.g., of children as individuals) yields to grosser forms of understanding (e.g.. of all children as being the same). Cognitive dimensions (e.g., relating to siblings of deceased child) are collapsed and combined rather than being further delineated (such that they all begin being treated alike). This reduces the person's ability to accurately predict and control his experiences. Therefore, his coping skills are less adequate than before the death.

Before he can restructure his cognitive constructs into a functional. entity again after the 1oss, there is a period of rapid disorganization. The traumatic rupture of a core dimension throws the relatively neat structure into disarray. Numerous segments of the matrix must now be rearranged; super and sub-ordirate dimensions must be re-assessed in light of the disruptive death event; the organized framework 
Wich was formerly based, to a substantial degree, on the relationship with the cleceased mist now be reworked to accommodate for the absence. For example, when an older child dies, there is a shift in the way younger siblings are perceived by parents with regard to reassignment of responsibilities; viewing them as needy of greater protection.

In a similar vein, the complex integration of conceptual categories and constructs is disturbed by the death. There is a period of disintegration as cognitive linkages which used to be affiliated with the deceased must now be re-integrated into the remainder of the matrix or they must be abandoned. The connections between elements of the framework are disrupted and new bonds need to be formed which take into account the major loss suffered by the individual. Until these re-integrative processes are underway, the cognitive network lacks firm linkages between many of its components, with resultant confusion and instability. For example, the widow now lacks conceptual links between herself and another on such dimensions as fellow parent, lover, companion, friend, financial advisor, etc. She must realign these connections to substitutes or abandon them.

The overall effects of sudden death in the cognitive sphere are summarized in Figure 7.

3. Effect in Somatic Sphere:

I have noted earlier that I believe the somatic symptomology of the acute grief reaction is secondary to the initial cognitive disruption. However, the cognitive model I have 
proposed does not directly describe the symptons in the somatic sphere without the use of the mediating concept stress. My proposal regarding the connection between cognitive disruption-somatic symptons, requires a brief discussion of the nature of stress and its physiological manifestations. The term 'stress' has often been used so broadly as to encompass virtually any novel or unpleasant experience or situation. My usage, however, refers more specifically to the state in which the individual encounters an environmental threat to his security or survival. This threat may present itself either directly as an assault, or indirectly by overloading the adaptive system to the point of breakdown. These threats typically result in physiological responses associated under the rubrics General Adaptation Syndrome or G.A.S. The origins of G.A.S. symptoms lie in hypothalmic arousal, adreno-cortical stimulation and output, and stimulation of the autonomic nervous system, particularly its sympathetic branch (Cannon, 1929; Parkes, 1972; Selye, 1956).

The cognitive inadequacy experienced by the acutely bereaved reduces his coping abilities and his adaptivity to environmental demands. Disruption has affected the refined cognitive stmucture with which he previously understood the complexities of daily living and with which he previously construed, controlled and predicted events. The mourner is at a serious disadvantage. His usual means of dealing with events is severely limited, placing him in a vulnerable position: that is, a position in which there exists a 
continual threat to his self-maintenance and survival. The cognitive regression which he undergoes in order to retain some sense over his interactions further reduces his effectiveness. Furthermore, the impingement of even routine stimuli upon the cognitive matrix poses an overload that threatens to weaken the damaged framework still more. These forces combine to constitute a considerable threat to the individual, which he experiences as a prolonged period of psychological stress.

Many investigators have emphasized that psychological threat or assault is responded to as if it were physical (Engle, 1962, Frederick, 1971; Lindemann, 1960, Parkes, 1972; Selye, 1956, Wolff, 1953). And Rees \& Lutkins (1967) state that the psychological aspects of grief are invariably translated into physiological reactions. In other words, the state of and subsequent strain of cognitive inadequacy and regression following a sudden death is postulated as sufficlent to place the mourner in a sustained stressful condition. This condition of prolonged and/or intense stress has certain definitive somatic manifestations associated with it (Selye, 1956). These physiological responses occur in virtually all the major organ systems and will be reviewed in detail in Part III of this dissertation. Here, I merely wish to emphasize the relationship between cognitive disruption and bodily stress as a reaction to that disruption.

Therefore, cognitive disruption of a core dimension is seen as extremely stressful to the bereaved because it seriously limits his adaptive abilities, while simultaneously 
making him vulnerable to overload. His conceptual resources are undercut at a time when he needs them most, and this is viewed as seriously threatening to his survival. Since high stress, of even noderate duration, leads to physiological symptoms, it is deduced that the stressful cognitive condition of the mourner will similarly lead to somatic responses. Indeed, as will be noted in later pages, the typical somatic symptoms of the acute grief reaction are basically physiological stress responses (see Figure 8).

4. Effect in Affective Sphere:

In a similar vein, it is my contention that affective responses of acute grief are secondary to the cognitive disruption. Since there are very early and very intense emotions aroused by a sudden death, the delineation of a primary cognitive and secondary emotional effect is both difficult and controversial. Furthermore, the traditional descriptions of the grief syndrome place considerable enphasis on the affective sequelae, both implying and directly stating that the emotional responses are the most important. I disagree. Without negating the reality of intense emotions during bereavement, I believe they are best explained as derivatives of the disarray in the cognitive matrix of the mourner, rather than primary reactions independent of the bereaved's conceptual state. The information is processed first, then the associated feelings are aroused (Beck, 1967). My notions are supported from three principle viewpoints: (a) the dis junctive regression process that follows cognitive disruption; (b) re-definition of the key affective 
Figure 8. Sumary Chart of the EFfect of Sudden Death Upon the Somatic Sphere

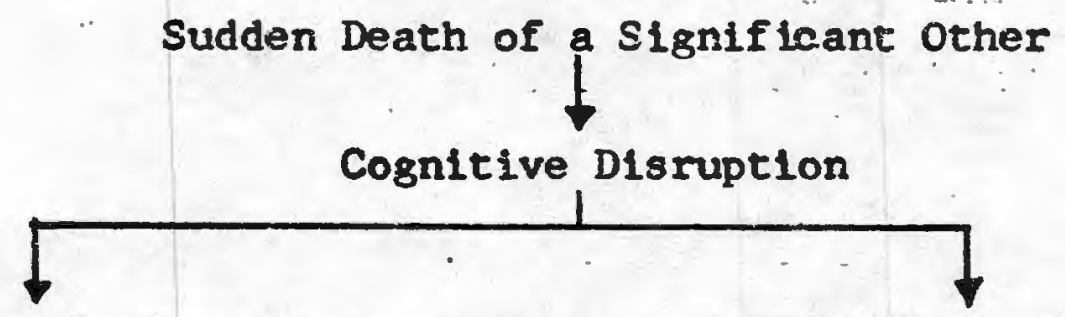

Cognitive Inadequacy

Cognitive Regression-- Psychological Stress $\rightarrow$ Disjunction
$\rightarrow$ Modification/Absorption
$\rightarrow$ Dilation/Constriction
$\rightarrow$ Subjectivity/Objectivity Physlological Stress Somatic Stress Symptoms 
symptoms of bereavement along the 11 nes of cognitive functioning, this has been alreaky proposed by Keliy (1963) regarding anxiety, hostility and guilt, and by Beck (1967) regarding depression; and (c) the hypothes is that certain physiological arousal states are cognitively labeled as emotions: the physiological states themselves having been discussed as secondary to cognitive stress.

(a) Dis junction

The dis junctive process, as a separation of conation and affection from cognition, has been discussed at length in previous sections. The only additional point of emphas is here is that events which are highly ambiguous (lack consensual validation) and complex are more difficult to disjoin than are simple physical events. Interpersonal interactions tend to be ambiguous and complex, and therefore are unlikely to be completely disjoined. Moreover, their complexity demands greater cognitive effort and sophistication for successful coping. Indeed, the construing of most interpersonal situations, though somewhat dis junctive, in the adult, is assumed to have some mixture of like/dislike (affect) and desire/rejection (conation) as factors contaminating the cognition.

I propose that when sudden death occurs and dis rupts the interpersonal dimensions associated with the deceased (which are only partially disjoined to begin with), then the cognitive inadequacy and regression that follows stimulates further merging of feelings and cognitions (e.g., previous discussions about deceased wife's career goals were only 
partially influenced by his feelings tomard her, now they are highly influenced by his feelings). Cognitive regression leads to a reduction in disjunction which, in turn, leads to an arousal of affect in the target area (i.e.. the dis. rupted core dimension) of the regression. In other words, whatever degree of separation has previously existed between enotions and cognitions relating to the deceased, it is likely to be reduced as disjunction is regressively reduced. If affective arousal has been stimulated in this way, then it provably feeds back into the originating cognitive confusion and inadequacy by contaminating thoughts of the deceased with intense desires and emotions (e.g., the newly aroused feelings of sadness make it even more difficult to objectively comprehend and discuss the dead wife's previous plans without still further confusion). Efforts to make sense out of the traumatic event are interfered with by the strong positive and negative feelings being generated. It alsc seems probable that most of these feelings are negatively loaded and unpleasant (e.g., sadness, guilt, depression), since the grief experience is one of distressing instability, insecurity and threat to the framework, which generate fear, anxiety and anger, respectively. Therefore, in addition to the cognitive uncertainty and disequilibrium of acute grief, there is an assumed upsurge of confounding negative emotions which add to the psychological stress of the period. Most importantly, the unpleasant affects aroused are centered in those content areas which have been disrupted by the death and which are already vuinerable to further 
overload. Even though internally generated, these emotions become added stimuil which the weakest zone of the matrix (i.e., those involving the deceased), must, nonetheless, cope with. The unpleasant emotions of grtef, therefore, add to the potential overloading of the system.

Thus, affect arousal is postulated: (a) to be partially a function of the reduced disjunction associated with cognttive inadequacy and regression, particularly since it occurs within an interpersonal content area that is only partially disjoined to begin with; (b) to involve primarily unpleasant and distressing feelings because it is a result of the threatening consequences of cognitive disruption, and (c) as constituting an additional burden, since it contaminates the construing abilities of the individual and adds to the overload of an already strained cognitive system (see Figure 9).

(b) Redefinition of Terms

Acute grief is asscciated with several enotions (e.g.. guilt, anxiety, anger, depression) and a survey of these will be presented in Part III. At this point, I wish to offer some alternate definitions and explanations for some of these affective responses in terms of the cognitive model of man. This re-definition has already been proposed for anxiety, guilt and hostility by Kelly $(1955,1961)$ and for depression by Beck (1967). My discussion of anxiety, guilt and hostility in this section and of depression in Part III. is drawn directly from these authors ideas and writings. According to Kelly (1963), anxiety is the experiential state of chaos that arises from the encountering of "events 
Flgure 9. Summary Chart of the Effect of Sudden Death Lpon the Affective Sphere

Sudien Death of a Significant other

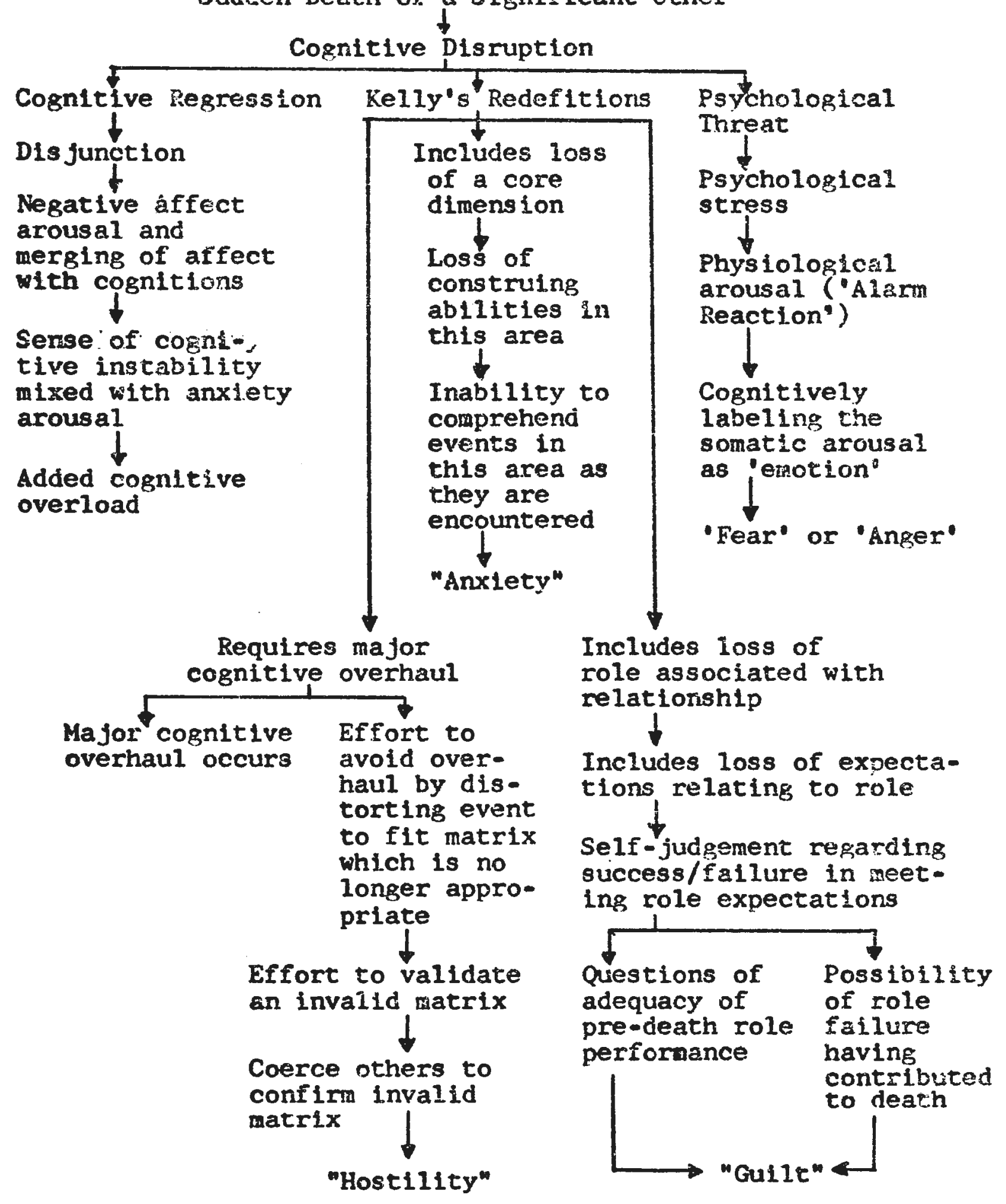


for which it seems one has no adequate constructs" or cognitive dimensions. Lacking the equipment for understanding what's occurring or for predicting events, "one seems helplessly caught up in events, with no idea of what to do after they arrive" (Kelly, 1961, p. 264) (e.g., preparation of meals without the fourth family member leaves the survivor anxious as to what to do). This is an apt description of the condition of the acutely bereaved whose loss of a core cognitive dimension leaves him lacking the means of coping with even routine events. He experiences them as unneetable challenges to his cognitive structure and is overwhelmed by these environmental demands (e.g., plans for the weekend; child's school work; call from old friends). The individual is in a state of emergency and finds himself unsuccessfully encountering events which were previously related to constructs assoctated with the deceased ... events for which he now lacks an operational structural dimension. Such an experiential state of cognitive confusion and overload, bordering on chaos, is defined like Kelly, as anxiety. Anger and its manifestation of hostility, are also components of the affective sphere of acute grief. They have similarly been given new meaning by Kelly (1963). When a situation arises, like a sudden death, which demands a massive revision of one's cognitive matrix in order to effectively cope with the reality of life, there is reluctance to undergo the uncertainty and distress attendant to a major cognitive overhaul. The choice is often the difficult one between either a najor revision of the matrix 
(E.g., acceptance of the 108 and the necessary readjustments attendant to $i t)$, or a major distortion of the event to make it forcenfit into a structure which is no longer viable (e.g., by rationalizing the continuance of the person's presence via the deceased's momentos). Wnen the individual chooses the latter alternative (force-fitting distortion), he may attempt to confirm or validate his distortion, by coercing others to share in accepting the distortion. Kelly (1961) terms this attempt to extort external validation of an invalidated conceptualization, as hostility. "It is not the desire to injure someone any injury is incidental, rather, it is an extortioner's trick designed to preserve the psychological status quo and to relieve him of the responsibility of revising his outlook" (Kelly, 1961, p. 265). The experience of guilt is also redefined by Kelly (1963), again from the cognitive perspective, in terms of role relationships (e.g., self-assessment in role as wife). It was noted that an important element of one's identity is concerned with the way an individual understands himself in relation to events, objects and especially people in his environment. These relationships anchor the person's sense of self, influencing his self-image, self-concept and selfexpectations. They form a set of role parameters (e.g., husband imposes criteria on this role concerning financial support, protection, declsion making) by which he judges important aspects of his success and failure in life. These roles, being interpersonal, seriously involve someone other than himself and usuaily someone to whom he is strongly 
committed.

When the individual loses a core relationship through sudden death (e.g., his wife), he simultaneousiy loses his role associated with that relationship (e.g., as her protector). Since the role included self-imposed role expectations (e.g., successful protection of spouse), these are also 1ost. Kelly defines guilt as this sense of loss of role. He notes that when such a loss occurs, the individual must make a self judgement about whether or not the role loss was a consequence of his fallure in it (i.e., his failure to meet the expectations of the role). For example, following an accidental autonobile death, he will question whether he had her car checked properly. Moreover, the questions that he has about his success/failure in the role relationship can no longer be appropriately tested in contact with the other person. Thus, the possibility of having made a mistake (i.e., been a failure) in the role of parent, child or spouse which may have resulted in the loss of the relationship upon which the very role was built, leaves the mourner with a sense of guilt. It also leaves him with unanswerable questions about the adequacy of his role performance prior to the death (i.e., was he generally and usually protective enough).

In these ways, Kelly $(1961,1963)$ has re-conceptualized anxiety, hostility and guilt so that they are consistent with the other cognitive descriptions of bereavement (see Figure 9).

(c) Physiological Arousal

The third basis of support for the contention that affective response to sudden death follows cognitive discuption, 
utilizes the physlological reaction to stress as an intermediate explanation. I have already discussed the effects of cognitive disruption upon somatic processes in terms of stress, and I've made reference to the 'alarm reaction' that is common to the stressful experience. This alarm reaction consists of intense physiologic arousal that includes stimulation of the autoriomic nervous system, the adrenai glands and several other organ systems (e.g., respiratory, circulatory, etc.). These somatic changes resulting from stress are similar to somatic responses occurring in people who are reporting intense emotional experiences such as fear and anger (e.g., Schacter \& Singer, 1962; Selye, 1956). For example, Schacter and Singer (1962) have found that the subjective experience of emotional excitement is a combined function of the physiological arousal of somatic systems (similar to those arousals experienced under stress) plus the individual subjectively and cognitively interpreting the arousal as emotion (e.g.. experiencing an increased heart rate and interpreting this as fear or anger). In other words, as the body is aroused, the person may label or identify what he's physically experiencing as some type of emotion. Which emotional label is assigned appears dependent on contextual cues and previous experiences with the particular somatic arousal signs.

My reasoning in support of cognitive dominance from this third viewpoint, is as follows: (a) The infurmation concerning death is presented, which causes cognitive disruption; (b) cognitive disruption causes stress: (c) people 
respond physiologically to stress, even if it's psychological stress; (d) the physiological arcusal resulting from stress is parallel to that reported during periods of emotional excitation; (e) the person senses the stress-based arousal and subjectively identifies (construes) it as emotional excitation: (f) the specific label assigned to the arousal (e.g., fear or anger) is determined by context cues and previous experience (see Figure 9).

\section{Effect in Behavioral Sphere:}

The adaptive importance and value of a stable and mature cognitive framework is in its utilization by the individual to understand and behaviorally interact with his environnent in order to survive, fulfill his needs and attain his objectives. The cognitive basis for behavior in general was discussed in Part I (Introduction) and in the opening section of Part II. It may be simply restated that man is an active organism that perceives (e.g.. sees person), construes (e.8., recognizes person as friend), decides upon (e.g., decides to shake hands), and then acts (e.g., extends arm to shake hands) with regard to events that he encounters. When there is damage to the structural matrix upon which these actions are based, such as the disruption following a sudden death, then the behavior of the individual is likely to be subsequently and similarly disrupted. Cognitive in. security, instability and confusion are poor foundations for productive and constructive activity.

The behavioral sequelae to sudden death are viewed as direct manifestations of the cognitive changes previously 
discussed. For example, the disruption of a core interpersonal dimension is likely to send ripples of disturbance through the matrix to other interpersonal dimensions. It is reasonably assumed that linkages existed between this core dimension and axes related to other people. Therefore, many of the behavioral changes would be expected to ... and do ... involve interpersonal interaction or its converse, social isolation (see Figure 10).

(a) Activity Levels

The mechanical behavior of the bereaved is seen as a function of the protective cognitive regression to simpler and less sophisticated methods of interacting with the world. In other words, as the individual retreats to safer, simpler and less complicated methods of understanding and dealing with events, his behavior takes on the characteristic of activity which requires minimal cognitive effort, i.e., automatic behavior.

However, the activity levels of the bereaved can vary from retarded to overly active. This appears related to cognitive constriction and dilation fluctuations. As a means to regain adequate coping faculties, the mourner may frantically expand his activities. His behavior will become aimless, erratic, without consistence or goal orientation (e.g., begins multiple hobbies). Or the person may attempt to preserve the minimal stability remaining by severely restricting and limiting his actions (e.g., by sitting around the house). He performs behaviorally in ways that parallel his cognitive activity level (see Figure 10). 
Figure 10, Sumary Chart of the Effect of Sudden Death Upon the Benavioral Sphere

Sudden Death of a Significant other

Cognitive Disruption

(Cognitive effects)

(Behavioral Manifestation)

- Occurs primarily in core

interpersonal dimensions

$\longrightarrow$ Changes in affiliated $\longrightarrow$ General social isolainterpersonal dinensions tion

Extreme Absorption in peripheral $\longrightarrow$ Stereotypic/rigid zones behavior

$\rightarrow$ Extreme Modification in discupted $\longrightarrow$ Searching environment zones for cues regarding deceased

Extreme dilation Erratic/aimless restlessness

$\rightarrow$ Extreme constriction Retarded motor behavoor

$\rightarrow$ Subjectivity increases $\longrightarrow$ Social isolation: hypochondrias is

Cognitive symptoms

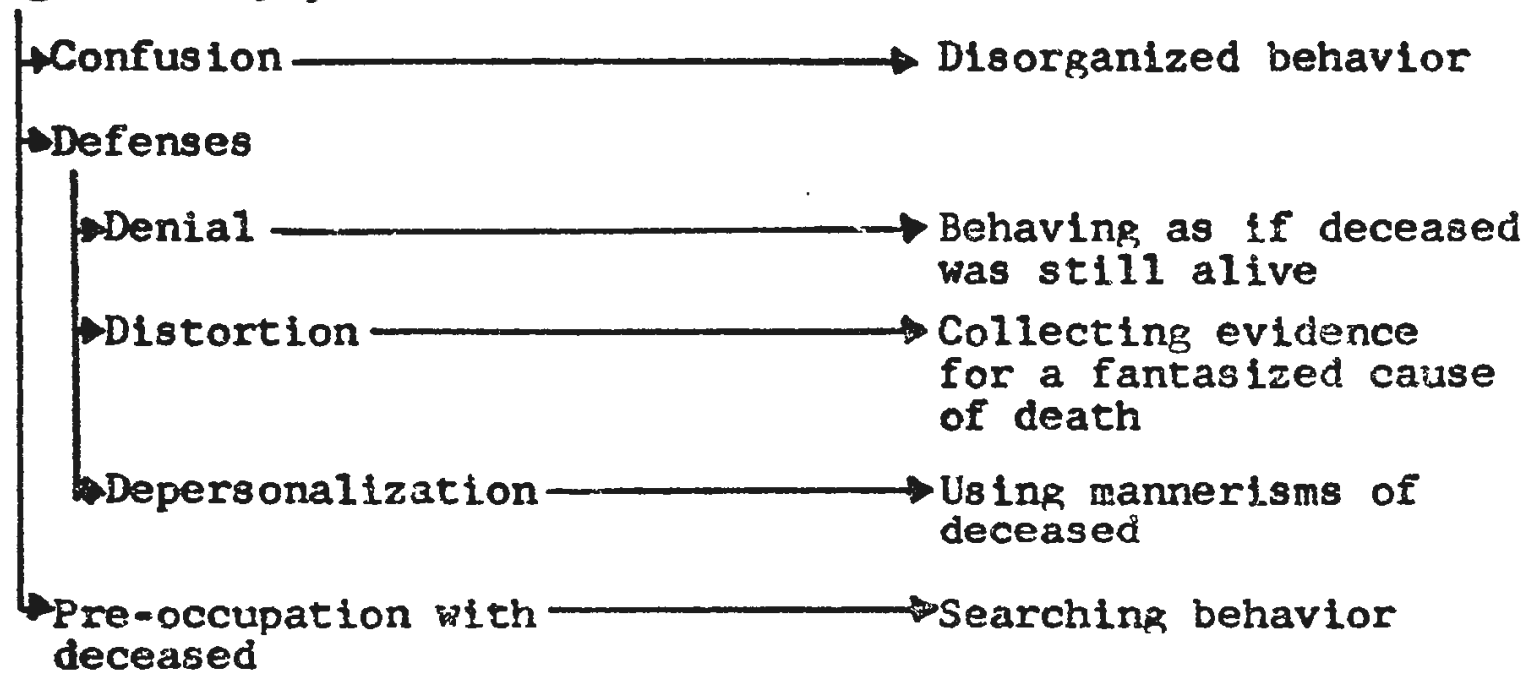




\section{(b) Searching}

Another exannle of the cognitive-behavioral parallels involves 'searching' activity. Pre-occupation with the deceased is a cognitive symptom that involves a reliving of past events of the disrupted relationship through memories and a heightened sensitivity to envirormental cues (e.g.. furniture, music) concerning the deceased. The process is important since it allows a gradual accommodation to the loss. It can take on mal-adaptive qualities if the pre-occupation develops into obsessive rumination. The behavioral deriva. tive of this cognitive symptom of grief is searching activity. The mourner behaviorally attempts to re-capture or replace some of the elements of the now defunct core relationship. By actively seeking out reminders (e.g., favorite pipe) or substitutes (e.g., other people with whom to interact), the bereaved can similarly lessen the trauma and slow down the adjustment demands to a tolerable pace. However, like its cognitive counterpart, searching can also become extreme and ma1-adaptive when persistent efforts are made at reunion, such as through the survivor's death by suicide.

The thrust of behavioral symptomology is, therefore, one of paralleling the cognitive changes resulting from the sudden death. This is expected since behavior is postulated as the external outcome of prior, internal, cognitive decisions (see Figure 10).

6. Concluding Note

In this final section of Part II, I have presented my views on the effects of cognitive disruption and inadequacy 
upon all major spheres of functioning. These effects are most directly seen in cognitive regression and the associated cognitive dysfunctions which reduce adaptive effectiveness. These primary dysfunctions of cognitive activity place the mourner in an exergency condition of intense and prolonged stress, with physiological stress reactions that give rise to somatic symptomology. In addition the affective arousal associated with grief has been discussed from the viewpoint of cognitive disjunction, re-definition of the emctions and their physiological basis. Finally the general behavioral manifestation of grief have been proposed as expected outcomes of the disrupted cognitive foundation upon which action decisions rest.

It is now appropriate to turn to the more specific symptoms of normal and pathological grief in order to test the descriptive power of this model upon the actual data of the known symptomology of the acute grief syndrome. 
III. NORMAZ AND PATHOLOGICAL SYMPTOMOLOGY OF ACUTE GRIEF A. Introduction

The purpose of including this part on symptomology is two-fold. First it is intended to provide the reader with an overview of the principle manifestations and processes of acute grief in its normal and pathological forms. Secondly, the descriptions of bereavement symptoms are presented as data for the support of the cognitive model proposed in Part II. In other words, does the model comprehensively describe the symptom manifestations of the syndrome? I contend that it does and beileve that the following discussion and analys is of acute grief symptomology will convince the reader, as well.

This Part (III) will focus on symptom descriptions as they are presented in the literature, experientially by the survivors, and as they may be viewed from the cognitive model perspective. Part IV will deal with several proposed determinants for why some individual's experience normal grief, while others undergo a pathological course; and cognitive model explanations for the effects of these influential factors will also be presented.

The plan here is to highlight the major symptom groups associated with acute grief within the four principle spheres of functioning - cognitive, somatic, affective and behavioral. Within each sphere, the symptoms will be grouped into main categories, with each category discussed in terms of normal and pathological manifestations, cognitive model analyses of the symptoms, and the literature relevant to the symptom category. Although several hundred published clinical and 
theoretical reports have been reviewed, some are overlapping and will not be referred to uniess they offer some meaningful additional information. Only a relative handful of these studies yield significant empirical data, the majority of reports being clinical-descriptive or theoreticalexplanatory. Where empirical data has been available. I have tried to include it.

Before variations of any basic pattern can be reasonably considered, it is necessary to establish some normal range against which deviations can be compared. Although grief reactions vary considerably between individuals, there are several general findings about bereavement which can and will be described. These normal grief responses serve as the baseline for comparison with pathological mourning. Normalcy, in this sense and in this dissertation, essentially refers to grief reactions that are statistically most common among white Americans and Britishers.

There is a paucity of literature on bereavement patterns of Blacks in the United States, although several studies in the anthropological literature provide data on mourning practices and funeral rites of other cultures (Ablon, 1971; Aginsky, 1940; Carpenter, 1954; Devereaux, 1942; Kennard, 1950; Opler, 1946; Racy, 1969; Yamamoto et al, 1969). Several reviews of mourning cross-culturally are also available (Bendann, 1930; Habenstein \& Lamers, 1961; Krupp \& Kligman, 1962; Saucier, 1967). I am making this particular notation of cross-cultural differences in order to underscore the fact that a socio-cultural effect 
probably irfluences mourning, though I as not examining that influence in this work. I also want to avoid any implication of universality for the symptoms to be discussed. While some commonalities exist between cultures, the overwhelming majority of the literature reviewed here is based on the observations and interviews with white Britishers and Americans. Any conclusions drawn must, therefore, be limited to this population. Other determinants of the grief reactions which exert an influence within this population are discussed at length in Part IV of this dissertation.

I noted above that one of the essential criteria for normal symptoms was its relative frequency of occurrence in the bereavement population under study. However, in addition to incidence, other criteria may also be used in distinguishing between normal and pathological grief symptoms, and I will be applying a few of these. Specifically, symptoms are considered pathological if: (a) they are Idiosyncratic or rare (e.g., exacerbation of pre-extsting physical ailments is common but the development of post-grief cancer lesions is rare); (b) their intensity is exaggerated so that a particular symptom dominates the syndrome (e.g., guilt is a natural component of the grief syndrome, but self-denigration and guilty seif-destructiveness is not): (c) they persist for longer durations than usually experienced by the survivors (e.g., early confusion is typical and predictable as noted above - but sustained confusion for 6 months to a year is unusual): (d) they are an extreme example of an otherwise normal sympton (e.g., palpitations are common, but 
not when they're intense erough to sause cardiac dysfunction); or (e) they are clinically associated with unhealthy bereavement outcomes $(e . g$. the persistent identification of the survivor with somatic complaints of the deceased is virtually pathognomonic of an unhealthy and unresolved bereavement).

The analysis of acute grief symptomology involves an. artificial separation of the cognitive, somatic, affective and behavioral components. In reality, these factors function inter-dependentiy as interacting elements of a complex reaction syndrome. Although clarity of presentation is enhanced by this artificial dissection, it must be remembered that responses from each sphere often occur together and are interrelated.

For a summary of the symptorn sections to be presented in Part III, see Figure 11.

\section{B. Cognitive Symptomology}

1. Confusions

(a) Introduction and Literature Review

There is general concensus that the immediate reaction upon learning of an unanticipated death is a stunned experience of shock. Thinking is blunted, clarity of comprehension is blurred, conceptual associations are loosened ... all this occurring abruptly, as if the impact of the event had shat. tered coherence. This type of response has been reported to me as the first and most immediate reaction by mourners whom I have interviewed; and also by coroner's deputies who themselves serve as daily informants of sudden death news. This 
Figure 11. Sunmary Chart of Symptom Sections to be Presented in Part III

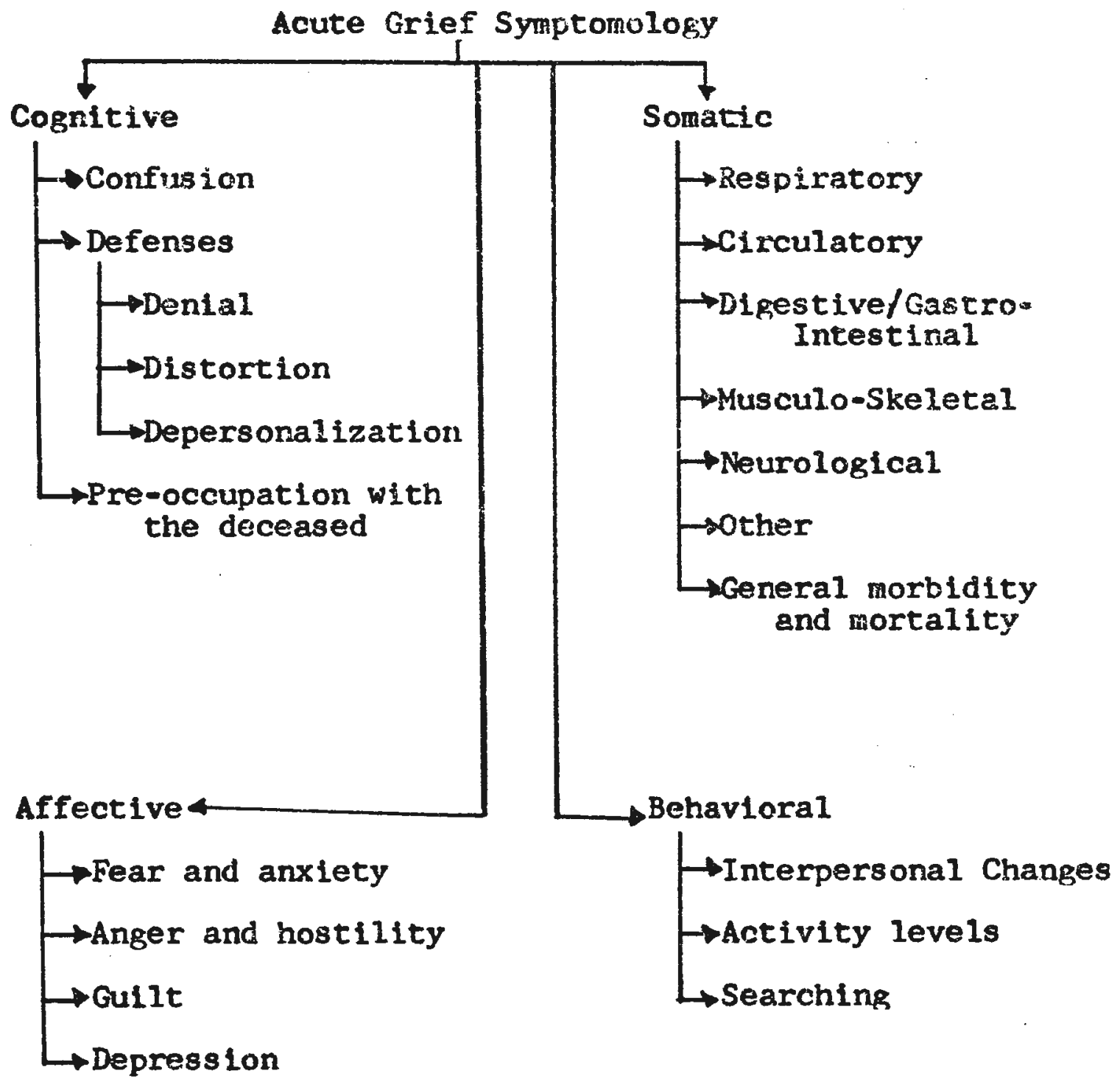


short-term cognitive blunting is also described by many investigators who have recorded the iritial grief reactions of Individuals ( Engel, 1961; Kutscher, 1969; Lifton, 1963, 1967; Lindemann, 1944; Parkes, 1972; Westberg, 1962),

families (Eliot, 1932; Vollman et al, 1971) and even rational samples reacting to presidential deaths (Greenstein, 1965; Johannsen, 1946; Kliman, 1965; Orlansky, 1947; 0'Toole, 1966; Wolfenstein, 1965; Wolff, 1947).

This immediate cognitive impact shortly evoives into an experience of uncertainty and confusion, regarding both the death itself and what to do about it. I have found that the acute mourner is acutely confused; he suddenly can't make sense out of much of the information input. Nolfi (1961) found that after a child's death, mothers had an intense need to talk to another person because they didn't know what to tell their other children and felt confused. Grossman (1967) also notes confusion amongst parents regardIng their communication to their children about death.

The form of confusion experienced by the bereaved varies but Bowlby (1961) emphasizes that the basic psychological process of grief includes disorganization, and this has been confirmed by others (Lindemann, 1960; Parkes, 1971). Disorganization of previous conceptual abilities generate a subjective sense of chaos, described to me by a young widow "... as if a picture window had been shattered in my face and I stood there erying to figure out how I'll ever be able to put the pieces back together ..." The neatly organized manner of understanding and coping with the world suddenly, 
abruptly becomes a litter of jagged, irreparable pieces.

Routine intellectual functioning may be impaired during grief as a result of the general confusion, and it may add to the disorganizational spiral. Memory problems (Lamers, 1972), concentration difficulties (Clayton et al, 1971) and difficulties in resolving daily problems (Lindemann, 1960) have been reported as symptoms of bereavement. The critical cognitive function of applying meaning to events is disrupted as survivors experience a sense of injustice (Marris, 1958; Yamamoto et al, 1969) and an inability to fathom the impact of the death. Their typical ability to think clearly and without internal distraction is altered, as the cognitive associarions to the deceased interfere with the routine construing patterns.

The sense of helplessness before the cognitive demands of day-to-day events (Paul, 1967; Schmale \& Iker, 1966) adds to the mourner's uncertainty. It seems to be partially responsible for the high proportion of young, recently bereaved widows and widowers who are among the first-time applicants to psychiatric clinics (Stern \& Susser, 1969).

Following the initial shock and disruption, the mourner usually experiences intense cognitive disorgarization and confusion for a brief period. He then begins to decelerate this downward spiral as his defenses start to take hold and temporarily stabilize the system until more permanent reconstruction occurs. Chaos is avoided eventually by the survivor's ability to partially regain his equilibrium at a lower level of functioning. He shuts down some of the 
input and interacts, in a very circusscribed way with many events.

However, some individuals are not able to accomplish this input limitation because of factors such as those discussed in Part IV (i.e., mode of death; relationship to the deceased; characteristics of the survivor). Their inability to functionally relate to events continues unabated. Each new encounter adds to the chaotic state, as the defenses are either unused or insufficient. The extent and duration of disorganized thinking is an important index for the presence of pathological grieving, since the degree of confusion may vary from odd thoughts (Maddison \& Viola, 1968) to mass hysteria (Helvic, 1968) to schizophrenia (Blum \& Rosenweig, 1944, Edelson \& Warren, 1963), with increased disintegration and pervasiveness representing greater likelihood of pathological process (Dabrowski, 1964).

The prolonged confusion further aggravates the individual's instability vis-a-vis the environment. There is a protracted period of falling to fully understand what is going on: and his convulsive efforts to comprehend events throws him into further disorganization and disarray. Basic relationships with a wide variety of events, objects and people become blurred in areas far removed from the deceased. Overload becomes a constant cognitive condition until there is eventual breakdown into chaotic or psychotic thinking disorders.

Thus, cognitive shock and confusion, with resultant disorganization, uncertainty, intellectual dysfunction and a 
sense of lost meaning and heiplessness combine to position the bereaved in jeopardy of cognitive breakdown into chaos. The instability of his comprehending atructure is considered normal if its intensity is moderate and it is within defined areas. However, as the confusion's intensity, disintegration or pervasiveness spreads to include non-related content areas. loose and global associations (i.e.. severe regression) and disorganized thinking arise and indicates that bereavenent has begun a pathological course.

(b) Cognitive Model Description for Normal Confusion This sense of confusion is a direct result of the acute rupture of a core relationship caused by the sudden death. The cognitive matrix is postulated as structurally dependent on these central dimensions for its stability and integrity. When there is damage to the structure - at its base - then the entire matrix is vulnerable to collapse. At the very least, the area of damage is no longer available to the individual, leaving him without adequate tools for coping with those events which demand construing via these defunct dimensions. Since these core dimensions, by definition have a quantitative centrality, there are numerous affiliated linkages and areas that are similarly affected. Thus, many routine interactions are abruptly foreign and unmanageable confrontations because of an acute absence of construing dimersions. The cognitive void created by the sudden death makes the day-to-day events overwhelming and chaotic impingemerts, restiting in cognitive oyerload and an experiential state of confusion. Furthermore, the trauna to the individual 
is as shocking and stuning to the cognitive systen as is the accidertal limb asputation to the somatic system. There is initial cognitive blunting because the magnitude of the event's information impact is beyond the individual's ability to imediately process. As the blunting eases and the information begins to be processed, the disorganization of cognitive functioning sets in, for a key pillar of the cognitive organizational matrix has been shattered, like "a picture window".

(c) Cognitive Model Description for Pathological Confusion Pathological confusion results from a combination of forces acting upon the cognitive framework. The individual's core dimension, which was damaged by the sudden death, may have had greater centrality than typically found. We can assume, for example, that overly dependent persons tend to base exaggerated and extensive cognitive functions upon the other. When the other dies unexpectedly, then the loss of cognitive functioning is similarly exaggerated and extensive because the core dimension had been carrying more than a normal loading in its support of the overall cognitive matrix. When such an unduly loaded core dimension is destroyed, the framework doesn't merely wobble, threatening to collapse... it actually crashes. This leaves relatively few intact areas of the matrix wish must then serve the survivor's routine interactions.

Or the individual may have a weakly developed cognitive matrix to begin with, such that overall organization and integration is unstabie and subject to disarray even with 
moderate trauma, When death sccurs, the loss of the core dinension destroys the supportive structure of an already susceptible framework.

Most probably, the pathological confusion results from the other events in the individual's life which he is unable to copew with in a weakened cognitive state. These pressures mount and sustain, giving him no respite from the overload situation. The constant impingement demands upon a cognitively inadequate matrix result in continual confusion as he tries valnly to cope with environmental interactions ... until finally, he finds even the simplest and most routine cognitive endeavors unnanageable.

See Figure 12 for a summary of this section.

\section{Cognitive Defenses:}

In an attempt to control the disruptive influence of the death, mourners typically resort to three principle defensive techniques, which I have characterized as denial, distortion and depersonalization. The cognitive defenses are not only normal, but also relatively healthy aspects of the bereavement process. In moderation, they give the mourner time to deal with the event of sudden death and to perhaps cope with the disruption more effectively. Eventually, the healthy cognitive defense mechanisms yield to the reality of the loss and the individual must then make cognitive adjustments to this fact. However, for some survivors, the defenses do not yield, but instead rigidify and diffuse. This is postulated to occur for some mourners because of the influence 
Figure 12. Summary Chart of Cognitive Confusion

Sudden Death of a Significant Other

Cognitive

Damage to many linkages

affiliated with cote

interpersonal dimension

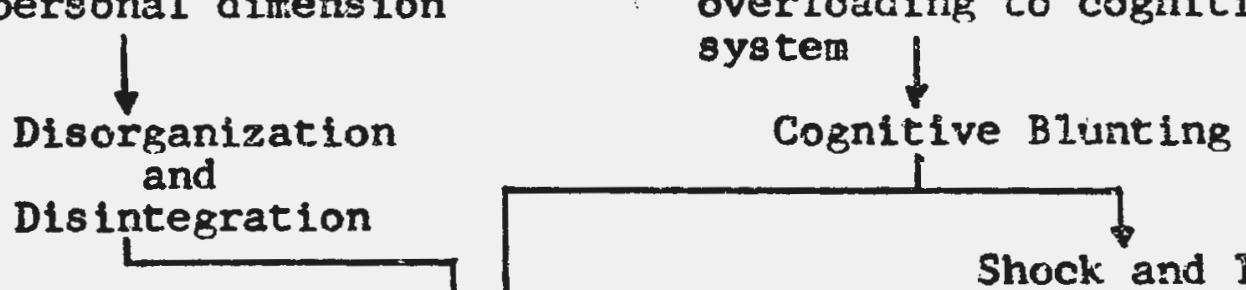

Magnitude of sudden death event information is overloading to cognitive system of comprehension

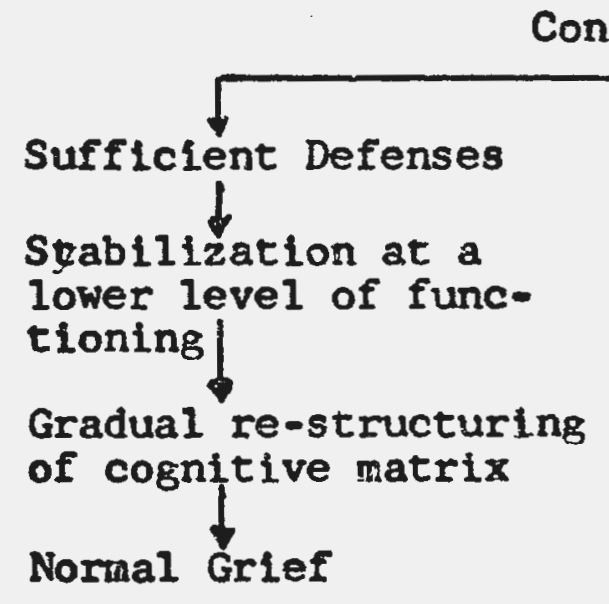

usion 
of factors described in part IV.

\section{(a) Denial}

1. Introduction and Literature Review

Denial refers here to disbelief, a refusal to accept the actuality of the death by insisting that the information is untrue or mistaken. This may vary in degree from the simple statement upon learning of the death. "I don't believe it:" to the more extreme denial manifested in retaining the belief that the deceased will be home for dinner the next evening (to the extent of setting the dinner table for him).

Probably the most commonly reported normal cognitive defense is denial or disbelief (e.8., Deutsch, 1937; Engel, 1961; Halpern, 1972; Hobson, 1964; Lamers, 1972; Lindemann, 1944; Lipson, 1963; McConville et al, 1970; Parkes, 1965, 1971, 1972; Westberg, 1962; Yamamoto et al, 1969). This occurs at the individual (see above references), family (Eliot, 1932; Vollman et al, 1971) and national levels (Orlansky, 1947, Wolff, 1947; re: Roosevelt's death - O'Toole, 1966; Wolfenstein \& Kliman, 1965, re, Kennedy's death). Although denial occurs very early in the grief process (Lindemann, 1944; Westberg, 1962), it involves a different effect than the cognitive blunting described under confusion (i.e., disbelief rather than a temporary stunned shock). Both effects, jointly and independently, serve to protect or anesthesize the individual against the impact of the loss (Lamers, 1972; Westberg, 1962).

Sudden death is such an overwhelming experience for survivors that they cannot immediately incorporate the information. Denial is therefore both a protective, delaying 
maneuver and a demonstration of the incomprehensible nature of the event for the bereaved. This particular cognitive defense has been referred to by psycho-analytic writers as a primitive method (read immature) of warding off anxiety (Cameron, 1963, Feniche1, 1945). However, within the context of the cognitive model, it is considered a functional effort at delaying potential chaos. The survivor who denies the death of a significant other is not, in this way, communicating simply an unwillingness to believe the event; he does not, in fact, accept the information and often pursues his routine as if the death had really not occurred. In the normal range of denial, there exists a breadth of variation as exemplified above; but denial of intense or diffuse or of stubborn prolongation must be viewed as pathological.

Prolonged denial (of a week or longer) is pathological since it involves the exclusion of a vitally important event from the person's cognitive framework. His interaction with the world and interaction in it is based on a gross fantasy (1.e., the false belief that the deceased is still alive), as he continues to reject the actuality of death. In order to support this fantasy, he soon finds it necessary to deny a wide variety of phenomena which might contradict the central disbelief. This diffusion of denial is particularly likely because until the damage to the core dimension is acknowledged, all damage in related areas must be denied as well (1. e.. quantitative centraikty is involved). The disbelief beconies pervasive and in time takes on delusional qualities (Pretzel, 1972) as nore and more of one"s realities must be 
disbelieved.

This may take the form of a paradoxical response to the death of a spouse (Freidman \& Zaris, 1964) in which activities and plans are carried out without any observable effect by the 10ss. Or it may take the form of decreased flexibility (because, as noted below, pathological denial results in framework petrification) leading to intellectual dysfunctioning associated with poor school adjustment after a death event (Kirkpatrick et al, 1965). Volkan (1970) interviewed a number of abnormally bereaved individuals and reported excessive denial with some selective amnesia concerning the death, occasional slips of the tongue referring to the deceased as if he were alive, and delayed reactions that finally emerged on the anniversary of the loss or at the time of a subsequent loss.

Several investigators have noted significant relationships between the intensity of the denial and the fact that the death involved a child. This is especially so with regard to the fathers of the deceased. Nolfi (1967) reported that surviving fathers in acute grief experienced a 'silent grief', were unwilling and unable to discuss their child's death ... as if it had not occurred. Similarly, interviews with parents of adolescent suicides (Herzog \& Resnik. 1968) revealed extreme denial and disbelief by fathers, as well as brothers of the deceased. Efforts to break through this protective shield were strongly rebuffed. The parents did not want to validate the death, even indirectly, by admitting to its actuality. 
The delay of grief is perhaps the most serious manifestation of exaggerated cognitive denial, and it is usualiy viewed as an example of pathological mourning (Deutsch, 1937, Hinton, 1967, Lindemann, 1944, Volkan, 1970). Lindemann (1944) states that the discomfort of bereavement must be experienced in order for the mourner to successfully resolve the problems associated with the sudden death of a significant other. Denial processes which delay or prevent the acceptance of the loss, necessarily preclude this resolution of grief problems.

11. Cognitive Model Description of Normal Denial

Both denial and distortion involve extremes of cognitive absorption in which the event is encountered, but has no significant effect in altering the cognitive matrix. The event is force-fitted into the structure without major change to the structure itseif. Denial represents a virtuaily total absorptive interaction in which the sudden death phenomenon has no effect on the bereaved's understanding and interaction with the environment. It is my contention that denial is not simply an ignoring of the information; rather, that the death information is cognitively processed so as to warp its relevance and meaning for the survivor. Since the conceptual dimensions involved are core elements of the matrix, the degree of waxping must be exaggerated if one is to accommodate such massive input data without it actually effecting structural change. I believe this can be accomplished by the mourner's construing the event as untrue, and therefore, unbelievable. If the sudden death information is conceived 
as untrue, then there is no need for cognitlve matrix modification. Rather, the information is absorbed and processed as irrelevant, and therefore, discardable.

Clinically, denial is an especially difficult defersive stance to oppose, for direct confrontation further rigidifies the cognitive matrix, making it even more impermeable to environmental input. Thus, the initial denial of loss may be exacerbated by well-intentioned efforts to force the reality of the loss into the bereaved's cognitive framework. Petrification of an unrealistic and inappropriate cognitive matrix (i.e., retention of a defunct core dimension) is difficult to sustain, considering the limited resources of a damaged matrix, and yields to more realistic openness in time. That is, if the denial isn't attacked, causing defensive entrenchment. It is unwise to try to force-fit the reality of a death into a cognitive structure during the initial denial-absorptive period.

iii. Cognitive Model Description of Pathological Denial All the cognitive defensive maneuvers can become pathological when they are prolonged. Concerning denial, an individual whose cognitive framework becomes pervasively rigid and closed to interactional change effects is not able to cope successfully. Adaptivity presupposes some degree of absorption and modification. The highly and increasingly absorptive cognitive functioning associated with extensive grief denial does not allow sufficient flexibility for the mourner to adequately meet envirormental demands. Rather, he construes and then acts upon events in a more and more 
sterectypic manner. This further Ientuces his effectiveness at coping adaftively, since the impinging scimuli retain their complexity. The stereotypic, rigid matrix of the pathologically bereaved denier is predictably overloaded by the complex stimuli demands. This set of circumstances leads to overload, breakjown and chaotic disorganization as the end result. The force-fitting of events into the preexisting structure is a delusional pattern which is one step on the road to that end (see Figure 13).

(b) Distortion

i. Introduction and Literature Review

Although denial may be construed as a form of distortion, the latter term refers here to those other thinking patterns which accept (rather than disbelleve) the fact of death, but grossly modify its meaning and importance in order to lessen the impact. The method of distorting the trauma of acute grief may be through extensive philosophical rationalizations Involving fate, God, patriotism, etc.: or it may take the form of paradoxical statements such as: "it was probably the best think that could have happened" "at least she had a good life while it lasted" (regarding a 24 year old woman).

The distortion occasionally focuses on the impact itself when mourners minimize the effect of the death by stating that they had a premonition which offered some preparation time (Parkes, 1942); or by accepting the fact of death so completely and easily, on the surface, that the observer may feel that bereavement is absent aitogether (Lindemann, i944). 


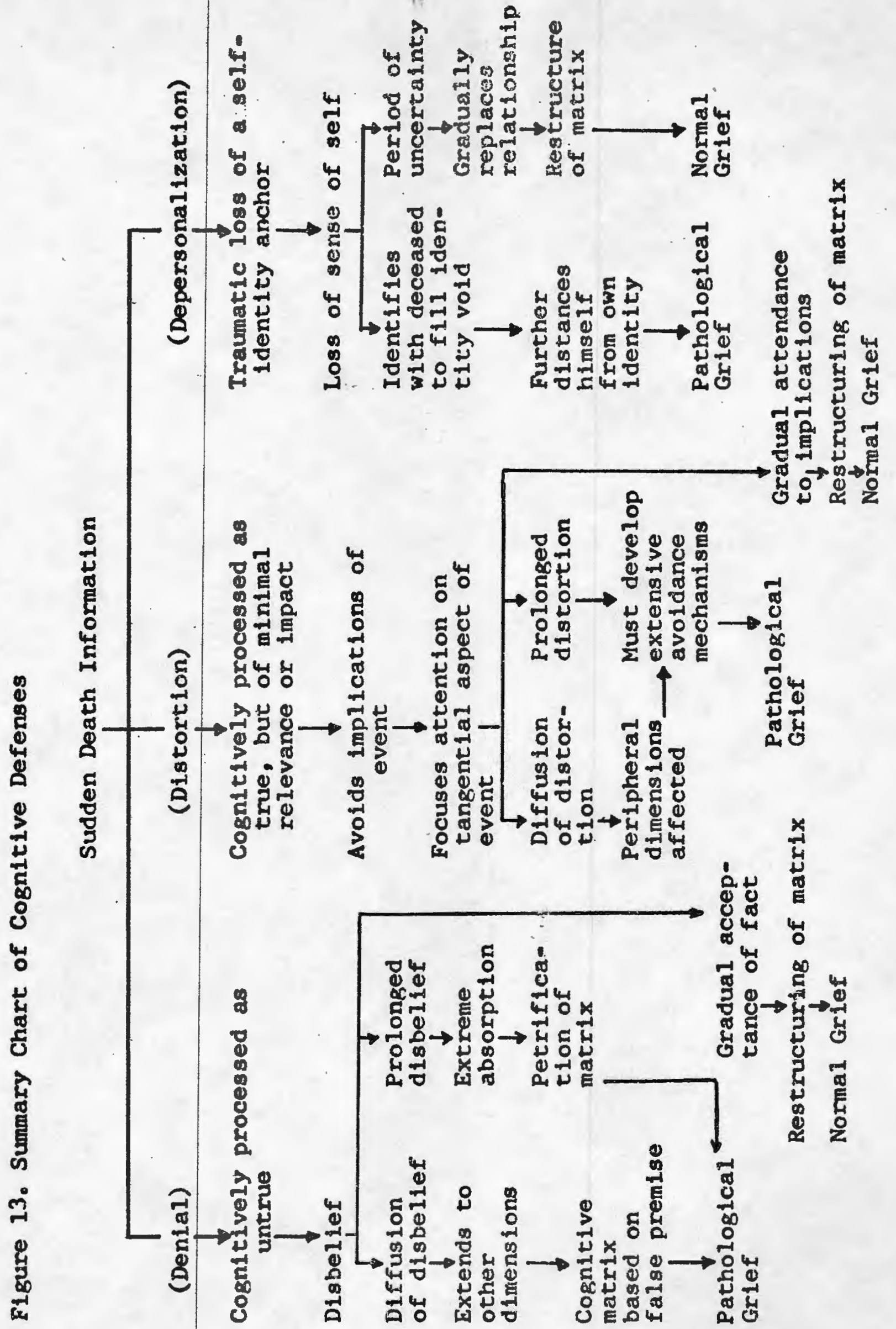


These are examples of normal distortion, since they are both comon and moderate in degree. Reactions of this type may even be considered - on a short term basis - healthy, since they provide the bereaved with an opportunity to more gradually accept the loss, and a chance to shore up his cognitive structure.

Thus, distortions associated with mourning are attempts at avoiding the full impact of the death, once the death itself has been accepted. Though most investigators have not tried to distinguish between denial and distortion, as I've done here, some particular references to defensive distorting have been noted. For example, Loveland (1968) and Stone (1971) describe changes in religious attitudes that provide cushioning rationalizations for the death, and justifications for its disruptive cognitive aftermath. Distortion and intellectualization are reported by Light (1972) regarding psychiatrists' attempts to divert attention from the fact of death and toward hypotheses of why the suicide occurred. Nolfi (1967) studied a group of bereaved fathers who made conscious efforts to avoid word reminders and other expressions that referred to their dead child, and Yanamoto et al ( 1969 notes this attitude in the bereaved of avoiding reminders.

Pathological distortion develops (as with denial) when it becones sustained and pervasive. The death is acknowledged, but its acceptance is so qualified and its impact so diluted that the mourner is unable to really make approprlate cognitive adjustments. For him, as with the 
denter, there is no need to nake these adjustments because the core dimension loss, although assimilated as having occurred, has not yet been genuinely experienced with regard to its implications.

For many pathological distorters, their attention is diverted to some secondary aspect of the death, so as to avold confronting the primary cognitive disruption of core damage. I have counseled individuals two or more years after the death who are still focusing their attention on 'how did it happen?' Until that question is answered for them, they won't fully deal with the fact that death did happen, irrespective of how.

Pathological distortions can be considered present whenever there is exaggerated or prolonged efforts at minimizing the full impact of the death, to the point of preventing reparative efforts. It may involve extreme avoidance of reminders such as staying away from the cemetery for years after the death (Volkan, 1970): It may manifest itself in gross, illogical rationalizations about the benefits accrued by the death (Kutscher, 1969), thereby not dealing with the death's disruptive consequences.

Most often, abnormal distortion concerns the acceptance of the fact of death, but stubborn distortion of some major aspect of the death ... such as how it occurred. This is frequent among survivors of a suicidal death (Herzog \& Resnik, 1968, Pretzel, 1972) in which the mode of death is cognitively altered by the bereaved. Their attention is focused, not on the major impact of the loss itself, but on the secondary 
factor of the mode of deach. Pretzel (1972) provides examples of family members who attribute a suicidal death to either accidental causes or to some mysterious intruder who perpertrated murder. The efforts of these mourners to validate their false belief take on severe pathological qualities as they try to rationalize a hanging suicide, accompanied by a suicide note as an accident. Or their belief system becomes delusional as they insist that police, physicians and other investigators are conspiring to label the death as a suicide, rather than capture the real murderer. They become so engrossed in finding the fantasized burglar/murderer that they never begin to mourn and readjust.

Those survivors who thus deny or distort the sudden death experience have converted the delaying cognitive defense methods into avoidance mechanisms. This forces then to function inappropriately and ineffectively, with a cognitive matrix that contains a vital, but unrecognized, flaw. In their attempt to prevent cognitive collapse and ensuing chaos, they build their understanding of events upon a structural foundation that is flawed and vulnerable; one which may, in fact, hasten rather than delay the very breakdown they're trying to shun.

i1. Cognitive Model Description of Normal Distortion Defensive distortion of the impact of death is also an extremely absorptive function, although it differs from denial. When defensive distortion occurs, the death is accepted, but Its full adjustment consequences upon the individual are not comprehended or dealt with. The fact of death is pro- 
cessed as true, but as relatively inconsequential. Cognitive activity and attention is diverted from the damaged zone of the core relationship loss (particularly its implications for the survivor), to a less threatening aspect of the event. such as the reason for or mechanics of the death.

In addition to providing some time before having to cope with the instability and vacuum created by the core dimensional loss, such a distortion has negative potential as well. It can, for example, force the mourner to distort other events in order to maintain his diversion of attention. Therefore, cognitive distortion, as with denial, is potentially dangerous, in terms of their rigidifying effects on the cognitive matrix and in the resulting need to expand or diffuse the distortion to otherwise unaffected areas.

i1i. Cognitive Model Description of Pathological Distortion

Pathological distortion follows much the same sequence. In addition, considerable cognitive effort is required to maintain the prolonged diversion which distortion serves. The individual becomes increasingly attendant to his cognitive search for the reasons for the death. He must simultaneous1y expand his distortion perimeters while avoiding the damaged core. He fails to cope well with routine events because he has had to rigidify his peripheral and extraneous dimensions, lest they require modifications that might add to the strain already upon the cognitive system. Thus, he builds a new and distorted framework on a fantasized foundation which disallows adaptive interaction, since its 
conceptualizations are not exue representations of events. Instead, they are warped facsimile which have been absorped into the rigid, stereotypic structure (see Figure 13).

(c) Depersonalization

i. Introduction and Literature Review

Depersonalization is related to the numbness that is frequently reported by those who are in the grief process (Hobson, 1965; Lamers, 1972; Lindemann, 1944; Parkes, 1972; Westberg, 1952). It, too, is a protective device which, in a sense, freezes the individual's cognizance of his traumatic loss and gives him some cognitive and emotional distance from the event. The depersonalization occurs at various stages of bereavement: at the initial point of learning about the death when shock and numbness are precipitated by the news; later on, when the individual behaves in rather automatic, mechanical ways; and whenever he is able to take a somewhat distant, uninvolved view of what has happened to him.

Depersonalization is not an absorptive tendency, but rather is postulated as a cognitive breakdown in dimensions concerning the understanding of oneself in relation to the world. Identity - knowing oneself - is based on these relationships and is severely traumatized when one of these supportive relationships is disrupted. The sudden death event places the mourner's knowledge of who he is in doubt, if not in jeopardy. Until the other self-identifying cognitive parameters are strengthened and expanded to partially 
correct for the new absence of a key identity component, the bereaved experiences depersonalization. This includes a sense of disharmony with himself, a sense of distance and uncertainty, a state of limbo while he re-establishes the remaining identity-anchoring relationships.

The relevance of grief to the problem of identity and depersonalization is noted by Becker (1962) who discusses theoretical notions regarding mourning as part of a class of depressions which present problems to the individual in his forming of a coherent identity. Hinton (1967) and Lindemann (1944) also refer to the process of depersonalization as a sense of loss of self, and they relate it to the mourner's pre-occupation with the deceased.

The gaining of a new identity is an important part of the grief syndrome which Parkes (1972) discusses in terms of changed role obligations and role relationships. He takes particular note of the "loss of self which is often referred to as a 'gap' - 'it's a great emptiness', 'an unhappy void" ". Parkes suggests that significant identification with their deceased husbands occurred in many of his interviewed widows as an attempt to fill that gap. In order to substitute for the absence, many widows detach from their pre-existing roles and identities and try to fill the wage-earner or family-leader slots, in ways that duplicate that of their former spouses. They have difficulty in seeing themselves as widows and many "still seemed to regard themselves as married to their dead husbands" (Parkes, 1972). which may partialiy account for Marris' (1958) figures showing 
a low remarriage rate. I bellewe these women are not rejecting widowhood status, so much as displaying uncertainty about who and what chey are as a result of a sudden death experience. This is not uncommon for mourners (Kutscher, 1969). In healthy grief syndromes, the survivors new identity is typically defined over time by gradual adjustment to new life situations which emerge and by new relationships that they form which provide alternate identity anchors (Lindemann, 1944).

The inability to re-define oneself as widow, orphan or other survivor may be a prognosticator of poor bereavement recovery. This type of mourning dysfunction results in an increasing loss of self-identity and loss of contact. with actual role responsibilities and role relations. The pathologically bereaved individual does not have a firm cognitive grounding in his relations with the world. Thus, he experiences critical breaks in his ability to adequately interact with the environment's reality. This may account for the higher incidence of psychotic conditions reported for those who have experienced deaths of other people (e.g.. mothers) upon whom their identities were largely dependent (Arthur \& Kemme, 1964; Barry, 1939; BIum \& Rosenweig, 1944; Edelson \& Warren, 1963; Hilgard \& Newman, 1961, 1963).

ii. Cognitive Model Description of Normal Depersonalization

Cognitive depersonalization, though it also permits some delay, has as its primary function the providing of some respite from the onslaughe of overloading stimulus 
demands. By distancing oneself from one's self, overload is temporarily avoided and efforts at cognitive repair can take a less under-pressure pace. The danger of too prolonged a respite is that the depersonalization becones routine and the mourner loses self-conceptualization/self-identity anchors which he later can't regain. Recall that self-identity is a function of the relationship of the individual to events, objects and most importantly, others in the environment. When a significant other is lost, along with the other cognitive damage, there is a corresponding disruption of the survivor's self-identity because one of its principle anchor-relationships is gone. Until this central dimension is replaced by other, substitutive relationships and linkages, the person experiences uncertainty regarding his selfidentity.

iii. Cognitive Model Description of Pathological Depersonalization

Loss of self-identity anchors increase the likelihood of pathological depersonalization because the individual's security is already weakened by the sudden death. In other words, the mourner is already less than assured of 'who he is', and if he firmly and continually avoids functioning as himself via depersonalization, then he may lose his selfconceptualization beyond recapture. This appears to be a partial explanation for the symptom of over-identification with the deceased that has been mentioned as pathognomonic for atypical grief (Lindemann, 1944). The bereaved excessively models the deceased, in part, because he has been 
able to excessively distance himself from his own experiences and his own cognitive structure.

The numbness that evolves into pathological depersonalization may have one of three precipitants. It may result from the overwhelming threat of loss to the mourner of his self-identity anchors. Or it may be caused by the lack of alternate cognitive dimensions for the individual to relate himself to the world. Or the initial set of parameters by which he knew hinself may have been weak.

Long-term loss of substantive identity is particularly tragic because it is one of the most susceptible symptoms for correction by appropriate external intervention. The acutely bereaved has lost the balance between who he is vis-a-vis the environment. He tends to distance himself from this unstable position by attempting to reassociate himself with the deceased through the modeling of some aspect of the deceased. However, this activity paradoxically pushes him still further from the reality of his situation and reduces the likelihood that he' 11 attempt to correct his actual cognitive matrix damage. On the contrary, to correct it first requires recognition and acceptance of the loss/damage as his loss and damage. Yet it is this very phenomenon that he is distancing himself from. An individual cannot reestablish an identity stability on the basis of a defunct relationship. Yet in order to re-establish some identity, that's exactly what he attempts to do. This pathological course can, nonetheless, be corrected if other dimensions can be provided for the mourner which permit him to 
cognttively archor intc the real world. Then he can form a revised, but authentic, set of relationships as a basis for knowing who he is (see filgure 13).

3. Pre-occupation with the Deceased

(a) Introduction and Literature Review

The symotcm of pre-occupation with the deceased usually

occurs later in the grief process than other cognitive manifestations. Beyond the mechanical focusing upon the death required by the funeral and other mourning rituals, the Individual who has suffered a sudden death experience tends to spend considerable time thinking about the significant other person whom he has lost. This pre-occupation takes many forms in its imagery, such as dreams, wakeful fantasies and memories.

The necessity for the bereaved to cognitively attend to his loss in order to repair the damage to his framework and bring the grief process to a healthy resolve is specified by grief counselors (e.g., Lindemann, 1944; Paul, 1966). Workers in the field of crisis intervention (see Parad, 1965, 1969) who often deal with the bereaved also emphasize the importance of focusing upon the lost relationship, in order to bring closure to various aspects of it and to re-construct the disrupeed matrix. Avoidance of this distressing process forces the individual to pathologically and excessively use defenses previously described to sustain this evasion. Through this revtew process, the significant other is kept cognitively viable as a riemory with reievance to the 
mourner's past history and presert circumstances. It is a procedure which allows a more graghul separation than the actual death itself permitted. Although many helpers have a desire to divert the mourner's pre-occupation to less distressing areas, this diversion may not be in the bereaved's best interests. 'Working through one's grief' (Freud, 1917; Lindemann, 1944) means 'attending to it', and moderate preoccupation following the initial shock is a common method for such a procedure. It is a painful process - as is grief in general - but a functional one that should not be inadvertently stifled.

However, most individual's experiencing grief do tend to give considerable thought to the deceased without solicitation or coercing (Hinton, 1967; Lester \& Kam, 1971; Lamers, 1972; Lindemann, 1944; McConville et al, 1970; Parkes, 1972; Paul, 1966; Pretze1, 1972; Rees, 1970). This may take the form of memories (Parkes \& Brown, 1972) which are described as being very clear and very intense, similar to an actual perception or re-living of the event. Or the pre-occupation can be experienced as an actual sense of the deceased being present (Hobson, 1964; Marris, 1958; Parkes, 1965, 1971; Rees, 1970; Yamamoto et a1, 1969).

Bowlby (1961) points out that the basic psychological phases of grief, as he views it, are divided into three sequences with the initial phase being the urge to recover the loss - defined by him as 'yearning' (Bowlby, 1961, Parkes (1971, 1972). The yearning is a restorative effort to replace the missing dimension. It is manifested in dreams (McConville 
et al, 1970; Rees, 1970) in which the deceased is alive (Pollack, 1961) and which irvolve vivid imagery of the deceased, but with the shadow of death falling over the contents (Waller, 1951). Volkan (1970) also refers to these repetitive dreams about the deceased being alive but in danger. He feels that they are pathological indicators when they include symbolic references to reincarnation. Volkan also suggests that verbal silps of the tongue referring to the deceased may be signs of unconscious pre-occupation.

There is some overlapping here between the mental preoccupation and the searching activity discussed under behavioral symptomology. Cognitive searching appears to occur as the mourner reviews the multitude of associations related to the 1oss. The cognitive (and the behavioral derivative) searching serves a valuable and vital purpose for the bereaved in his attempt at coping with his grief. In moderation, this cognitive activity permits the individual to deal directly with the disruption rather than avoid it. He has opportunities to review positive and negative components of the relationship, in order to bring some degree of effective closure to bonds that have been abruptly severed.

Parkes (1972) has described a process of selective perception in widows, whereby perceptions not related to the deceased are screened out, with a concomitant focusing on perceptions that bear upon the 1oss. There is, Parkes believes, the development of a perceptual set concerning ambiguous impressions which fits then into the mourner's effort to focus on the death. This may result in visual or auditory 
11lusions. Both Parkes (1972) and Pees (1970) characterize this pre-occupational iliusion phenomenon as a component of normal grief. They report that these illusions are helpful experiences for the mourners, particularly if the grief counselor explains it as a common reaction. Thus, most investigators view the various forms of pre-occupation as normal and as helpful for the bereaved in re-constructing a revised perspective on 1 ife which includes the reality of the recent disruption.

In referring to moderate pre-occupation with images and memories of the deceased, I have been careful to abstain from characterizing this normal symptom as obsessive. When the tendency to give thought to the deceased is pervasive and constant and non-distractable, then pre-occupation has magnified into an obsession. The obsession, by its degree of exaggeration of the normal symptom, is considered pathological. There is room for no other comprehensions and there is distortion of non-related contents so as to make them refer to the deceased. The individual finds himself literally flooded with memories and images which he cannot control or terminate. His dreams are manifestly death related, his ideation is limited to the loss and its ramifications, his fantasies are those of union. The pathological obsession need not be triggered by some event or object or recal1, for the bereaved himself is predisposed to affiliate events with the deach.

Pathological obsessing about the death can prevent the mourner from coping with the multiple and complex events 
of daily living. Halpern (1972) notes that obsessive rumination may focus on the circumstances of the death; and reference has already been made here to those who have become obsessively pre-occupied with proving that a suicidal death is really an accident or homocide (Herzog \& Resnik, 1968; Pretzel. 1972). Certain types of cognitive pre-occupation have been identified as relatively specific to pathological mourning. These include prolonged concern with the deceased for years after the death (Bowlby 1961; Volkan, 1970), or focusing on tangential aspects of the death, such as the weight of the gravestone (Volkan, 1970). Another exaggeration of normal pre-occupation involves the magnification of sensory illusions (i.e.. misinterpretations of ambiguous stimuli) into visual and auditory hallucinations of the deceased for which there are no sensory basis (Hinton, 1967; Matchett, 1972, Rees, 1970).

This obsession is typically bonded to behavioral symptoms in which compulsivity to repeat shared experiences, from the trivial to the extravagant, is dominant. The cognitive searching of the normal mourning process takes an unhealthy turn, because in obsessive pre-occupation, the search has ended. There's been a cognitive 're-capturing' of the deceased, in which the cognitions have a common thread of similarity where the world is one of death, death reminders, death stimuli.

(b) Cognitive Model Description of Normal Pre-Occupation with the Deceased

When there is a disruption resulting from sudden death, 
there is a damage to the survivor's cognitive framework. This is accompanied by a tenriency to repair the linkages which were formerly bound to the core dimension. Those 'spokes of the wheel', metaphorically described in an earlier chapter, remain un-anchored to a central construct. The objects, events and people conceptually related to the deceased are unstable at one end. Therefore, they require attention in order that they may perhaps be reassociated with some other or new dimension. Normal pre-occupation is less a narrow focusing than a reparative effort at cognitive re-stabilization.

There is moderate constriction as the mourner rechannels his cognitive attention into the damaged area of his matrix (i,e., the deceased); and moderate dilation as he cognitively searches for new poles to anchor these adrift linkages of the old core constellation (i.e., memories of the deceased). The bereaved is confronted with routine interactions that previously were coped with via routine cognitive categories. These categories are no longer firm. Therefore, when environmental demands require their adequate functioning, the matrix is stressed. This can occur whenever an event happens to evoke a cognitive response from the damaged area; for example, when the survivor sees the deceased's favorite chair or a film that they once shared. The symptom of preoccupation is the manifestation of the peripheral ripples of cognitive damage to affiliated conceptual axes. It is stress. ful, but also functional.

The increased attention to the dis rupted parts of the 
matrix is partially a function of the increased subjectivity resulting from the general cognitive regression of acute grief. The mourner becomes more ego-centric in order to protect his vulnerable framework from further, avoidable, overload; and simultaneously to concentrate his efforts on repair and replacement.-The foundation by which the bereaved comprehends his experiences has been wounded. His increased subjectivity enables him to nurse his wound and the radiating pain around it.

(c) Cognitive Model Description of Pathological Pre-occupation with the Deceased

While normal pre-occupation permits the mourner to productively attend to the re-anchoring needs of core dimension linkages, obsessional pre-occupation with the deceased results in a rigidified cognitive matrix. As the individual becomes increasingly absorbed with the instability and threat of floating linkages, the other areas of his cognitive framework are ignored. His daily activities - unrelated to the death - are no longer sufficiently attended to: hence, overall adaptivity declines because his cognitive efforts are being over-extended in the damaged area (i.e., the death event), to the exclusion of other zones (i.e., work). Therefore, the obsessional pre-occupation leaves otherwise nonaffected cognitive dimensions more susceptible to overload and breakdown.

Constriction and dilation oscillate rapidly, as the individual focuses down very narrowly onto the dimensions of the deceased and those associated with them. Then he errat- 
ically expands in an attempt to grossly re-capture the loss by filling the void with other related, but inappropriate, cognitive elements. For example, a particular event they'd shared or song he liked or holiday remembered will be used as a replacement anchor for the defunct core dimension. It does not serve as an effective replacement, of course; but the search for such a substitute goes on through the dilation process.

The degree of cognitive regression is greater in pathological obsession than it is in normal pre-occupation. Consequently, subjectivity is more intense. Events that are actually not related to the sudden death event or to the mourner's condition, nonetheless, take on relevance as they are distorted to fit the exaggerated subjectivity of the bereaved. A neighbor's cat dies; an automobile accident is passed on the road; a movie about children ... all trigger associations to the acute grief that is being experienced. The subjective framework of the pathological mourner will tend to stress the tangential reference of these and similar events to his bereaved situation. While an objective stance will allow these encounters to be understood within their own context, the obsessively pre-occupied mourner is subjectively pre-disposed to construe these phenomena from his narrowly defined mourning context (see Flgure 14).

\section{Somatic Symptomology}

1. Introduction

In Part II, I have pointed out that the cognitive 
Figure 14. Sumary Chart of Cognitive Pre-occupation with the Deceased

Sudden death event

Cognitive disruption of core dimension

(quantitative centrality)

Cognitive disruption of peripheral dimensions related to core

Requires reparative cognitive attention for re-associating these Iinkages to new matrix anchors.

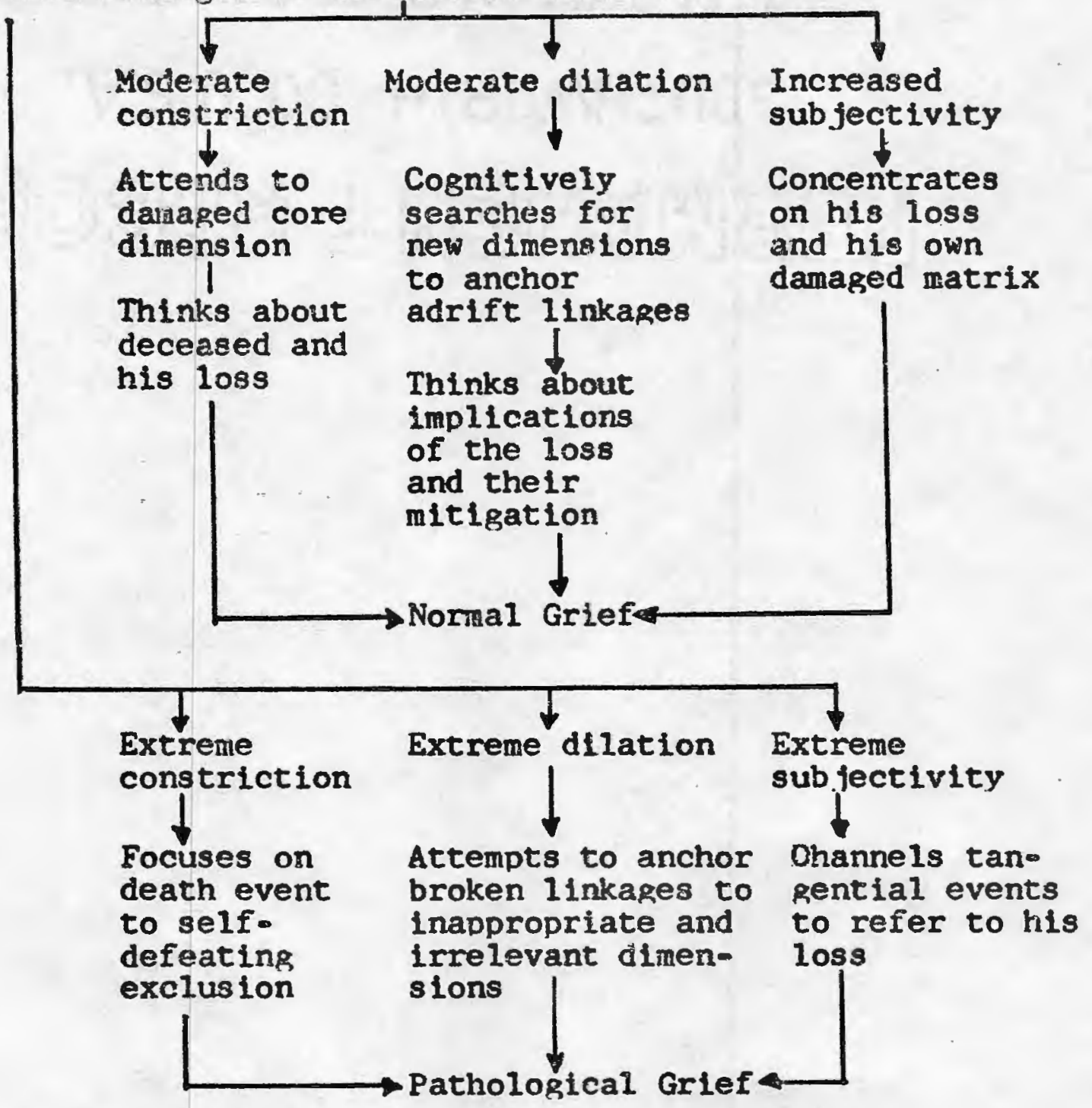


disruption of a core dimension subsequent to a sudden death acts as a major stressor upon the individual since it seriously threatens his continued coherent survival. It is generally accepted that psychological stress is responded to by the body as if it were a physical assault (Engel, 1962; Frederick, 1971; Lindemann, 1960; Parkes, 1972; Selye, 1956, Rees \& Lutkins, 1967; Wolff, 1953).

I contend that mourning is psychologically (hence, physiologically) stressful to the mourner, and that the somatic symptomology of acute grief is, therefore, related to those bodily responses associated with stress. These stress reactions are normal, protective, defensive, physiological activities that have been studied and detailed at length (see Selye, 1956 for a complete review). Selye describes the body's response to stress as being a relatively consistent pattern of somatic changes in various organ systems. The response pattern has been characterized as the General Adaptation Syndrome or G.A.S.

The General Adaptation Syndrome is a tri-phasic sequence of events beginning with an 'Alarm Reaction' consisting of two stages; (1) a shock stage in which there is lowered resistance with adrenal cortex enlargement, some degenerative changes in the thymus gland and early gastro-intestinal ulceration due to hyper-secretion. This is followed closely by (2) a countershock stage of temporary recovery from these symptoms. Overall, these changes tend to be degenerative and result from a complex glandular interaction involving the pituitary and adrenal giands. If either of these glands are 
surgically removed, then research animals do not display the 'Alarn Reaction'.

If the stress is more prolonged, a 'Stage of Resistance' evolves in which most of the "Alarm Reaction' symptoms subside. For example, the adrenais reduce to normal size, as does the thymus gland, and blood glucose levels (often depleted in the alarm phase) return to normal. Although biological adjustment appears optimal in this 'Stage of Resistance', the individual is subtly in a highly vulnerable state. This is because the adjustment appears to be limited to the particular stress that the person was originally exposed to. Any new or additional stressors will lead dramatically to further and more serious degeneration. In effect, it appears that physiological defenses to stress are limited and can be overloaded even during this optimally responsive phase.

Even if the overload of a new stressor does not occur, there exists a temporal limitation to the amount of stress that can be endured with satisfactory somatic adaptation. If the stress continues, the individual eventually weakens and the 'State of Exhaustion' begins. This can lead to ominous physical changes involving many of the body's organ systems. While the overall General Adaptation Syndrome's effects comprise a series of changes occurring over falrly extended periods of time, stress also evokes more immediate responses that act as preparatory changes for some type of behavioral protection (e.g., fight or flight) against the perceived survival threat. These more rapid changes parallel the 
'Alarm Reaction' of the G.A.S. They refiect the activation of the autoromic nervous system. The autonomic nervous system acts directly upon certain somatic systems and indirectly upon others through its influence upon hormonal glands.

The autonomic nervous system is an efferent system whose fibers innervate the smooth muscles and glands which control many of the involuntary functions of the body. It is composed of two divisions which act antagonisticallys the sympathetic branch and the para-sympathetic branch. Activity of the sympathetic branch prepares the individual for an emergency by mobilizing the body's resources. For example, by increasing blood sugar levels, heart and respiratory rate, while simultaneously inhibiting the less critical digestive processes. Conversely, the activation of the parasympathetic branch calms the individual's physiology, for example, by reducing heart rate and enhancing digestion. Symptoms of sympathetic arousal will vary as a function of the overall threat and the individual's particular reaction to it. Short-term sympathetic stimulation manifested as dryness in the mouth (i.e., salivary inhibition) may evolve into long-term symptomology such as peptic ulcers. More serious symptoms appear as the prolonged emergency footing of the body under stress begins to fatigue over time. As explained with regard to the G.A.S., a 'state of exhaustion' eventually sets in and normal bodily responses to emergency and stress break down.

Most of the somatic symptoms of acute grief can be traced back to the effects of autonomic nervous system arousal 
at different phases of the General Adaptation Syndrome. Such effects are quite broad and touch upon most major organ systems. Both short and long term manifestations of autonomic activation are demonstrated by individuals who are under the stress of bereavement.

I believe that the chain of effects connecting a sudden death event to somatic symptoms are as follows: The sudden death of a significant other person disrupts the coherent cognitive abilities of the survivor. This is due to the fact that a basic-core dimension by which he knows and interacts with his environment is no longer functionally available to him. This condition leaves the mourner in a state of vulnerability because he can't adapt to stimuli impingement as adequately as he did before. He now experiences even routine events as overloading. This reduced adaptive effectiveness and simultaneous overload demand are serious threats to continued psychological functioning and survival. The body of the individual responds to the psychological threat of cognitive breakdown as if it were as stressful as physical assault. The bereaved, physiologically, prepares for emergency by activation of the sympathetic branch of the autonomic nervous system. This activation results in a wide variety of physiological changes, as observed in aspects of the common General Adaptation Syndrome. These autonomic nervous system changes, both functional ones and degenerative ones, are manifested as somatic symptoms in the acutely bereaved. In essence, virtually ali the principle bodily symptoms of mourning have their etlology in these autonomic changes 
asscciated with stress. Stress and ito physiological concomitants are the mediating factors between cognitive disruption and somatic symptomology.

The following sections will review the individual's major organ systems with regard to the changes occurring in them during bereavement. Such a review is intended to demonstrate both the somatic symptom effects of grief and their derivation from stress-induced autonomic activation.

\section{Respiratory Symptoms}

The gasp of shock upon learning about the sudden death of a significant other (Jackson, 1957, Kutscher, 1969) may be the prototype for the sustained sighing and irregular breathing which occurs throughout bereavement. Lindemann (1944) has noted that sighing seems to be pathognomonic for the grief process. Others (Lamers, 1972; Volkan, 1970) have similarly noted that gasping and sighing are common respiratory signs of grief. Associated with this response is a general absence of regular breathing rhythus and apparent difficulty in obtaining sufficient inhalation. Respiratory rate increases (Parkes, 1972) with obvious shortness of breath (Maddison \& Viola, 1968) or breathlessness (Lindemann, 1944) associated with a choking sensation. While crying is not in itself a respiratory effect, the dry sobbing that often accompanies weeping (Clayton et al, 1968, 1971, 1972, Volkan, 1970) may be construed as further efforts to obtain more alr through spasmodic respiratory action.

Several investigators have noted a significantly higher 
Figure 15. Summary Chart of Bases for Somatic Symptomology

Sudden Death of a Significant Other

Lowered cognitive effectiveness in

interaction with environment

$\downarrow$

State of cognitive vulnerability

Routine events are overloading

Threat of cognitive breakdown

of contimued functioning<smiles>[AlH2]</smiles>

Psychologically stressful<smiles>[Te]</smiles>

Physlologically equivalent to a physical threat and a physical stress

Autonomic Nervous System Arousal

Bodily Changes

Somatic symptoms associated

with bereavenent 
incidence of acute asthmatic attacks during bereavement (Cobb \& Lindemann, 1943; Hinton, 1957; Lindemann, 1944; Marris, 1958; McDermott \& Cobb, 1939, Sohmale \& Iker, 1966). Since asthma is understood to be an inflammatory allergic reaction of the bronchial tubes which may be precipitated by allergies (Guyton, 1969) or psychological stress (Buss, 1966; Selye, 1956), it is considered a normal stress response; that is, when it involves the acute exacerbation of a preexisting asthmatic condition. However, the development of bronchitis (Marris, 1958) or chronic bronchial asthma (Hinton, 1967; Lindemann, 1944; Maddison \& Viola, 1968) subsequent to a sudden death is an unusual and extreme respiratory symptom which must be viewed as pathological.

\section{Circulatory Symptoms}

An immediate pallor (Kutscher, 1969; Marris, 1958)

marks the initial observable effect on the circulatory system. This results from peripheral vasoconstriction (Guyton, 1969; Selye, 1956; Woodburne, 1969) which serves to direct blood from non-essential organs (e.g., skin and abdomen) to the heart and musculature where blood vessels are dilating. It is this circulatory reduction to which Marris (1958) attributes the report of leg ulcers in widows he interviewed. Centrally, tachycardia (Marris, 1958) or heart palpitation (Maddison \& Viola, 1968) are frequently reported by the bereaved, as overall cardiac activity increases, along with a rise in blood pressure (Brunn et al, 1970, Marris, 1958; Parkes, 1972) and pulse rate (Marris, 1958). Chest pains are 
a normal complaint (Maddisor \& Viola, 1968, Marris, 1958) which appear to be related to the stress of sudden and sustained rise in coronary demand and output. Headaches of the migraine type are also part of the grief syndrome (Maddison \& Viola, 1968; Marris, 1958; Parkes, 1972) and may be caused by spasm and dilation of the blood vessels supplying the intra-cranial tissues (Guyton, 1969).

While the foregoing circulatory changes are typical of the acute grief syndrome and while overall exacerbations of pre-existing conditions are common in bereavement (Parkes, 1964, 1972), such aggravations are particularly dangerous in this area. Increased morbidity and mortality in the bereaved will be discussed separately, but it is important to note here that the principle factor in these higher mortality rates, especially for widowers over 50 years old, was the degenerative coronary diseases. Young et al (1963) studied. almost 5000 widowers and found a mortality rate $40 \%$ higher than that normally expected. Of these, three-quarters of the increase was due to death from coronary thrombosis, arteriosclerosis and other cardiac allments. These findings have been supported by other investigators (Cox \& Ford, 1964; Parkes et al, 1969) and for widows as well as widowers (Symposium Report, 1967). All have emphasized that the stress of grief is an exacerbating, though not causative, influence upon coronary disease leading to death during the 6 months after the loss. It appears that the addition of circulatory reactions of bereavement upon an already weak heart jeopardizes the heart's fragile maintenance of bodily demands. Sustained 
demand for high cardiac output. With concurrent elevation of blood pressure way lead to coronary tapazment in even an otherwise normally functioning individual, or to chronic hypertension and its many sequelas (Guyton, 1969).

4. Digestive and Gastro-Intestinal Symptoms Nausea and/or vomiting and stomach contractions often occur during the first few hours of grief (Kutscher, 1969; Parkes, 1972), as part of the cognitive shock/physiological alarm reaction mediated by the autonomic nervous sustem. As stress-precipitated diversion of blood from the digestive organs to the heart and musculature progresses, there is general digestive discomfort and indigestion reported by the bereaved (Lamers, 1972; Lindemann, 1944; Maddison \& Viola, 1968; Marris, 1958). Gastric tone decreases precipitously and largely accounts for the overall experience of digestive upset. It also influences the anorexia and significant weight loss that is typical during mourning (Clayton et a1, 1971; Lamers, 1972; Lindemann, 1944: Maddison \& Viola, 1968: Marris, 1958; Parkes \& Brown, 1972; Stern \& Larviere, 1957). Reduced salivation with subsequent drying of the mouth may also occur and play a roie in appetite suppression (Kutscher, 1969; Schoenberg et al, 1970).

Prolonged stress is a known etiological factor in the development of gastric and duodenal ulcers (Buss, 1966) and Marris (1958) found that ulcer incidence was higher than expected in the recently widowed that he studied. It must be mentioned that a pre-existing ulcer, as with asthma and 
coronary disease, may be exacerbated by the strain of a sudden death event. Thus, either serious aggravation of a pre-existing ulcer or development of an ulcer are considered extreme and, hence, pathological responses.

Nonetheless, duodenal and gastric ulcers appear to be less frequent pathological concomitants of grief than ulcerative colitis (Hinton, 1967, Lindemann, 1944; Schmale \& Iker, 1966). The latter disease is often precipitated by prolonged and severe diarrhea which allows the rapid flow of digestive enzymes from the small intestine into the lower bowel. These enzymes are extremely irritating, especially upon the colon's walls. Usually, the lining of the large intestine is coated with mucous secretions for protection and lubrication. However, stress-induced sympathetic stimulation inhibits the protective secretions and increases sphincter tone. The net result is severe diarrhea and high enzyme irritation to (and holes in) the walls of the colon, a condition known as ulcerative colitis (Guyton, 1969). Cobb \& Lindemann (1943) made early note of a relationship between acute grief and ulcerative colitis during their investigation of the survivors of the Boston Coconut Grove fire. Lindemann (1945, 1950) more specifically stated that acute grief acted as a stressful psychogenic precipitant to ulcerative colitis, a potentially life-threatening disease. An experimental study by Almy of the irritable colon (1951) further supported these relationships by showing that healthy subjects demonstrated colon disturbances induced by experimental stress which were similar to that seen in psychologically distressed 
persons and in persons facing life crises such as bereavement. Thus, while diarrhea may be frequently exhibited as a physiological symptom in grief, prolongation of this condition is abnormal and a precipitant for the more serious complications of ulcerative colitis.

\section{Musculo-Skeletal Symptoms}

Tension accompanies the grief syndrome (Lindemann, 1944) and manifests itself in muscular readiness throughout the body. Although this adaptive response to stress is useful against direct physical assault, its appropriazeness and functional usefullness during bereavement is minimal. The prolongation of tension in the muscles usually results in fatigue (Lindemanr, 1944; Maddison \& Viola, 1968; Stern \& Lariviere, 1957) and overall aching (Maddison \& Viola, 1958). A tense muscular state cannot be maintained for prolonged periods without such consequences. Furthermore, spasms may be associated with muscular tension, and in fact are reported in the bereaved. These spasms appear to be localized in the neck and throat, with resultant sensations of choking and throat tightness (Lindemann, 1944) or difficulty in swallowing (Maddison \& Viola, 1968).

As with other conditions, grief has been identified as a psychogenic aggravator, rather than cause, of preexisting joint diseases such as rheumatoid arthritis (Cobb et al, 1939; Cobb \& Lindemann, 1943; Marris, 1958; Parkes, 1964) and fibrocitis (Marris, 1958). Parkes (1964) suggests that the reported aggravation of arthritis may simply serve as 
an excuse for the widows to talk to theit physicians about their grief. Nonetheless, he concedes that the probability of authentic joint inflammation for many mourners remains high.

6. Neurological Symptoms

Many of the neurological symptoms reported during bereavement are associated with underlying autonomic nervous systen arousal (Parkes, 1971, 1972, Parkes \& Brown, 1972). such as insomnia (Clayton et al, 1968, 1971, 1972; Hobson, 1964; Lamers, 1972; Maddison \& Viola, 1968; Parkes, 1971; Parkes \& Brown, 1972; Stern \& Lariviers, 1957; Yamamoto et al, 1969). Other frequent somatic grief complaints also appear to be based on autonomic arousal. These include restlessness, trembling and nervousness (Maddison \& Viola, 1968; Marris, 1958; Parkes \& Brown, 1972).

In addition to these symptoms which seem to be concerned with neural over-activation, the mourner may experience neurodermatological changes such as skin rashes (Maddison \& Viola, 1968; Marris, 1958); dizziness or fainting (Maddison \& Viola, 1968); and sensory distortions (Lindemann, 1944). The latter can escalate into hallucinatory proportions in those suffering from pathologicai grief (Matchett, 1972; Rees, 1970).

\section{Other Somatic Symptoms}

In addition to the forementioned effects on certain organ systems, grief-related stress reactions may be 
manifested in other general boully responses, as well. Frederick (1971) emphasizes that over-adaptation by man's highly developed and integrated nervous system can be a consequence of such non-specific stressors as grief. He notes that inflammation, a walling-off process, is important to the body's immune response because it prevents the spread of disease to other areas by encapsulating it. Corticoster. oids are anti-inflammatory agents, i.e.. they suppress this immune response, usually in a short-term sense. An overadaptation is exemplified by the $\mathrm{ACTH}$-corticosteroid response, which under a continuous stress, does not turn off. Hence, an individual who is stressed by grief, with the resulting physiologic picture of increased and continuous corticosteroid levels, might not be in an immunological state of readiness. In other words, the high steroid output reduces immunity and increases susceptibility. One result is that a person may contract the malignant rather than benign form of a disease caused by the same virus. Frederick (1971) suggests that such an over-adaptation with corticosteroidInduced complications may well result in greater susceptibility of the bereaved to a variety of serious disease states. These include glaucoma (Boyd \& McLeod, 1964), insulin-resistant diabetes (Frawley, 1955), fungal infections (Louria, 1962), tuberculos is (McLean, 1962), viral infections (Hallett et a1, 1951; Ormsby et a1, 1951) and possibly malignancies (Taliaferro, 1957).

The relationship between recent life losses and the development of malignant diseases is particulariy interesting. 
Schmale \& Iker (1966) 8tuãied 51 women at Strong Memorial Hospital in Rochester, who were hospitalized for suspicion of cervical cancer following atypical PAP smears. The aim of their investigation was to test their theoretical notion that the feelings of hopelessness and helplessness, which often accompanied a loss, may be responsible for physical ilnesses. Each of the women were interviewed by a psychiatrist prior to the biopsy and inquiries were made regarding recent losses. If the patient had experienced such a loss and also experienced feelings of hopelessness and helplessness, a prediction was made that the biopsy would confirm cervical cancer. If these predictor criteria were not met, then the absence of cancer was predicted. In 36 of the 51 women $(71 \%)$, the diagnosis was accurately made prior to the exploratory surgery, i.e., on the basis of recent loss, hopeless and helpless feelings. Schmale and Iker conclude that their study may be indicative of the physiologically stressful state of the bereaved which make them more vulnerable (because of lowered immunological readiness) to malignant diseases.

Schmale \& Iker (1966) and Green (1966) also make note of a high incidence of recent losses among a group of patients suffering from leukemia and lymphoma. And these relationships between loss and cancer have also been supported by findings that significant separation experiences were common in patients with malignant breast tumors, but not in patients whose breast lesions were benign (Muslin et al, 1966). 
Finally, many avthors (e.g., Lindemann, 1944; Maddison \& Viola, 1968: Parkes, 1972) have made reference to the frequency of symptom identification with the deceased by those individuals who are on the pathological bereavement course. Typically, such identification is related to the last illness of the deceased, if one existed. For example, a widow may develop chest pains following her young husband's recent death from acute cardiac arrest. Since these manifestations may vary according to the actual death inducing illness or according to the mourner's symbolic representation of it, this class of symptom is referred to this general category. The appearance of identificatory symptoms is an important index of the degree of abnormality in the grief process.

8. General Morbidity and Mortality of the Bereaved While the previous sections have dealt with specific symptomology, some studies have taken overviews of the bereaved population in order to assess the general morbidity and mortality incidence of this group. The findings have consistently demonstrated that ill health and premature death are higher in mourners than in the general population. In addition to the greater frequency of particular symptoms and diseases already noted, Hobson (1958), Maddison \& Viola (1968) and Marris (1958) found that widows gave self-reports of overall poorer health after the death of their spouses than before the death. Parkes $(1971,1972)$ and Parkes \& Brown (1972) point out that any pre-existing physical dysfunction 
is likely to be a target of stress, with consequential aggravation of the target dysfunction duxing the grief period. Certain types of families also display higher morbidity in the surviving family members following a sudden death (Vollman et al, 1971). And grief has been desaribed as a hazardous condition for those contemplating oral surgery (Kutscher et al, 1970) or elective surgery in general (Schoenberg, 1969) because of the higher susceptibility of the bereaved to complications. Postponement of these procedures is recommended by these authors.

The six-month period immediately following the death of a significant person in one's life is a critical interim, during which the risk of the survivor's own death is great. The variety of causes for this higher mortality rate among recently bereaved has been suggested earlier in this chapter. The fact that grief-related diseases actually lead to fatal outcomes is indicated by several studies with different populations. Kraus \& Lillenfield (1959) found an outstanding excess of deaths among the young widowed (under age 35) and Young et al (1963) reported similar findings of higher mortality anongst older (over 55 years) widowers during the first 6 months of bereavement ... an increase of over $40 \%$. The latter study is based on a five-year follow-up of almost 4500 widowers and has been supported by other investigators (Cox \& Ford, 1964; Parkes, 1964). Family members other than spouses are similarly higher risks for fatal illnesses shortly after their loss (Rees \& Lutkins, 1967; Vollman et al, 1971), especially if the death is sudden. Rees and lutkins (1967) 
found the mortality rate for relatives of the deceased to be seven times that of a comparable group in a similar area of semi-rural Wales who had not experienced a recent death.

Several author's have suggested explanations for this higher mortality incidence in the bereaved, such as psychological dysfunction leading to self-neglect (Hinton, 1967), additional environmental pressures of widowhood (Kraus \& Lilienfield, 1959) and physiological vulnerability resulting from stress (Frederick, 1971; Parkes, 1964, 1971, 1972). Though each of these factors appear to be influential, it has been my contention that stress-related physiological effects are the most critical.

\section{Affective Symptomology}

1. General Explanation for Cognitive Basis of Affective Symptoms

The rationale for the cognitive influence over affective symptomology has already been detailed in Part II. However, as a means of rekindling those reasons prior to a description of the symptoms themselves, the following summarization is offered.

Three perspectives converged to support the model of cognitive primacy regarding the emotional aspects of the acute grief syndrome. The regressive process which accompanies the disruption of the core cognitive dimension includes a loss of dis junctiveness between the cognitive, conative and affective modes of interacting with events. Interpersonal phenomena, which are ambiguous and, therefore, 
poorly disjoined to begin with, are especially. vulnerable to affective arousal when cognitive regression occurs. This effect of high affect arousal and involvement, subsequent to interpersonal loss, partially accounts for the strong emotional symptomology of bereavement. The regression of cognitive functioning has as a corollary - emotional stimulation。

In addition, Kelly's (1963) re-definitions of certain relevant affects into cognitive terminology and explanation gave support to the idea of emotions related to grief being understood as cognitively derived. Thus, anxiety was defined as the experience of encountering events for which the individual lacked an adequate cognitive dimension for comprehension or coping. Anger and hostility were described as feelings of (a) having to choose between restructuring one's matrix or force-fitting events into the old innappropriate structure; and feelings of (b) actually attempting the force-fitting, while extorting validation for the distorted perspective. Guilt was explained as the sense of loss of interpersonal roie responsibilities and expectations, with attendant questions about the degree of one's failure in the prior, now lost, role.

Finally, the physiological state that signifies stress (which is activated by the psychological stress subsequene to disruption and inadequacy) places the mourner in a somatic arousal condition that is subject to cognitive interpretation. The bodily responses of stress are similar to those of high emotional tension. Therefore, it is possible that the mourner 
identifies his experience as certain feelings such as anger or fear, on the basis of physical sersations that are actually cognitively-induced reactions to stress.

The reader may also refer to Figure 9, page 62.

The plan of this section will be to present a 1iterature review of the emotion under consideration, followed by a cognitive model explanation of the respective affective symptom. The affects discussed include (a) fear and anxiety, (b) anger and hostility and (c) guilt. These descriptions will be followed by an expanded section on (d) depression, based on Beck's (1967) previously published cognitive explanation for that syndrome.

\section{Fear and Anxiety}

(a) Introduction and Literature Review

The frequency of anxiety and fear in the bereaved is high (Bruhn et a1, 1970; Krupp, 1965; Lamers, 1972; Lindemann, 1944; Maddison \& Viola, 1968, Parkes, 1964,1965,1971,1972; Yamamoto et al, 1969). However, its intensity and duration can vary. Most anxiety reactions occur early in the bereavement process with occasional exacerbations later. Persistent and extreme fears may indicate pathological grief. These can include recurring nightmares (Maddison \& Viola, 1968), panic attacks after the first month of bereavement (Maddison \& Viola, 1968; Parkes, 1971, 1972) or terror fears (Paul, 1967). It should also be noted that sustained anxiety/fear has as its corollary a sustained somatic arousal condition which is potentially dysfunctional 
to normal physiology (Selye, 1956). In other words, the body begins to wear down after a prolonged period of fearful tension ... the keneral Adaptation Syrdrome's "Exhaustion Stage".

Other investigators have described anxiety based symptoms of grief, including school phobias (Jakab \& Howard, 1969), phobias of being alone or of death-related stimuli (Hinton, 1967), fears about maintaining their sanity (Lindemann, 1944; Maddison \& Viola, 1968) and realistic fears about allegations of child neglect or child abuse following an infant's unexpected demise (Halpern, 1972) as occurs in the 'Sudden Infant Death Syndrome'.

(b) Cognitive Model Explanation

The sudden death of a significant person in one's life is a very frightening experience. Anong its immediate effects are a sense of vulnerability and inadequacy in the face of previously routine stimuli that now become overwhelming. The world is confusing and impinging, since the normal resources for dealing with events is disrupted. The potential for chaotic disorganization is great. The individual responas to this psychological assault as if it were a physical assault (Wolff, 1953) because the threat to security and survival are similar.

Fear reactions are generated because of the acute absence of another person upon whom the bereaved may have depended in some important ways. This loss of, for example, genuine protection gives rise to authentic potential for harm from external sources; therefore, normal fear is aroused. 
Internally, anxiety reactions are generated because the individual is voided of a core dimension with which he had understood and coped wich a multitude of events. Psychologically, the bereaved finds his functional survival unexpectedly threatened and his matrix foundation de-stabilized. There really is possibility for collapse, especially as the overload increases, and the mourner's anxiety and fear must be viewed with that reality in mind.

Comprehension of the threat results in somatic arousal, as wel1. The mourner is under stress and experiences a physiological alarm reaction involving increased reticular stimulation and autonomic arousal. These changes yield somatic cues that are identified by the mourner as fear or anxiety. Such fears are a normal component of the acute grief syndrome since they are realistic responses to the genuinely hazardous sequelae to a sudden death experience.

That the anxiety may be dependent on survival threat is suggested by Bowlby (1961) in his analysis of 'separation anxiety'. He notes that attachment to a mother figure is a functional necessity to the infant and that the severing of this attachment is Iiterally life-threatening. He and Krupp (1962) have also noted - though from different theoretical bases - that there are similarities between adult grief anxiety and infant separation anxiety (Bowlby, 1960). Whereas Bowlby and Krupp conceptualize grief as either a recapitulation or a special case of infant separation anxiety, my contention is that each is a realistic survival threat in its own right. Westberg (1962) lends some support for this 
notion of survival threat in his reporting that the bereaved indicate an experience of panicky feelings due to fear for their continued survival and their inability to cope or function as adequately as they had been able to previously (see Figure 1.6).

3. Anger and Hostility

(a) Introduction and Literature Review

Indeed, anger is a common affective symptom reported by the bereaved (Lamers, 1972; Paul, 1966; Siggins, 1967). Whether it takes the forn of irritability and loss of interpersonal warmth (Lindemann, 1944; Westberg, 1962), rage (Halpern, 1972; Paul, 1967) or aggression (McConville et 21, 1970; Volkan, 1970). The resentment is experienced by individual survivors (see the foregoing; Hinton, 1967) and by families as a whole (Kalish, 1961; Vollman et al, 1971).

The targets of grief hostility are often persons who are tangentially associated with the death. Thus, in Herzog and Resnick's study (1968) of parents of adolescent suicides, the anger was directed at police, coroner's deputies and the researchers themselves. The displaced hostility in Nolfi's (1967) sample of survivors of children's deaths, was targeted at a diagnosing physicians, the treatment doctors and nurses, the hospital at large and, here too, at the interviewers. Parents of victims of 'Sudden Infant Death Syndrome' often express their anger, resentment and blame toward older siblings of the deceased child (Halpern, 1972). This suggests considerabie projection as well as displacement because these parents tend to feel quite guilty and responsible for the 


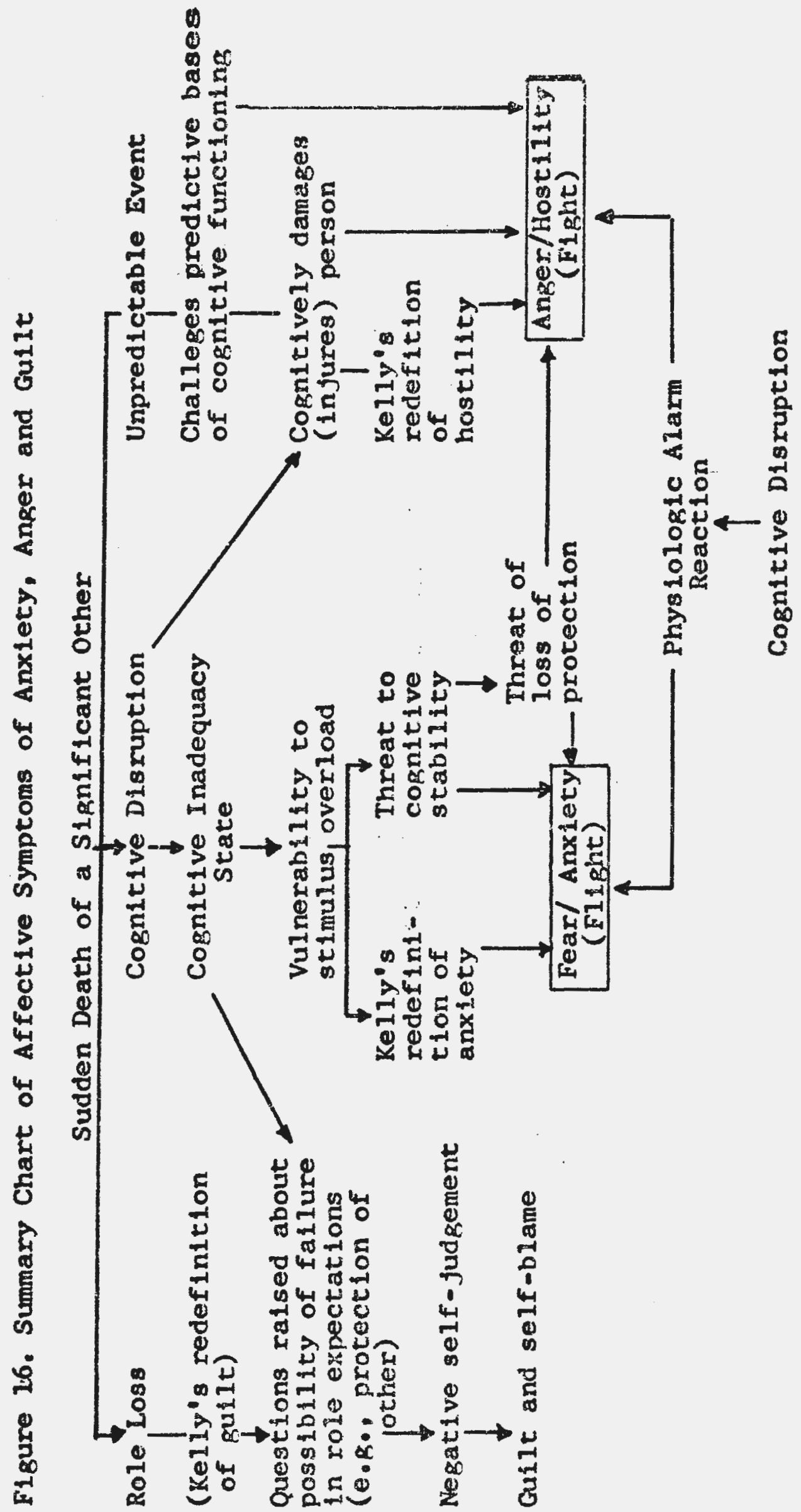


child's death. In many instances, the deceased is the object of rage (Hinton, 1967; Pretze1, 1972, Vestberg, 1962). Bowlby (1960, 1961) and Westberg (1962) suggest that this displaced anger at the deceased is generated by rage over a sense of abandonment. Others who have observed suicide survivors (Cain, 1972; Pretzel, 1972) view the grief hostility toward the deceased as arising from the sense of having been attacked through the suicidal act. While intense hostility can be directed toward specific persons, some investigators believe that a generalized anger is aiso a frequent mourning symptom (Hobson, 1964; Parkes, 1965, 1971, 1972; Yamamoto et al, 1969).

Expressions of hostility can be quite distressing to the targeted individuals. Nevertheless, they are basically normal components of the grief syndrome. However, when the anger has a shotgun effect; that is, spread indescriminately toward everyone and everything at peak intensities, then it is no longer typical, but exaggerated and pathological (Sigging, 1967). Volkart and Michael (1957) measure the pathology of anger in bereavement on the basis of intensity. They found that hostility was normal at relatively low strengths with concomitant low vulnerability to mental health problems. Highly intense rage, however, was correlated with a much greater risk of overall psychological dysfunction. And Becker (1933) makes the connection between angry feelings and behavior, by stating that one type of bereavement response involves the free ventilation of violent and aggressive behavior: and that this must be considered abnornal because 
of its rarity and its potentially dangerous consequences.

\section{(b) Cognitive Model Explanation}

Man has been conceptualized here as a being who attempts to make serise out of events. Yet sudden death is often a phenomenon that is senseless. As such, it is an event which challenges the very basis of the individual's functioning, thereby confusing him and by its assaultive nature, enraging him. The bereaved has been injured, damaged and insulted by the meaninglessness of the inopportune loss of a significant component of his world. And part of his response is to get angry: However, individuals apparently have difficulty maintaining rage against an abstraction, i.e.. death ... a target is required, though rarely does an appropriate target exist. Therefore, the mourner tends to express his anger toward environmental objects that are opportunistic rather than appropriate. For this reason, most anger displayed during bereavement is displaced upon whatever targets are readily available. I have consistently been impressed with the rhetorical question so often shouted by mourners: "Why did this have to happen to me?" And I have noted that the question appears to have more of the quality of indignation and outrage, than of wailing bereavement.

Anger and hostility is generated from two other bases. as we11. As suggested earlier, the individual must either re-structure his cognitive matrix to accommodate for the 1oss, or he must exert effort at making events which really don't fit, slide into his cognitive framework. The latter involves an extortion or illegitimate confirmation from reality in order 
to validate a defunct framework. Keily (1963) has called this extortion 'hostility'. Also, the state of alarm triggered by the stress of cognitive disruption is known, appropriately, as a 'fight or flight' reaction. Therefore, the bereaved's physiological state is in readiness for confrontation. If the somatic experience is identified by the individual as fear, then he'll react on the 'flight'side of the choice; if identified as anger, then he'll reach from a hostile 'fight' stance (see Figure 16).

\section{Guilt}

(a) Introduction and Literature Review

It is not surprising that acutely bereaved people, who are already in a state of cognitive inadequacy, would be more susceptible to negative self-judgements regarding their adequacy of role fulfillment. And many mourners do, in fact, experience intense guilt feelings that focus on a sense of failure, self-blame, and inadequacy (Clayton et al, 1971; Hinton, 1967; Kalish, 1963; Lamers, 1972; Lindemann, 1944; Mosley, 1969; Parkes, 1965, 1972; Siggins, 1967; Westberg, 1962). The feeling may be expressed as self-reproach or self-recrimination for acts of real or fantasized omission or commission.

A child's death appears to be especially provocative for intense guilt feelings (Cain \& Cain, 1964) because the parent role is heavily weighted with expectations and responsibilities which the surviving parent judges himself as having failed to meet. Nolfi (1967) found parental guilt 
to be centered on a) the etiolrgy of death and theis own contribution to it; b) the possitility of having delayed recognition of the symptoins that. led to the death, and;

c) the failure to provide the best possible care and treatment because of lack of sufficient runds. Suicidal death of a child is perhaps the most difficult experience of loss for parents to bear. In these cases, self-blame and guilt are the most dominant affects (Cain, 1972; Herzog \& Resnick, 1968; Pretzel, 1972; Whitis, 1968) and are fueled by the public shame and stigma attendant to suicide. There is also the subtle interpersonal message of self-destructive deaths which tend to, in the act itself, point a finger of blame at the survivors. This is discussed more completely in Part IV under 'differing modes of death'. In other than suicidal deaths, such as those associated with the Sudden Infant Death Syndrome, guilt in the parents is generated as well (Halpern, 1972). This is especially true of mothers who may become overwhelmed by guilt and self-doubt regarding their maternal adequacy.

Spouses (Clayton et al, 1971) and siblings (Cain et al. 1964; Holland et al, 1971) are not immune to these feelings of failure, and often experience guilt over minor omissions, or search their pre-death behavior for faults and negligence (Lindemann, 1944). Thus, regardless of the particular role, the loss of that role creates self-doubts about the survivor's adequacy of filling it, and this leads to the emotion of guilt.

Pathological intensity of guilt occurs (Siggins, 196́; Volkart \& Michael, 1957) most often in those bereaved who 
are subject to a high sense of failure. This can be due to the fact that they did actually fail in their role, rather than i.t simply being a distorted self-assessment; or because the nature of the death ( $e_{\cdot} g_{\bullet}$, suicide or Sudden Infant Death) carries implicit accusations regarding their role competency. The danger of prolonged and intense guilt feelings is the potential for self-abuse or suicide. The acutely bereaved, especially those who are themselves survivors to a suicidal death, are a high-suicide-risk group (Cain, 1972). And the higher mortaility rates in the recently bereaved, which were discussed earlier, may represent a tendency toward the passive self-destruction of guilty mourners of simply neglecting to routinely care for their health and well-being (Hinton, 1967).

(b) Cognitive Model Explanation

The affective experience of guilt is intimately linked to a sense of failure. The mourner typically understands the death of a significant other as a demonstration of his own inadequacy in successfully meeting his responsibilities regarding the relationship. He had assumed certain obligations in hi.s role as parent, spouse, child or sibling, and tends to attrivute the death to his failure to fulfill the expectations of that role. This explanation differs somewhat from other definitions that are based on moral transgression, actual culpability or ambivalence surrounding anger at the deceased. Instead, my belief is that an individual in relation with another defines for himself certain explicit and major expectations which he intends to meet. When the 
role is irretrievably los upon the other person's death, the survivor judges himself with regard to his sense of success or failure in realizing those expectations, and judges whether his role fulfillment (or lack of it) affected the death event. Whan he judges himself as having failed to meet his role responsibilities (even though they're selfdefined), then he experiences the role loss with a sense of guilt. At least partially, in this way, he blames himself for the death.

Figure 16 is provided as a summary for these affective notions.

5. Depression

(a) Introduction and Literature Review

Bowlby (1966) points out that all forms of grief have a sequence of stages that must include despair, and Paul (1967) terms these feelings as universal and consisting of profound sadness and despondence. The literature of grief reactions virtually always includes some reference to the depression which accompanies bereavement (e.g., Clayton et al, 1968, 1971, 1972; Crisp \& Priest, 1972; Hinton, 1967; Lamers, 1972; Lester \& Kam, 1971; Lindemann, 1944; Maddison \& Viola, 1968; Marris, 1958; Parkes, 1965, 1971, 1972; Parkes \& Brown, 1972; Yamamoto et al, 1969).

Several investigators have found in their retrospective studies of adult depression which have no known situational precipitant, that these depressive reactions are manifestations of prolonged grief processes originating with some 
childhood loss of a significant other person (Beck et al, 1963; Birtchne11, 1953, 1970; Capian \& Douglas, 1963; Hilgard \& Newman, 1961; Hill, 1967, 1970).

Pathological depression in bereavement is indicated by Parkes (1964) in the large proportion of hospitalizations for acute depressive episode within the first 6 months after the deati of a spouse. The form of the atypical depressive reaction may be one of agitated depression (Lindemann, 1944) or simply the undue prolongation of depressive affect which develops into a chronic condition (Herzog \& Resnick, 1968).

(b) Beck's Cognitive Explanation of Depression i. Introduction

Since depression appears to be the dominant affective symptom of the grief syndrome, it seems worthwhile to provide a more detailed analys is of this mood disorder in order to support the contention that depressive affect is a function of cognitive disruption. Such an analys is has already been put forth by Aaron Beck in his book Depression: Causes and Treatment (1967), which has become a standard reference work in its field. The presentation that follows is derived from Beck's work.

Although witers have traditionaliy and formally (see DSM II, 1968) characterized depression as essentially a mood disorder, Beck construes the syndrome as "primarily a thought disorder with resultant disturbances of affect and behavior consonant with cognitive distortions" (Beck, 1967). He proposes that the "way an individual structures an experience 
determines his affective response to it" (Beck, 1967) and that the "rypical depressive affects are evoked by erroneous conceptualizations" (Beck, 1967). The specific thematic content of these erroneous cognitions and the types of cognitive distortions being applied to them have been categorized.

ii. Cognitive Content Areas in Depression Accordingly, six major areas of content are delineated with regard to depressive distortions: 1) Low self-regard and low self-evaluation is a prominent component of depressive ideation and usually consists of devaluating themselves in areas of particular importance to them. This may apply to personal attributes (e.g., ability or health), to acquisitions of tangibles and intangibles (e.g., friendship) or past performance in one's role (e.g., parent). The latter was discussed in the last section in particular with reference to guilt feelings. A common feature of these negative selfevaluations is the magnification of failure and inferiority, with minimization of favorable traits ... especially in comparison with others.

2) Ideas of deprivation and destitution are allied to these low self-appriasals and are manifested in thoughts of loneliness and lack of material goods, contrary to reality evidence of both friendship and goods. 3) Self-criticism and self-blame, unlike the comparative low self-regard, simply refers to perceived shortcomings irrespective of their presence in others. 4) Overwhelming duties and problems are 
described although they represent magnifications of responsibilities considered insignificant when not depressed. 5) Self-coercive cognitions involving self-commands and injunctions ('shoulds' and 'musts') form a substantial portion of the thoughts of the depressive. They usually consist of self-proddings to do things which are inpractical, undesirable or impossible to implement. They typically apply to a broad range of activities, many of which are mutually exclusive. 6) The final theme of depressive cognitions involve escapist and suicidal wishes, in an effort to evade the problems of life. Perceiving the problems as unsolvable, yet formidable, the depressive tends to withdraw. When the situation is construed as untenable or hopeless, then suicidal ideation develops as the only possible solution.

\section{iii. Thinking Errors in Depression}

Each of these cognitive areas represent varying degrees of reality distortion in that they demonstrate a systematic bias against the cognizer. A manner. in which these typical depressive cognitions can be categorized is in their mode of deviation from logical thinking. Beck (1967) has suggested the following thinking errors as explanations for these distortions (Also see Table 2 ).

'Arbitrary inference' (a form of paralogical error) is defined as the process of drawing a conclusion from a situation, event or experience, when there's no supportive evidence for the conclusion, or when the evidence, in fact, 

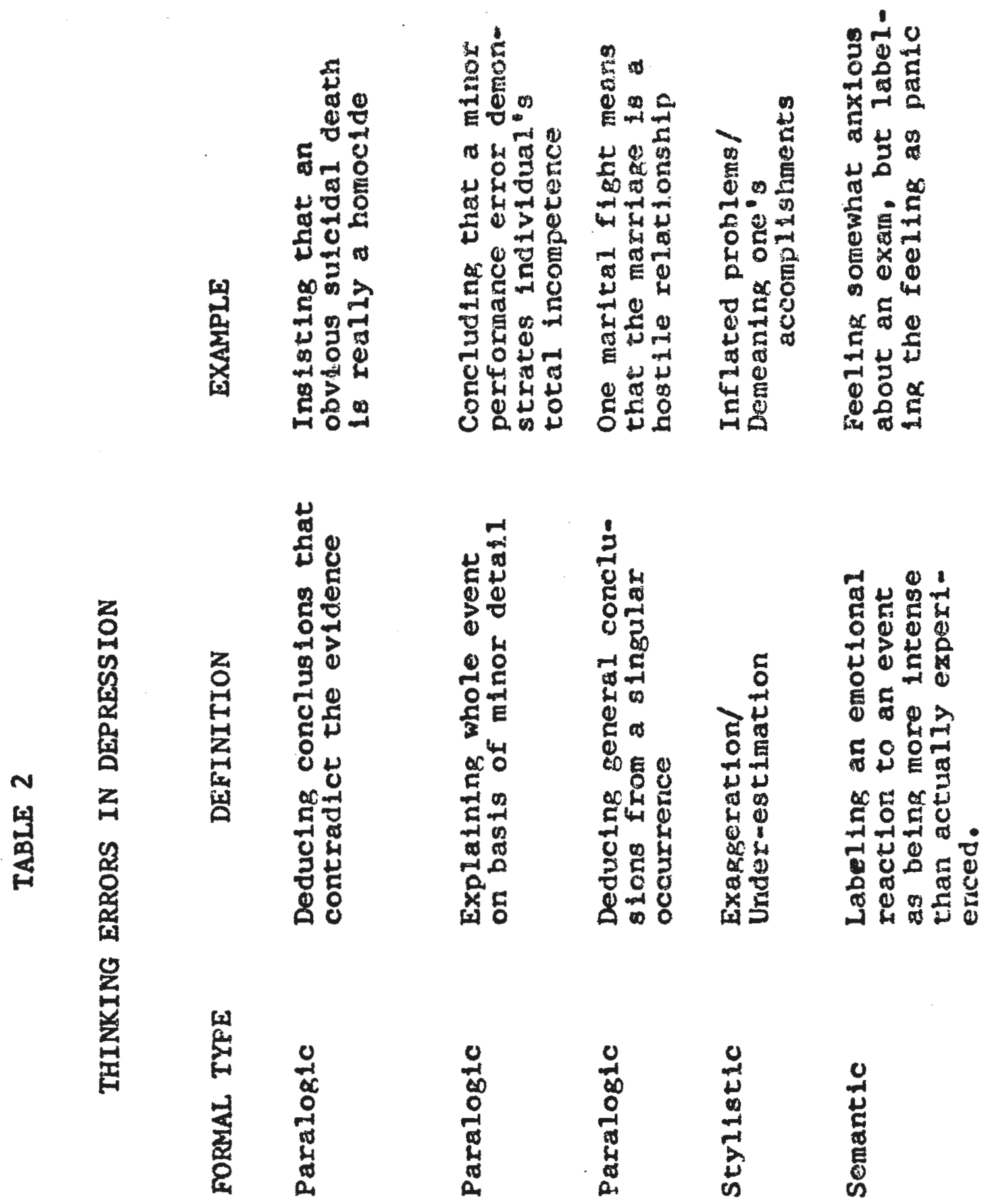

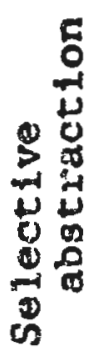

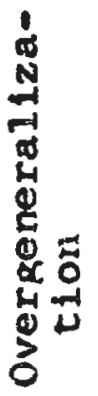

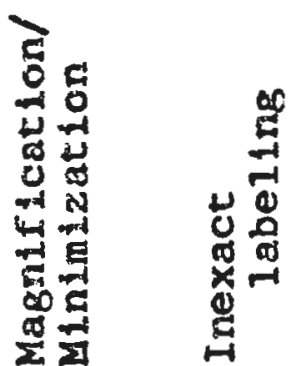


contradicts the conclusion. Such dedictive errors are especially likely to occur when the informational cues are ambiguous; and this type of thinking typically involves a lack of regard for alternative explanations that are more probable and more plausible. For example, assuming that an obviously suicidal death was actually a homocide.

'Selective abstraction' (another paralogical error) refers to the process of focusing on some detail of an event without consideration for the rest of the context or for more important details, and then conceptualizing the whole event on the basis of this singular element; for exampie, deciding that an open window (on a warm night) is evidence of an intruder/murderer, despite the suicide note.

'Overgeneralization' (also a paralogical error) refers to the cognitive pattern of deducing general conclusions about abilities, performance and worth on the basis of a solitary occurrence; for example, viewing a minor argument as a demonstration of a wholly hostile relationship.

'Magnification' and 'minimization' (stylistic errors) refer to evaluative errors of gross over or under estimation (e.g., of poor performance or inflated problems).

'Inexact labeling' (a semantic error) occurs when the affective reaction is proportional to the descriptive labeling of the event, rather than the actual intensity of the trauma (e.g., labeling an event as panic producing and experiencing panic, though event is only somewhat anxiety arousing). 
iv. Formal Characteristics of Depressive Cognitions

The foregoing sections have attempted to describe the cognitive characteristics of depressive symptoms in terms of their typical content and the cognitive processes involved in the depressive's conceptual errors and distortions which allow these content biases.

Formal characteristics of depressive cognitions have also been observed and described by Beck (1967). They include: 1) the automatic nature of the depressive thoughts, without any apparent preceding reflection or consideration and 2) their involuntary quality even when the depressed person has resolved not to have them. The cognitions are also 3 ) very plausible to the depressive and tend to be accepted without critical assessment.

With regard to plausibility, Beck (1967) has provided some support for my own earlier notions about disjunction. He finds that the more plausible the distorted cognition, the stronger the affective reaction; and conversely, when the affective reaction to a thought is particularly strong, its plausibility (despite its erroneousness) is enhanced and the individual finds it more difficult to assess its true validity. Furthermore, once the strong affect is aroused in response to a distorted cognition, any subsequent distortions seem to have an increased plausibility. This occurs regardless of whether the affect aroused is sadness, anger, anxiety or euphoria. In other words, affect arousal interferes with accurate cognition, which I postulated earlier as a function of reduced disjunction. 
The final characteristic of depressive cognition is its stubborn 4) perseveration, in which there is a stereotypic interpretation of highly complex and heterogenous stiuation.

v. Cognition as the Determinant of Depressed Mood On the basis of this analysis of the thematic content the logical errors and the formal characteristics of the depressive's cognitions, Beck (1967) proposes that the distorted conceptualizations (e.g., of inadequacy, being deserted, or being sinful) are responsible for the corresponding affects (e.g., of sadness, loneliness, or guilt). "The affective state can be regarded as a corsequence of the way the individual views himself or his environment" (Beck, 1967). "The way an individual structures his experiences determines his mood. Since the depressed person consistentiy makes negative conceptualizations, he is prone to have a consistently negative mood" (Beck, 1967). Beck refers to clinical studies in which changes in the person's cognitions evoked congruent changes in the depressed feelings (Loeb et al, 1964). He finds that there is a definite temporal contiguity of thought and affect, as well as a logical consistence between them; 1.e.. the specific affect (e.g., humiliation) is congruent with specific thought content (e.g., of being inferior).

The linkage which Beck postulates between cognition and affect is one of 'conceptual schema', parallel to my ideas about 'cognitive dimensions'. The cognitive structuring or conceptualization of an event, according to Beck, is dependent on the schema elicited to understand it; and the 
specific schena has a direct infirence on the affective response to the event. In the earlier discussion of the triema and logical fallacies of the depressives, it was noted that there is a tendency to utilize depression eliciting schema in the construing of certain events; and to cognitively distort interpretations in order to make the interpretation fit the schema involved.

For erample, if the schema is concerned with selfdepreciation, a feeling of sadness will be associated with it; if its concerned with self-blame, then guilt feelings are evoked. The particular types of depressive affects are related to the specific types of thought patterns (schema) used to construe the event. Therefore, patterns (or dimensions) that have a content relevant to being deserted, thwarted, undesirable or a failure in one's role will yieid, respectively, feelings of loneliness, frustration, humiliation and guilt.

As these types of cognitive schema (e.g., being deserted) are employed to understand some phenomenon, their respective affective components (e.g., loneliness) become activated, thereby providing the overall subjective feeling aspect of depression. Furthermore, it is proposed by Beck (1967) that once affect is generated, a circular feedback process occurs that partially explains the downward spiral of depression. In other words, the evoked affect interacts with the initial cognition to escalate the negative thinking ... then, the more negative he thinks, the more depressed he gets and feels; the more depressed he feels, the more 
negative he thinks.

However, it must be emphasized that not all negative thoughts (with their resulting negative feelings) are automatically distortions. I have gone to considerable length in support of the fact that the sudden death of a significant other is realistically construed as a traumatic, negative experience of major importance and threat potential. The depressed feelings associated with the realistic conceptualization of the loss are still determined by the cognitions, though, in this case, they don't have to be distorted to be negative. The pervasiveness and severity of the trauma can, however, create an exaggerated cognitive response which is partially realistic and partially distorted. One of the principle tasks of the grief counselor would seem to be the sorting out of realistic conceptualizations about the death with their affiliated depressive affect from the distorted negative cognitions and their associated affect.

vi. The Primary Triad of Depression

It is useful to discuss Beck's (1967) 'Primary Triad of Depression' in order to relate the views thus far presented to a general descriptive paradigm of depressive feelings and to note the applicability of the paradigm to the depression associated with grief.

Depressive dysfunction may be viewed in terms of the activation of a set of three principle cognitive patterns. These patterns predispose, or force, the individual to construe himself, his world and his future in negative ways, such that 
associated affects are arcused which characterize the depressive state. It is my contention that a sudden death reasonably and logically activates this triadic cognitive pattern; and that acute grief symptomology embodies both the negative thoughts and the affiliated affects of the triad.

The first triadic component described by Beck (1967) is the pattern of construing experiences in a negative way by consistently interpreting interactions with the environment as representing defeat, deprivation or disparagement. Life is perceived as being comprised of a sequence of burdens, obstacles or traumatic situations which significantly detract from the cognizer.

Such interpretations and perceptions by the acutely bereaved of their environmental interactions are often quite accurate. Their reduced coping abilities, due to disruption of a core dimension, increase their vulnerability to defeat and make previously routine events overwhelmingly difficult and burdensome. Their experience is one of continual overload which leads to a realistic assessment of being able to meet many environmental demands. The sense of deprivation is similarly based on the genuine irretrievable loss of an external resource. These cognitions are no less depressing because they are realistic, nor are the affiliated feelings less intense. Acute grief includes a normal, depressive affect element based on this pattern of construing these realistic interactional consequences of the death.

The pathological depression of grief arises from the 
exaggerations $=n d$ distortions of these normal and realistic conceptualizations. In these instances of pathological depression, the individuai selectively and inappropriately interprets his experiences by automatically making negative assumptions about his situation even though more obvious and plausible expianations exist. His typical cognitions show deviations from logical thinking, including arbitrary inferences, selective abstractions and overgeneralizations. While some obstacles are really not surmountable for the bebeaved, even those which are manageable are viewed as impossible; and the understandable difficulty in dealing with problems is misinterpreted as total failure. The real loss they have encountered sensitizes the pathologically depressed mourner to exaggerate relatively trivial events as constituting additional substantial deprivations. And their sense of vulnerability and damage predisposes them to think that their defect is exposed to others and subject to frequent disparagement and derogation (see Figure 17).

The second component in the triad of depression is the cognitive pattern of viewing oneself in a negative way. The individual regards himself as deficient, inadequate or unworthy and tends to attribute his unpleasant experiences to some defect in himself. Furthermore, he may regard himself as undesirable and worthless because of his defect, and may then reject himself because of it (Beck, 1967).

Sudden death is both dis ruptive and destructive to the survivor's cognitive matrix. He experiences a condition of cognitive inadequacy resulting from a defect in a 


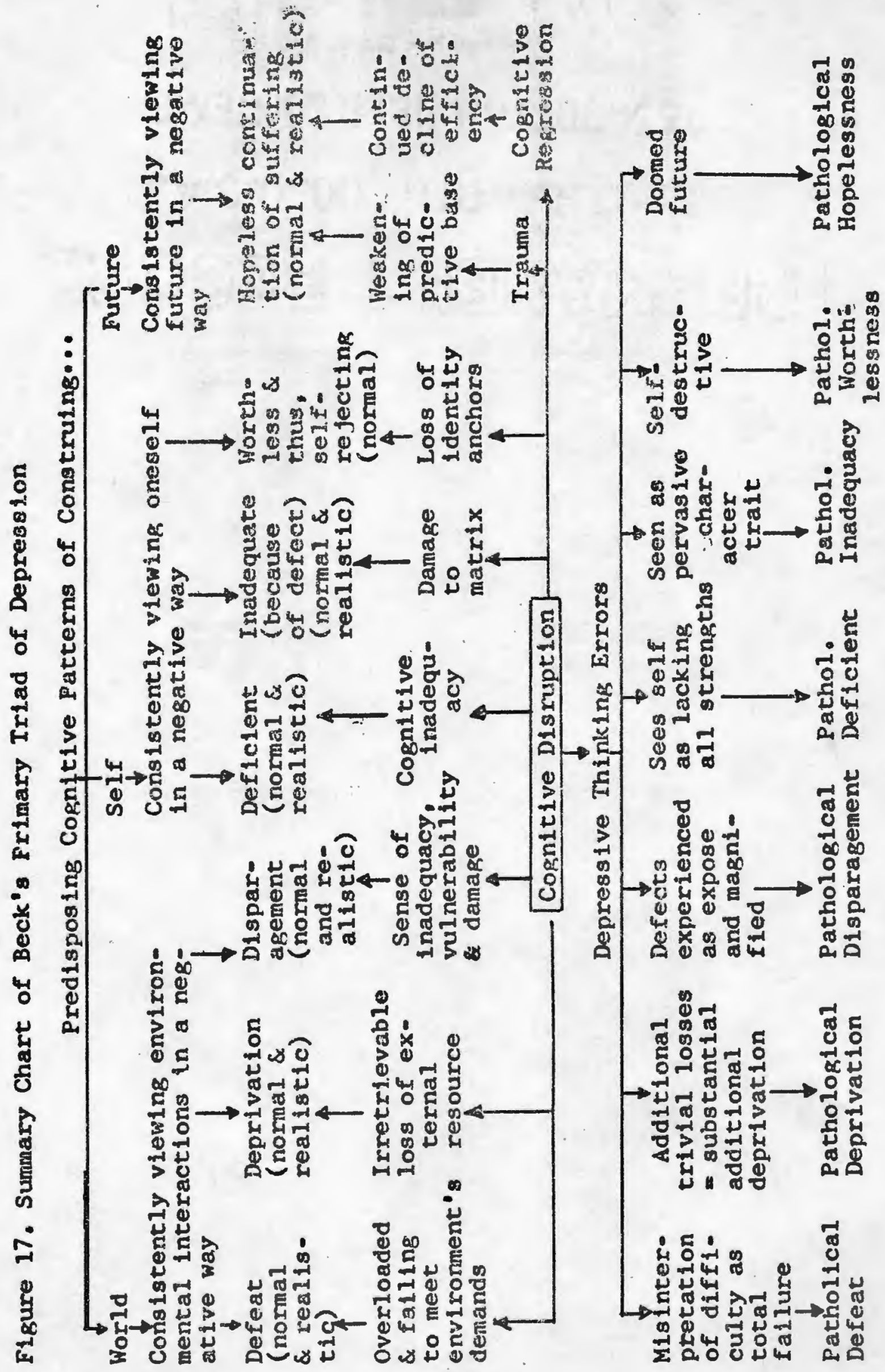


central/core dimension of his copnitive structure. There is real deficiency during acute grief and the attribution of a negative cognition and affect to this experience is an appropriate connection to make. Even the element of selfrejection can be understood as normal on the basis of some loss of identity anchors that were previously associated with the relationship to the deceased. These are common and reality-based reactions to the trauma of a sudden death and the depressive feelings are expected derivatives of the mourner's accurate self assessment of his situation.

However, when the deficiency becomes so magnified that it occupies the individual's total self-concept or he seems incapable of viewing himself in any other terms, then a pathological depression is involved. Here, the bereaved tends to generalize from a particular inadequacy to an overall character trait and to regard himself as a generally inferior person (i.e., selective abstraction). Not only does he have an intensified sense of identity loss, but additionally rejects and reproaches himself for being so defective and inefficient (see Figure 17).

The final component of the depressive triad consists of viewing the future in a negative way. The person anticipates that his current difficulties or suffering will continue indefinitely. His hopefulress is meager as he perceives life as constituting relentless hardship, frustration and deprivation (Beck, 1967).

Again, these conceptualizations, though arousing strong depressive feelings are, nonetheless, based on the realities 
of the loss. The trauma of a sudden death leaves the world uncertain and unpredictable. The cognitive tools for predicting and controlling future encounters are severely weakened, making reliable anticipation difficult ... except in the expectation that the current situation will continue or degenerate, since cognitive regression is progressing and adequacy is failing over time. Thus, the prospects for the future are negative and the normal mourner is, indeed, likely to feel hopeless.

Pathological grief is manifested by the obsessive preoccupation with a doomed future. The ruminations and fantasies are so ominous that suicidal ideation appears to be the only escape from burdensome tomorrows. Moss and Hamilton (1956) reported bereavement as a precipitant in a very large proportion of suicide attempts. The sense of endless misery is related to an absence of temporal grounding, which the suddenness of the death has traumatized by its unpredictability. The mourner's prophecies begin to distort reality improvements in his situation, such that the expectation becomes self-fulfilling (see Figure 17).

In this summary of Beck's cognitive paradigm of depression, followed by my application of it to the normal and pathological depression of bereavement, the intent was to support the contention of cognitive influence over the major affective symptom of grief, namely depression. By describing the thinking content, distorting processes and triadic construing patterns of depression. I believe such 
support was offered.

\section{E. Behavioral Symptomology}

1. General Explanation for Cognitive Basis of Behavioral Symptoms

The behavioral changes that accompany bereavement are postulated as direct manifestations of the cognitive alterations. Action is the observable outcome of cognitive functioning. Therefore, when the latter is disrupted by the trauma of a sudden death, behavioral outcomes will consequently be affected. The individual is conceptualized as using his construing abilities in order to make decisions about what actions to take upon his environment. These actions will be aimed at increasing his probabilities of success in maintaining his survival, obtaining his objectives and accurately predicting events. A major purpose of cognitive functioning is in the control of behavior toward those ends. As grief affects the underlying cognitive functions, behavioral symptoms will appear. These are described on the following pages.

This section is concerned with three categories of behavioral response to sudden death: (a) interpersonal changes, (b) changes in typical activity levels and, (c) searching behavior. A brief explanation of the cognitive origins is provided prior to a review of the literature dealing with these behaviors during bereavement. 


\section{Interper'sonal Changes}

\section{(a) Introduction and Literature Review}

The constriction of interpersonal behavior has been reporced by Earardo (1970) as social isolation in aged widowers; by Hobson (196á), Hinton (1967), Marris (1958), and Parkes $(1965,1971,1972)$ as general social withdrawal; by Lamers (1972) as social inhibition and loss of socializing desires; by Lindemann (1944) as overaj.1 changes in relations with others, including isolation (which he considers pathological) and loss of social interaction patterns. Moreno (1947) also notes loss of interaction patterns during bereavement. Family cohesion often appears after a sudden death, with an increase in solidarity and overall inter-member interaction, usually to the exclusion of non-family members (Eliot, 1932; Jensen \& Wallace, 1967; Vollman et al, 1971). However, the stress of having to re-shape family roles after the death of a key member may take its toll on the family unity and cause transcient disturbances (Eliot, 1932; Vollman et a1, 1971).

Apparently, some specific types of death have idiosyncratic consequences for the survivors. Several studies (Cain, 1972; Herzog \& Resnik, 1968; Pretze1, 1972) found that the stigma associated with suicidal death results in peripheral relatives and friends withdrawing from the mourners, rather than offering social support. This is also true of those who might otherwise be supportive to survivors of children's deaths (Nolfi, 1967) but who, because of their own feelings of inadequacy in coping with the event, tend to withdraw 
and thereby force the bereaved to urdergo further isolation. Another interpersonal behavior that occurs in the bereaved has been referred to in the description of affective anger and hostility symptoms. Many survivors experience angry feelings for which there is no appropriate target. These feelings are frequently discharged upon others who are simply opportunistic targets, such as Halpern's (1972) description of mothers angrily blaming older siblings for the loss of a child to Sudden Infant Death Syndrome. It is this displacement of hostility which elicited the comment by Lindemann (1944) that in acute grief there is often a loss of interpersonal warmth.

As with other symptomology, atypical grief manifests itself behaviorally through exaggeration. In this case, constriction of interpersonal relations to the point of isolation is considered representative of a pathological grief syndrome (Hinton, 1967; Lindemann, 1944; Parkes, 1965). Such behavior prevents needed social support, precludes the reestablishment of alternate interpersonal linkages, and often is associated with pathological under-activity described in the next section.

(b) Cognitive Mode1. Explanation

The primary disruption of cognitive functioning occurs in the interpersonal sphere with the core dimersion - the relationship with a significant other - being the focus of matrix damage. The constellation of linkages around this core dimension involves many conceptual categories. However, those most directly associated with it involve other people 
either by affiliation (e.g., siblings of the deceased) or by comparison (e.g., father-in-lath when father dies) or by a social sharing histcry (e.g., married friends when a spouse dies). These linkages are without a central anchorage after a sudden death because their prior stability was intimately related to the deceased. The mourner, therefore, does not have the cognitive means for dealing with other people as adequately as he was able to in the past. His frame-ofreference for interpersonal interaction has been damaged and he must first re-establish stable and appropriate cognitive dimensions for dealing with others.

Furthermore, there exists a particular vulnerability and sensitivity in the interpersonal area of the cognitive matrix because it is the center of disruption. The bereaved becomes especially protective lest the wound be further injured. He attempts to seal off the structural damage by constricting his interpersonal cognitive functioning, hence his social behavior changes. His modes of interpersonal behavior change, as well, since cognitive regression reduces his sophistication and imposes a simpler and more global style. This ail serves to permit reparative efforts to procede on the core dimension, without the complications of complex and ambiguous interactions with others.

Pathological outcomes can eventuate if benignly intentioned others force complicated interactions upon the vuinerable mourner. This will create a condition of overload that is focused on the core of structural instability, which can easily result in brealdown. While social support is a 
necessary aid during bereavement, it must be offered at the level and intensity which the mourner is able to tolerate (see Figure 18).

\section{Activity Levels}

\section{(a) Introduction and Literature Review}

The behavioral rigidity of normal bereavement may be characterized as psychomotor retardation, automatic behavior, zombie-1ike motions (Lamers, 1972) or as simply mechanical activity (Lindemann, 1944). Westberg describes it as a general loss of regular behavior patterns (1962). Normal grief also includes behavioral dilation seen as restlessness (Lindemann, 1944; Parkes, 1972) or verbally as a pressure of speech (Lindemann, 1944). The increases amongst the bereaved in physician, psychiatirc and clergyman visits (Parkes, 1964; Parkes \& Brown, 1972) and in their usage of tranquilizers, tobacco and alcohol (Parkes \& Brown, 1972) may also be construed as behavioral overactivity symptoms. The converse of constricted behavior is normally seen in apathy (Hobson, 1964; Parkes, 1965, 1971; Yamamoto et al, 1969), inertia (Lindemann, 1944 ) or reduction in occupational committments (Maddison \& Viola, 1968).

Pathological symptomology is present when there is failure to recover the equilibrium between either absorption/ modification or the moderate wavering between dilation and constriction. When the behaviors themselves become stylistic of the mourner or excessive, he is considered to be experiencing an aypical grief reaction. Inability to recapture the vitality of behavior (e.g., remaining mechanical) is 
exemplified in the extreme by catatonic schizophrenia which is described by Edelson and Warren (1963) as one form of mourning. Mourning which involves excessive behavioral dilation is described as Frenzied activity (Becker, 1933) and overactivity without a genuine sense of loss (Lindemann, 1944). Shoor and Speet (1963) describe bereaved adolescents who experience parhological diversion of normal mourning and show behavioral symptoms of delinquency, burglary, running away and promiscuity. And manic reactions in bereavement, certainly a form of pathological and dilatory over-activity, have been reported (Abely \& Leconte, 1938; Klein, 1940; Scott, 1964).

(b) Cognitive Model Explanation

Variations of behavioral activity level occur during grief as a corollary to activity in the cognitive matrix after a sudden death. These changes in behavior are dependent upon the cognitive regression process, including the degree of balance between cognitive absorption and modification, and the rate of fluctuation between constriction and dilation.

It will be recalled that the disruption of a core cognitive dimension results in a loss of interactional equilibrium vis-a-vis the environment. The mourner becomes highly modifiable in those areas related to the deceased, the zones of the matrix most damaged by the death. Conversely, in other non-directly affected zones, he becomes rigid and unchangeable in order to protect his remaining structural integrity and stability. There are behaviorai changes paralleling these cognitive alterations. 
Activity invclving the deceased or death event increases dramatically in both speech and motor behavior. He talks about the other, returns frequently to the other's room, sits in his chair, visits the scene of death. These behaviors, derived from the cognitive openness in the discupted area are significant erough that they are discussed separately later in this section under 'Searching'. They are relevent for notation here since they represent an over-activity within the behavioral sphere that is congruent with an overall openness in the same general area of the cognitive sphere, i.e., the death event.

The behavioral derivative of cognitive rigidity is the motor retardation and automatism that occurs during bereavement. The individual finds himself unable and protectively unwilling to cope with the many complex interactions of life; and because of his weakened structural state, unable to risk even the minimal cognitive modifications of routine demands. Therefore, he reduces the complexity of his life by behaviorally withdrawing from most activities. Those which are engaged in are typically performed at low levels of sophistication ... a manifestation of the regressive loss of certain behavioral refinements. By applying stereotypic behaviors to events, the mourner is able to solidify the intact cognitive dimensions and avoid some risk of their collapse and overload during the period of general instability.

Under normal circumstances, an individual wavers between moderate expansion and moderate contraction of his cognitive framework. During bereavement, this moderate wavering can 
escalate to rapid oscillation between extremes of dilation and constriction as the mourner tries to alternately find reparative elements in the enviromental universe ... then protectively consolidates the matrix into a delimited enclave by reducing the interaction. These cognitive shifts have concordant behavicral symptom consequences. The dilation yields a restlessness and aimlessness that is not goal-directed, and is not part of the searching phenomenon because the areas of attention are diffuse and not related to the deceased. Rather, there is simply an abundance of activity without any apparent connectedness or objective.

The constriction derivative in the behavioral symptomology is evidence by behavioral apathy and deliberately restricted functioning, such as quitting one's job. The consolidation of behavior is probably most noticeable in the interpersonal area, which has already been discussed regarding social withdrawal (see Figure 18).

\section{Searching}

(a) Introduction and Literature Review

Searching behavior is normal to the grief process (Bowlby, 1961; Lamers, 1972; Lindemann, 1944; Parkes, 1970) and is usually directed at an attempt to somehow recover the loss which Bowlby (1961) consiaers to be the first of three basic psychological phases of mourning. The restoration/ replacement effort is exemplified by parents who are mourning a child's death and state their intent to conceive another child as a substitute (Nolfi, 1967). However, Cain \& Cain 
(1964) found that parencs who actualiy act upon this intent and do conceive a child after the death of another, may induce pathological problems in the replacement child because of their complicated attitudes toward him as if he were the other.

Pathological searching has as its primary feature the persistent seeking of reunion with a permanent lost object (Bowlby, 1961). It may take the form of compulsive wandering (Stengel, 1943) or the chronic wandering of individuals who seek their lost parents of childhood, well into their adult years (Parkes, 1972; Stengel, 1939)。 Hinton (1967), Lindemann (1944) and Parkes (1972) consider the over-identification or modeling of the deceased's behavior, attitudes, personality, interests or somatic complaints to be pathognomonic of atypical grief. It is a magical form of seeking reunion that can potentially escalate into reunion behavior involving suicidal attempts (Moss \& Hamilton, 1956) in an effort to join the lost other in death.

(b) Cognitive Model Explanation

There is a selective overactivity relating to the deceased which, in the previous section, was referred to as a derivative of extreme cognitive modification. Because of the disruption in the core dimension, the bereaved is in serious need of reparative resources and is especially open to suggestion and replacement in this area. This is in contrast to the rigidity and closing off of other matrix spheres that are less directly involved with the deceased.

In addition, a primary cognitive symptom of bereavement 
is a pre-cccugation with the deceased and with events/ objects associated witi him. One of the purposes of preoccupation is to gradualize the loss (i.e., slow down the readjustment by mitigacing the impact) until the cognitive structure restabilizes and until alternate dimensions and linkages are developed in lieu of the core disruption. This pre-occupation involves reviewing memories of the deceased, the circumstances of the death, as well as a heightened sensitivity to environmental stimuli associated with the loss or the lost person.

Cognitive openness (modification) and pre-occupation together manifest behavioral symptoms in the form of searching activity. Like its cognitive counterpart, searching is aimed at obtaining reparative and substitutive resources for the damaged structure, as well as being a method for gradualizing the loss' impact. Just as normal pre-occupation can evolve into pathological obsession, so normal searching for reminders and replacements concerning the broken relationship can develop into pathological seeking of magical reunion. This may occur via over-identification with the deceased or through the death of the survivor himself by suicide. 


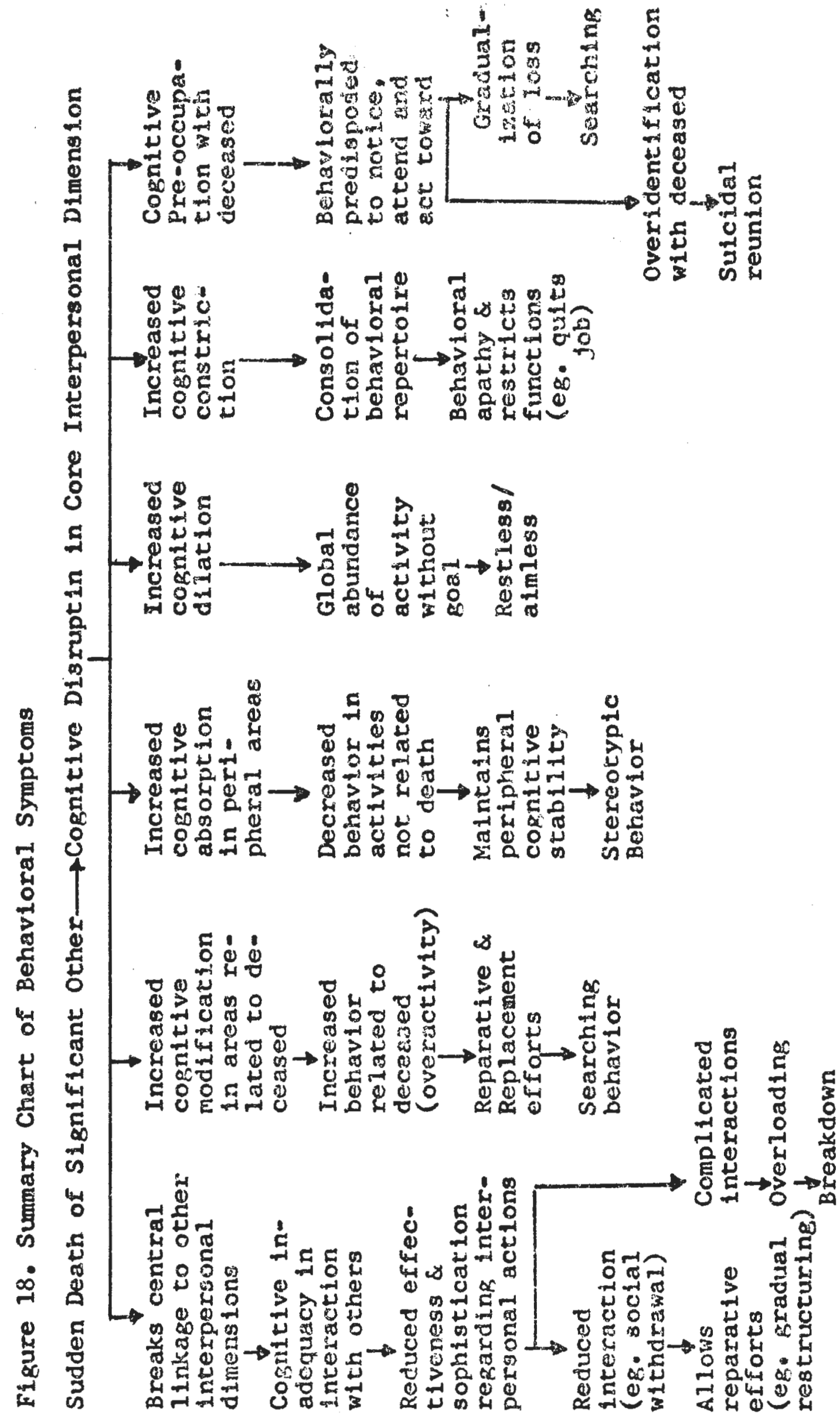




\section{DETERMTNANTS OF THE COURSE OF BERTAVEMENT}

A - Introductior

I have repeatedly referred to the fact that grief can take either a normal/healthy or atypical/pathological course, the particular direction being signified by the nature of the symptomology displayed. The purpose of this section is to present a summary of those factors which appear to have a determining influence on the course of normal versus pathological bereavement. There is no single variable which explains, nor by itself, governs the process. However, there are factors which have been investigated that appear to have a significant effect; as weil as others which, though not specifically studied at length, should hypothetically have a determinant influence. A survey of these variables will be presented on the following pages.

The particular grouping of these variables is arbitrary. I have chosen categorization which seems to incorporate most of the major influences on the bereavement process. These groupings are, (I) the cause or circumstances or mode of death, incorporating sections on a) anticipatory dying. b) sudden death, c) suicidal death, d) accidental death e) Sudden Infant Death Syndrome and f) notes on other modes; (2) the relationship of the survivor to the deceased, incorporating sections on a) spouse survivors, b) parent survivors and c) notes on other relationshipsincluding child, sibling and general family survivors; (3) the characteristics of the survivor such as a) age, b) sex and c) general traits. 
It is my belief that these variables exert their principle influence upon either or both of the two fundamental cognitive processes associated with bereavement; namely, (a) the dagree of cognitive disruption and (b) the meaning attributed by the survivor to the death event (i.e., how he construes the death).

Cognitive disruption has been postulated as the process underlying grief symptomology, from the general symptom of cognitive inadequacy to the specific symptoms in the four major spheres of functioning. Thererore, in order to support my contentions that grief is basically a cognitive syndrome, and that certain determinants have an important effect on grief, I must build an explanatory linkage between these influencling factors (e.g, mode of death) and their primary impact (i,e.,cognitive disruption). I must describe how the particular variable plays a slgnificant role in the basic disruption from which all other symptoms derive. Once this connection is established, then those variables which are shown to maximize cognitive disruption (e.8., suddenness of the death event) can be indicted also as exacerbators of the symptoms derived from this increased disruption. This latter effect, symptom exaggeration, has been consistently associated with pathological mourning. Therefore, the theoretical coupling to be proposed involves the determinants' relevance and influence upon cognitive disruption. If the effect is one of escalating the disruption, then concomitant escalation of derivative symptoms will cccur. Since such symptom ex- 
aggeration is considered patrologioal, the determinant wil have been shown - through these steps - to haque a major bearing on the course of nomal versus atypleal grief.

The other cognitive effect of these influential factors is upon the manner in which the survivor conceptualizes the death. A basic premise of the entire cognitive model is that man understands phenomena according to the varied cognitive resources available to him, thereby actively attributing personal meanings to those events which he encounters. Since the individusl is fundamentally motivated toward survival, he tends to apply meanings and understandings which will increase his adaptiveness, or relatedly, increase the stability and/or development of his cognitive matrix. All events are given meaning or construed in some way. The virtually universal reaction of intial denial by the bereaved is an example of this self-preservative meaning attribution which may be applied to an event; i.e. "It is not true!", and therefore it is not disruptive. Since the most adaptive meaning attribution is one which accurately construes the event rather than distorting it, then eventually protective meanings, like denial above, give way to authentic construction of the experience. Nonetheless, what ever meaning the bereaved does apply to the death of another, whether accurate or not, has an effect upon the understanding, bodily, emotional reactions, and behavior which follows $i t$. Certain modes of construing or giving meaning to the death of a significant other, if not corrected, can lead to atypical extremes of grief symptomology. 
For example, the attribution of reversibllity to death, thereby making re-union a possibility for that individual, can lead to self-destructive ideation and behavior. It is my contention that some of the foregoing determinant factors do enhance or encourage the misconstruing and misinterpreting of the loss, and through this step, influence the course of bereavement in a pathological direction. The wisconceptionenhancing effect appears due to either a) the innate ambiguity of the death (e.g.,Sudden Infant Death Syndrome), giving the survivor too muct latitude for interpretation: or b) because the death event imposes its own intolerable meaning upon the inoividual (e.g., sulcidal death), giving him too little latitude for interpretation. In this case, the authentic construction is even more disruptive than a false meaning attribution, so the survivor applies his own grossly distorted interpretation which permits at least some semblance of cognitive stability.

Figure 19 summarizes these notions.

B - Mode of Death

1. Anticipated Death

(a) Introduction and Review of Liserature

Many deaths are expected and unsurprising when they occur. This results from the tenporal span between the early signs of geriatric 111 nesses and final death, perhaps years later; or between the diagnosis of a terminal illness and the death event itself. These forms of anticipatory dying have been investigated at lengti from the standpoint of the patient. 


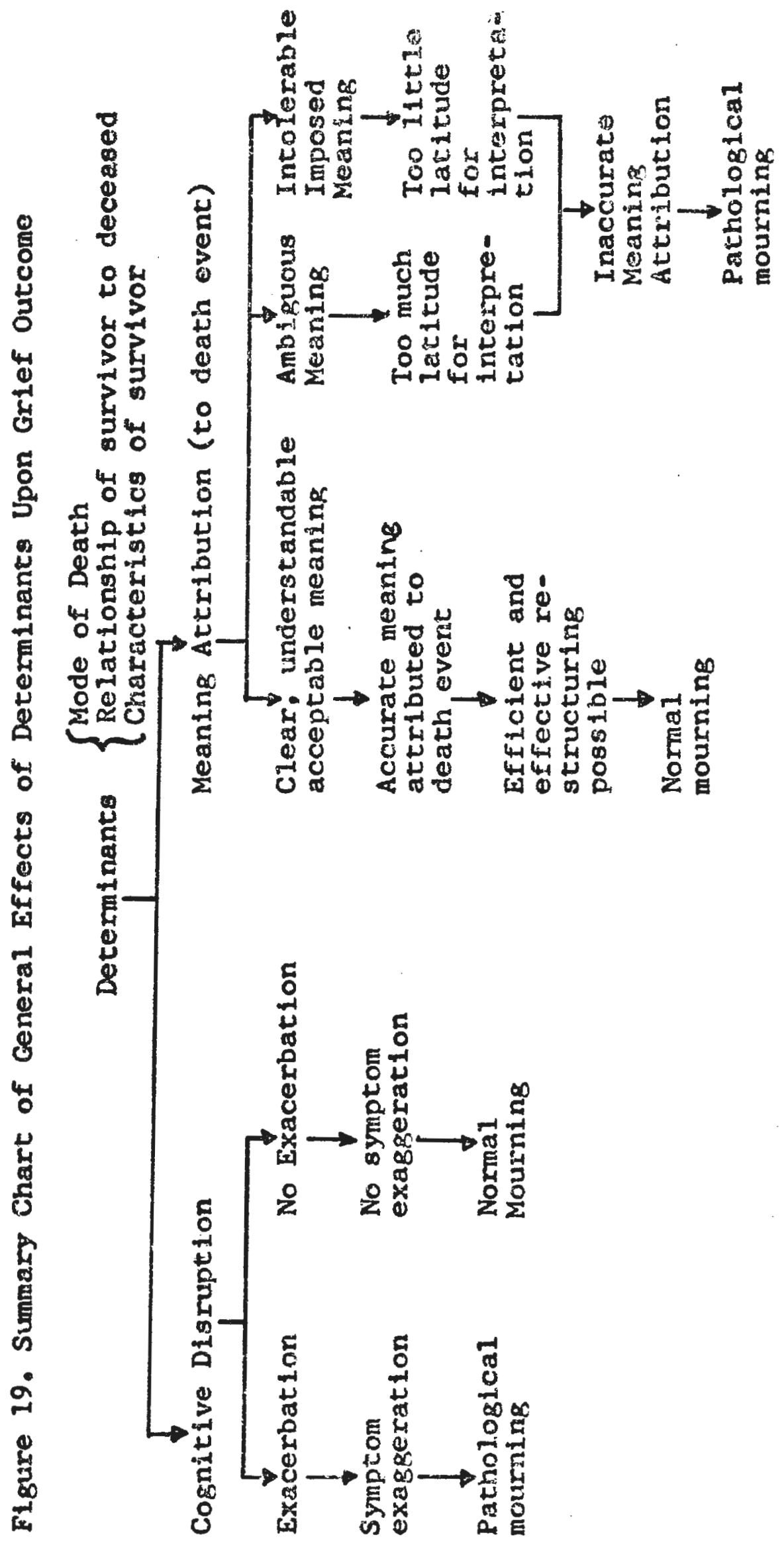


who is dying ( Brim et al,1970, Kastenbaum \& Aisenberg,1972, Hinton, 1967: Kubler-Ross, 1969).

Anticlpated death has also been studied in terms of its impact upon the survivors who experience a phenomenon that is characterized as 'anticipatory grief' (Fulton,1971; Fulton \& Fulton, 1971, Lindemann, 1944) or'pre-mortem grief' (Buxbaum, 1966) or 'pre-mourning' (Rosner, 1970). This occurs when family members are concerned with their adjustment in the face of potential loss. They slowly experience all the phases of normal grief during the period that they are coping with the Illness or enduring the necessitated separation (e.g.. for hospitalization) prior to the death.

They expect the death, and in order to cushion against the shock when it arrives, they dissipate their grief during the waiting interim. For example, anticipatory bereavement includes heightened pre-occupation with the patient, mental rehearsal of the death and associated mourning behavior, depression, occassional symptom identification with the patlent and overt efforts at preparing for the re-adjustment that will be necessary. When death Hoes occur, minimal symptomology is displayed because the survivors have already experienced much of the grief process, have essentialiy disengaged from the deceased and have made initial efforts at the re-organization of their lives.

This process has been described by several authors who were involved in research studies of mothers of fatally ill children (Ablin et al,1971; Bozeman et al,1955; Hamovitch, 1964,1965;Orbach et al,1955). Natterson and Knudson (1960) 
reported on 33 mothers, most of whom reacted initially with early symptoms of grief when told of their child's disease. They experienced tension, anxlety, social withdrawal, depression and denial of both the diagnosis and prognosis, However, after a period of four months, when the children of many of the women had already died, the event was received with a calm acceptance. They had experienced a reasonable length of time to re-adapt, re-adjust and re-align some of their expectations and responsibllities. They would often Indicate their resolution of their pre-mortem grief by reducing their pre-occupation with the $i 11$ child and speaking about their obligations to other family members.

Binger et al (1969) confirmed these anticipatory grief reactions in a retrospective study of 20 families who lost children to leukemia. An important mitigating effect upon the trauma of child loss (and which has been repeatedly suggested by researchers in this field) is the opportunity for the fullest possible participation by the family in the care of the child. The hospitals offering such an opportinity thereby provide a context for reasonably healthy grief resolution.

It is noteworthy that if death does not occur as anticipated (for example, in the unexpected return of soldiers whose relatives didn't think they'd survive their military assignments), then serious problems can arise in the re-estab1ishment of the prior intimate relationship (Eliott,1946, Lindemann, 1944, Rosenbaum, 1944). Emancipation from the 
potential deceased creates certain readjustment problems. Nonetheless, the usual effect of anticipatory grief is generally positive for the survivors because it allows gradualization of the loss over an extended period of time.

(b) Cognitive Model Explanation for Effects of Anticipated Death

The expectation that a significant other will die has some similarity to the effect on cognitive functioning as does death itself... but extended over a longer period of time. This extension is important since it allows the cognitive dis-integration and re-organization to proceed at a more gradual and manageable pace. Although initial confusion and denial are followed by the common symptons of bereavement, there is opportunity for respite. The anticipation of 10ss, prior to the actual death, is a hypothetical event, with the posslbility of reversibility (i,e., hope for a cure) available for the pre-mourner. At the time that death finally occurs, the bereaved has had a chance to partially re-order his cognitive matrix without this core dimension. He has been able to dis-engage linkages to the central cognitive axis, piece-meal, rather than having them abruptly shattered. Instead of a sudden void in the cognitive framework, there has occurred a gradual vacating and dismanting process with parallel re-construction.

The integrity of the structure is not undermined because there's been opportunity to shore-up the damaged area with soine temporary and some permanent scaffolding of substitute 
relationships and altermate expectations of how to deal with events. The prior coping jepencience on the core dimenslon can be taken over by other cognitive components, sothat environmental demands are not suddenly overloading, but can be sequenced and controlled.

A basic premise of the cognitive model is that the individual is better able to cope with and adapt to confronting events, as a function of his predictive skills in regard to the events. The more accurate his prediction, the more effective is the adaptation. Anticipatory grief is, therefore, effective adaptation since it is based on a realistic preoiction. When death occurs the cognitive disruption is minimai because the cognitive matrix has already been re-delineated for acceptance of the loss. Its stability has been grounded in aiternate foundations. It is for these reasons that bereavement after a relatively lengthy illness Is not commonly associated with major, pathological or intense grief symptomology (see Figure 20 ).

\section{Sudden Death}

(a) Introduction and Review of Literature

Sudden death is actually a generic tera referring to a variety of modes of dying which are traumatic and unexpected. These include deaths by suicide, homocide, accident or some natural causes that strike fatally without early warning (e.g., Sudden Infant Death Syndrome). Although formally classed as one of these modes, other causes of death can 


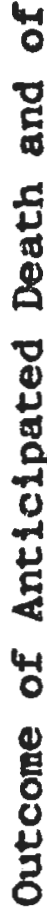

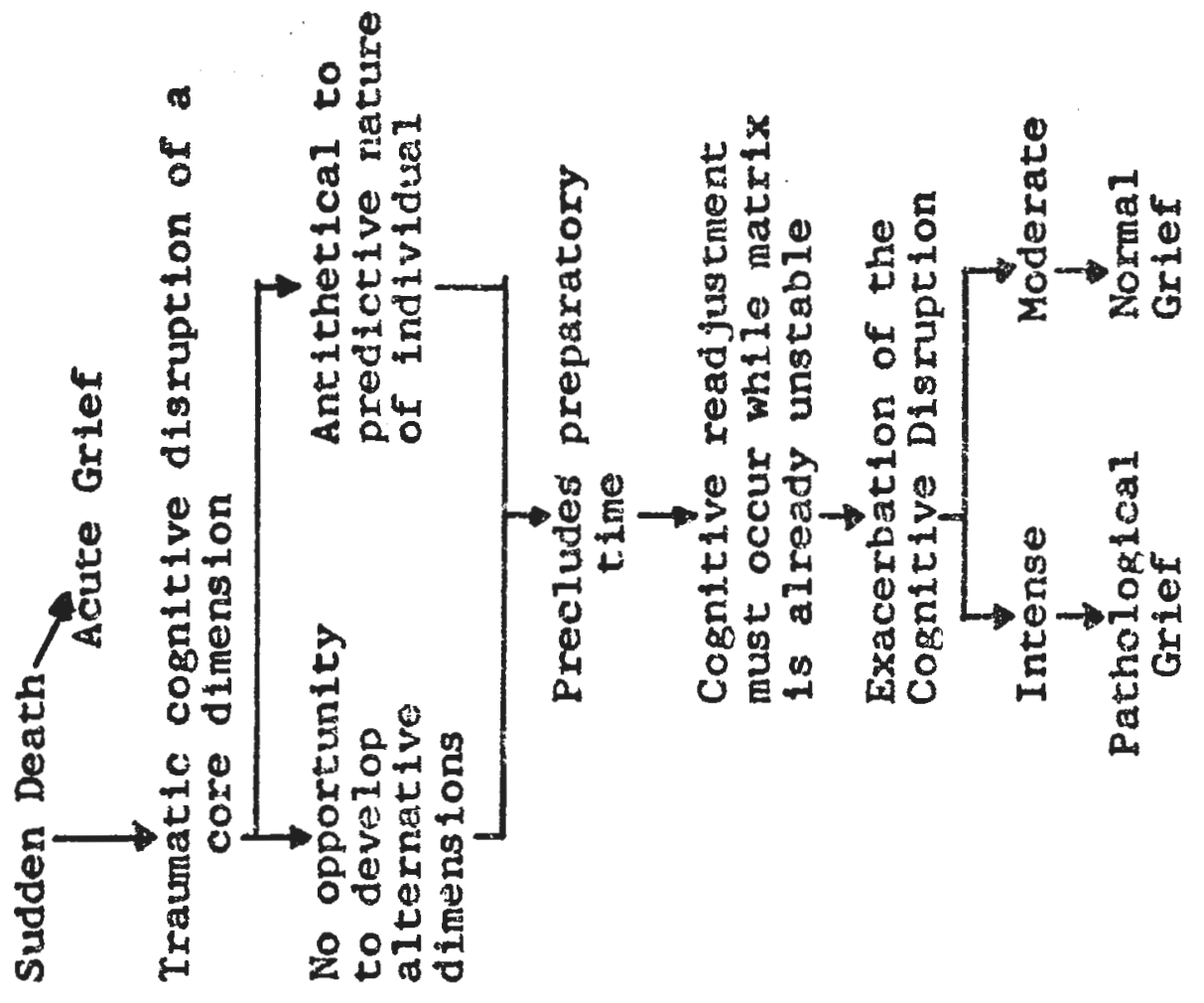

4

g

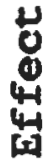

岁

항

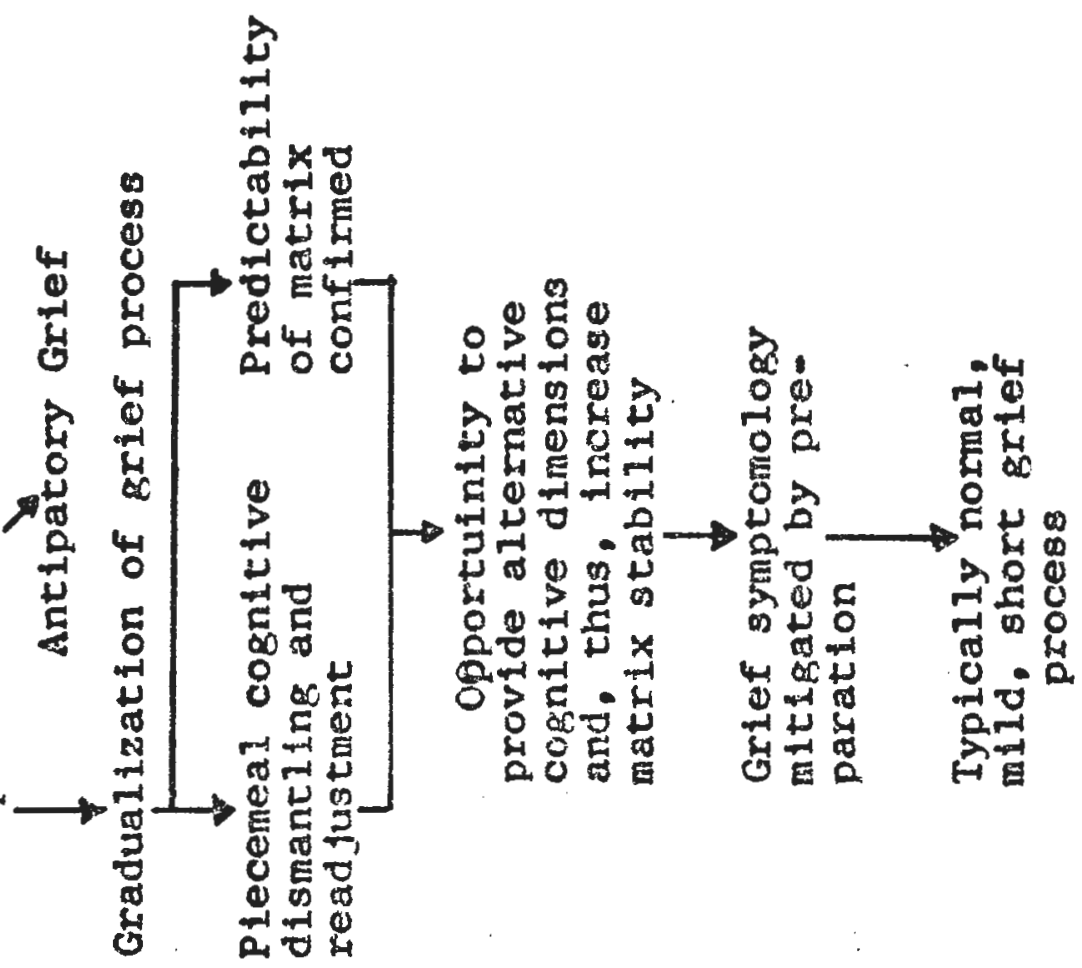


be considerad to have ldiogyzcratic effects (e.g., heroic wartime deaths, inass disasters and spontaneous abortions; miscarriages). Each of these modes impose their own unique influence upon the survivors, and some of these modes will be reviewed shortly to consider their effects. However, all these modes share a common element, namely, their suddenriess and the abrupt manner in which they confront the survivors with an acute grief experience.

Although the researchers discussed in the following sections are dealing with a particular mode of death, their is virtual unanimity that the very suddenness of death (irrespective of the mode involved) and its concomitant lack of preparation for the mourners, is a significant deterninant of the grief process.

In addition, some authors have specifically looked at the abruptness variable as a relevant and important influence on grief course and outcome. Vollman et al (1971) investigated the success of crisis intervention approaches in helping those family members acutely bereaved by different types of sudden and unexpected death. It was their premise that higher incidence of morbidity and mortality in surviving fanily members(e.g., Rees \& Lutkins, 1967; also see PartIII) was partly a function of the higher risk of grief complications with agute bereavement after a sudden death. Hinton (1967) and Lehrman(1956) report that there is greater initial shock and a higher incidence of later mental disturbance after an unexpected death. They attribute this 
directly to the lack of opyortunity for anticipatory mourning, And Volkan found that of the 2.3 individuals he interviewed and determined to be suffering from pathological grief, al1 23 were survivors to a sudden death event (Volkan, 1970). In a study of young Boston widows and widowers (Parkes \& Brown, 1972), the bereaved were grouped according to the length of their preparation-for-death time. Under three days was considered 'short preparation' (or sudden death/acute grtef) and over 3 days ciassed as 'Ionger preparation' (or anticipatory grief). The acutely bereaved group, during the first manth of bereavement, demonstrated a significantly higher incidence of inmediate denial, anxiety, guilt and depression, along with expressions of apathy concerning their own death or statements of a desire to die. A year later (Parkes,1972), the sudden death survivors continued to be more hopeless toward the future, more tearful, anxious and depressed than were those with longer preparatory time.

Another group, of London widows, were investigated (Parkes, 1971) and classed according to the suddenness of the death of their husbands. Those who suffered the mpst abrupt grief showed significantly greater pre-occupation with the deceased with a stronger sense of presence and a tendency to retain possessions and reminders of the deceased.

It appears, therefore, that the suddenness of death alone is a major factor influencing process, symptoms and outcome of bereavement. It is also important to emphasize that anticipatory grief is not an automatic consequence of the 
preparatory opportunity provided by a long-term 111ness. Sone people do not take advantage of this opportunity for anticipatory grieving. Their rejection of the fatal prognosis persists until the actual death confronts them. For these indiviuals, the phenomenon of grief is as acute and disruptive as a sudden and unexpected death, since they are equally unprepared and traumatized (Volkan, 1970).

(b) Cognitive Model Explanation for Effects of Sudden Death

Although I believe that different modes of sudden death have their own idiosyncratic effects upon cognitive functioning, I propose that they do share some common features with regard to cognitive disruptian, Unpredictable encounters imposed on the individual reduces his adaptive efficiency because he lacks the conceptual resources for immediately dealing with these events, He must first develop these resources ...either through some further differentiation of a pre-existing dimension or by a structural reorganization of some form. Most non-routine encounters of this nature are not critical or major determinants of functioning. However, if an unpredictable event occurs relevant to a core dimension, its effect is more crucial and functioning may be interfered with. Core dimensions are particularly vulnerable to unpredictable implingements because so many other cognitive functions are associated with these central axes. Minor surprises can be tolerated with relative ease; core dimensicn surprises send rippies of uncertainty throughrout 
the cognitive syster.

The surprise event has, thus far, been discussed in terms of an unexpected and significant change demand made upon the individual's framework. This essentially involves a major modification of the matrix and even a major modification can have serious ramifications. However, when the surprise event involves the elimination, not simply the modification, of a core dimension, then the consequences are many times more disruptive. Unlike an antipipated event, the individual has no time to plan, prepare, build substitutive elements, schedule the linkage realignment or otherwise reduce the impact. Instead the frame-of-reference by which the individual ordinarily understands events is severely damaged ... traumatically.

Sudden death, therefore, is a highly disruptive influence upon cognitive functioning in two prime wayss (a) death of a significant other is an irreversible elimination of a core dimension of cognitive functioning, that requires considerable time and effort for its repair, yet (b) its immediacy is both antithetical to the fredictive nature of the individual, and it precludes adequate preparation for the type of event that could use preparation most, All cognitive re-adjustment (and major adjustrent is necessary) must follow the event, at a time when there is structural instability because of the damage to the framework's core. My conclusion is that specific modes of sudden death, while lending their own effect to the bereavement reaction, 
are additive to the basic trauma of sudden elimination. That, in itself can have a significantly disruptive influence upon cognitive functioning and the eventual course of mourning (See Figure 20).

3. Suiçidal Death

(a) Introduction and Review of Literature

Given the disruptive effects of a traumatically sudden death, irrespective of etiology, most survivors still have concerned others to whom they can turn for environmental support in this time of crisis (Gain \& Fast, 1966a; Kalish, 1963,1967; Jackson,1957,1964). This interpersonal support has some mitigating effect on bereavement by partially protecting the mourner from external demands, especially during the initial stages of bereavement (Lamers,1972). There is one group of survivors, however, who are faced with the same disruptive dilemma and its symptonatic consequences, yet who are often abandoned and criticized, rather than helped during this crucial time. These are the surviving family members of individuals who have taken their own lives by suicide (Cain \& Cain,1972; Cain \& Fast,1966,1966a; Pretzel,1972, vilman et 21,1971$)$. Although progress has been made by public educational efforts, suicide remains a stignatizing event in a family's history (Cain, 1972: Ginsberg, 1971). As such, the survivor's must often deal with their loss in the face of withdrawal and blame by friends and relatives, rather than the support which $m_{\text {ght }}$ otinerwise be forthcoming (Cain \& Fast, 1966a, Pretzei, 1972).

Furthermore, suicide is often viewed as a communicative 
act directed toward significant others in the perpertrator's IIfe space (Farberow \& Shneidman, 1961, Lester \& Lester,1971, Resnik, 1968; Sinneidman, 1968, 1970). Sulcide notes or family conflicts, arguments and threats prior to the death frequently make it clear that the suicioe is intended as a final interpersonal communication (Jacobs, 1971, Shneldman \& Farberow, 1957, Shneidman et al, 1970), The content of the suicidal message conveys a psychic intentionality on the part of the deceased and imposes on the survivor a morbid, rejecting, accusatory meaning (Cain, 1972; Hinton, 1967, Pretze1,1972, Shneidnan \& Farberow, 1957).

It appears, therefore, that three aspects of a suicidal death account for a large part of its impact upon the survivors: (1) its suddenness, similar to the disruptive effect of other forms of sudden death; (2) the unique reversal from social support to social accusaticn which is associated with the stigmatizing nature of suicide, and, (3) the overwhelmingly negative meanings communicated to and imposed on the survivors by a significant other's intentional self-destructive act. I believe that the social stigna/accusation aspect ( -2- above) actually serves as an exacerbating influence upon the other two aspects mentioned, that of disruption and negative meanings. Social withdrawal/condemnation aggravates the disruption by removing a usual interpersonal supportive sheild, making the bereaved more susceptible to stimulus overload, and itseif acts as an overloading event. Social withdrawal/condemation worsens the negative meaning 
aspect by valdating the suryivors se]f-biame interpretations rather than alding his efforts to lessen these meaning cognitions.

The effect of suicidal death is virtually always pathological beyond the impact of other forns of death. (Cain,1972; Cain \& Fast, 1966a) and the grief process is more intensified and more difficult at every stage (Cain,1972; Pretze1,1972). These conclusions are supported by investigators, regardless of survivor differences in age, sex, or familial relationship with the deceased (Augenbaum \& Neuringer,1972; Berkenkemp, 1961, Bunch,1972; Cain,1972; Cain \& Fast, 1966,1966a; Goldberg \& Mudd,1968; HensIin, 1970,1972; Herzog \& Resnik,1968, Lindemann \& Greer, 1953, Pretze1,1972; Resnik,1968,1972; Silverman 1972, Stone,1971; Swanson, 1960; Vol1man et ai.,1971). A review of some of these studies will demonstrate the pathor logical impact of suicidal death.

A suicide's effect on the surviving spouse has been described by Pretzel (1972). He notes that society prescribes certain normal and natural grief reactions; except for suicidal deaths when the bereaved is left without any socially anchored structures regarding what reactions to have and how to express them. There is loss of the usual social support that is typically provided mourners. This is partiy due to their own intense guilt and shame which causes them to withdraw from others, and due to the stigma of suicide which causes embarassment and a sense of inadequacy in potential helpers ...so they also withdraw. This leaves the sur- 
vivor reeling even more abardoned and tends to confirm the bereaved"s sense of responsibility for the death.

Pretzel goes on to note that all symptomology is intensified, particularly guilt and depression, which makes the mourner himself a high risk for potential suicide. Considerable anger and hostility is generated with the suicide viewed as an attack on the survivors, as an effective'last word' leaving the mourner frustrated and unable to discharge the frustration. Guilt and anger tend to interact, making it difficult to diffuse either. Pretzel finds the primary characteristic of a suicide survivor's reaction to be an inability to accept the reality of the suicidal nature of the death. There is persistent and irrational insistence at denying that suicide was the cause of death. The survivors develop bizarre alternative explanations which have a paranofd quality, such as the "myth of the mysterious prowler" who 'really'killed the spouse.

Cain \& Fast(1966a) found similarly distorted suspicions about the cause of death in a separate group of spouse survivors of a suicidal death who felt that the police, coroner's office, insurance companies and unsympathetic ministers were involved in a conspiracy to attribute the death to suicide rather than homocide. Cain \& Fast, in this same study, also noted the replacement of social support with social condemnation as a major factor in the pathological outcome, with a resulting avoidance of those "who know". They similarly reported intense guilt and shame feelings 
which caused a rassive denial of the suicide as mode, and prevented any communfcation about the death. This denial, concealment and refusal or inability to talk about the death froze the mourning process and yielded a "conspiracy of silence" regarding the suicide. This prevented dealing with the realities of the event and its consequences, such that distict pathological patterns evolved, which Cain \& Fast (1966a) have grouped as follows, Pattern (1) involving reparation by re-marriage to a grossly physically or psychologically handicapped person. . The choice of a new spouse seemed to be dominated by a defensive effort to give, nurture, repair or undo and thereby define themselves as good and loving, but primarily not destructive. Pattern (2) was also reparative in the sense of world rescue fantasies (e.8., grand economic schemes, cancer cures etc,) which were extensively rationalized and legitimized, although totally unrealistic. These schemes expanded to total preoccupations bordering on fanaticism, as the rest of the survivor's 1ife structure deteriorated. Pattern (3) was manifested by direct and openly self-destructive ideation and behavior, which was either consciously self-punitive or distortedly vengeful and retaliatory. Pattern (4) involved the externalizing of the bereaved's self-accusations by selecting and using the new spouse to play out the complaints, grievances and accusations of his previous partner against him. The final pattern(5) was the survivor's attraction to and involvement with other suicidal people either as an effort 
to re-live the traumatic event or to vicariotisly act out his own suicidal Eantasies.

A study of parentai survivors of adolescent suicides was detalled by Herzog and Resnik (1968). They described these parents in the most fragile terms: "As we entered the lives of these parents, we upset their tenuous equilibrium. They became anxious and angry at us". Indeed, the researchers found that the inmediate parental response to the sudden loss of their adolescent by suicide was "overwhe1ming hostility. and denial followed by guilt and depression". Al1 parents expressed sone form of denial toward the cause of death, though they were much more accepting of the fact of death. They maintained that death was caused by a honocide or an accident, and expressed their denial through anger at those tangentially involved with the death event (e.g.,police hospital personnel, the authors). Herzog and Resnik warn of the real danger of breaking down these necessary, but fragile, defenses, behind which lies a tremendous sense of guilt, depression and fallure which persist indefinitely. These bereaved parents were emphatically opposed to having another child, for fear of failing with that one too. Their atypical grief responses were long lasting, and seen in other symptoms, as well, such as social isolation, insomnia, sadness, exaggerated hypochondriasis. The death of a child by suicide appears to generate the nost severe and extended pathological grief responses in the surviving parents (Pretzel,1972, Whitis, 1968). 
Similarly distressing conseguences of suicidal death are found in studies of children survivors of parental sulcide (Berkenkamp, 1961, Cain \& Fast, 1965,1966) and sibling survivors (Starison, 1960). There is virtually no evidence in the literature which indicates that a healthy, normal bereavement follows a suicidal death. The combined effects of acute disruption, social condemnation and overwhelmingly negative meaning implications apparently preclude a normal grief process.

(b) Cognitive Model Explanation for Effects of Suicidal Death

While it is not necessary to repeat the previous explanation concerning the negative effects of suddenness of death upon the cognitive disruption, it is worth underscoring that the resulting disruptive state is one in which the individual is in a position of high vulnerability to overload. His cognitive matrix is inadequate to meet even routine cognitive demands. Ordinarily, nourners are aided by family and friends during the earlyperiod of bereavement. This aid buffers some of the environmental input to reduce the likelihood of a cognitive overload and possible breakdown. However, suicide survivors lack this buffer because potential helpers withdraw. In addition, the bereaved are likely to be the objects of condemnation and blame for the death by many of those in the enviroment(Cain \& Fast,1956a). Thus, rather than cognitive disruption being partially tempered by others-as-helpers... following a suicidal death, the cognitive disruption is fueled 
by others.Ard the nature of the overload (i.e., condemnation), also fuels the second major effect of a suicidal death, the attribution by the mourner of oyerwhelmingly negative meanings to the death.

A suicidal event, like any other event, forces the individual to attribute meaning to his experience. The manner of understanding a significant other's suicidal death is restricted, however, by certain aspects and implication of the act itself. In other words, suicide imposes meanings for the death upon the survivor. These meanings and implications, though recognized by the bereaved, are, nonetheless, of such an intensely negative quality. that they are intolerable. They must be, therefore, denied, distorted or otherwise misinterpreted. A suicide is an intentional, deliberate, volitional act of overt rejection of the world and those immediate others, including in particular the survivor. Suicide is a form of behavioral statement that overtly implies that the survivor could not or would not help the deceased toward happiness, or at least out of despair (Cain, 1972, Cain \& Fast,1966a, Shneidman \& Farberow, 1957). These are some of the meanings imposed by the death as a suicidal demise.

Suicide is also experienced as an attack and as an index of failure and inadequacy on the bereaved's part. Though these latter meanings of failure are often given to other forms of sudden death by the mourner, in cases of suicide the implications of blame toward the survivors are 
erhanced by the deceased's choice of voluntary death over continuation with the survivor.

Sulcide is unique lin that meanings for the death are not open to broad construction by the survivor, but are largely a function of the mode of death itself. It will be recalled that the affective experience of bereavement guilt is associated with a sense of failure in meeting the role expectations of the relationship. The survivor typically construes the role loss through death as partially a function of his inadequate fulfillment of the self-defined responsibilities in that role, hence he partially blames himself for the death. This is the reason that guilt is experienced even in the healthiest of bereavement processes. The dominant emotion of guilt in the symptom picture of survivors of a suicidal death can, thus, be traced back to its cognitive origins. However, with suicidal death the guilt is exaggerated. This occurs because the sense of failure is reinforced by both the accusatory message from the deceased (via his self-intentioned death) and from the social condemnation by others. The combined effects of this failure/blame meaning being attributed to the death by the deceased and by others is intolerable for the survivor. The acceptance of such an overwhelming set of interpretations is usually beyond the lifits of the individual's conceptual framework. Most sulcide survivors do not construe themselves to be murderers, even indirectly or remotely; it is beyond their comprehension. Yet to accept a death as suicide, along with 
its component statements and implications about the survivor, is to accept considerable responsibility for the death. They must ask themselves 'What about me made him do 1.?' And this appears to be cutside most suvivor's cognitive facility; it is intolerable to ask, lest an answer emerges. Therefore, the meanings and implications must be rejected. This is done either by denying that suicide was, in fact, the cause of death (which is the most frequent and persistent way of handling - rather, not handling- suicidal deaths); or by grossly distorting the implied accusation toward the survivor (e.g., asserting that the deceased was crazy, though it is established by research that most suicides are not at all crazy, or e.g., by scapegoating, such as blaming the children as the true provocateurs). This seems to explain why most suicide survivors are able to readily accept the fact of death, but not the cause of death. Their focus is upon the more traumatic aspect for them .....the meanings, rather than the loss and damage itself.

Such denial or distortion, however, is a false constuction of the event which is very weak, unstable, and vulnerable to realityconfrontation.Hence, the exacerbating effect of $30 c i a l$ condemnation which tends to confinm and enhance the very meanings which the bereaved is trying to avoid. That is the reason for the mourner's own social withdrawal and his anger at those peripheral reminders of the fact of suicide. They are genuine threats to the fraglle, false cognitive understanding of the death which he seeks desperately to 
maintain。

It is these combined effects of suicidal death on cognitive disruption and cognitive attribution of meaning which make this particular mode potentially pathological for most mourner's grief.

\section{4 - Accidental Death}

(a) Introduction and Review of Literature

One initial definitional problem arises conceraing accidental death. For example, it may be broadly defined as any untimely demise, regardless of cause, or it may be narrowly restricted to specific causations, such as auto accidents or ftires. I believe Shneidman's (1961) taxonomy of death provides a framework consistent with ny views as presented in this dissertation. The criteria applied in Shneidman's taxonomy is one of intentionality. Any sudden death which is neither self-intentioned (suicide) nor otherintentioned (homocide) is considered accidental. This holds whether the causative agent is intra-somatic (such as a cardiac arrest which is usually and legally classed as 'natural') or extra-somatic (such as an automobile accident). This leaves the catabolic processes of aging and diseases of pre-mature death (e.g., leukemia) as examples of natural death, i.e., those involving anticipatory dying as discussed earlier. This definition of accidental death incorporates most unintentioned sudden death events. As such, accidental death is the most common mode associated with acute grief. It 
13 known to generate both the normal and pathological bereavement processes. If otiter determinants (i.e., relationship factors and survivor characteristic factors) are of minimal influence, then ascidentai death generally results in the normal or prototypic grief symptonology already reviewed in Part III.

Although many researchers have broadly discussed acute grief symptomology in both its normai form (e.g., Barnacle, 1949; Bowlby,1961; Claytón et al, 1961; Kutscher,1969, Lamers, 1972, McConville et al.1970, Parkes,1972, Shoenberg et al, 1970) and pathological form (e,g., Anderson, 1949; Bowlby, 1963, Kutscher, 1969, Parkes,1972; Schoenberg,et al, 1970; Volkan, 1970), the study by Lindemann (1944) which reported on the survivors of the Boston Coconut Grove fire remains the classic study of acute grief following accidental death.

Lindemann (1944) describes normal grief symptomology after an accidental death as including many of the sequelae that have been detailed on earlier pages: cognitive dysfunctions of confusion, denial and pre-occupation with the deceased; somatic distress in different organ systems; guilt, hostility and depression; temporary loss of typical patterns of behavior and some identificatory symptoms related to the deceased, He notes that "grief work", which is necessary for healthy resolution of the loss, involves experiencing and coping with the subjective distress of these symptoms, rather than avoiding them. Only by accepting these consequences to the loss and dealing with them as they arise can the bereaved 
resolve his grief effectlveiy. This resolution, according to Lindemann includes re-adjugtment to the environment without the deceased, the formation of new relationships and disengagement from the bonds to the deceased. This is Lindemann's profile of normal acute grief after an accidental death.

He also describes the nature of a pathological response to sudden and unintentioned death as originating from either a delayed (i.e., denied)reaction or from a distortion (i.e., exaggeration) of the normal processes. These include exaggerations of activity levels, of guilt, hostility or depression, of withdrawal from others and persistent changes in behavior. Lindemann attributes a pathological progression of mourning, as I do, to the presence of determinant factors supplementary to the accidental death itself. He suggests both the relationship to the deceased $\left(e_{.}\right.$. , mothers of young children) and characteristics of the survivor $(\mathrm{e}, \mathrm{g}$, a predisposition to depression or obsessiveness) as potential influencing factors.

In sum, accidental death (1.e., unexpected and unintentioned) results in a syndrome of acute grief whose symptomology is variable and subjectively distressing, but typical for this experience. When other contaminating factors are prominent, such as certain relationships and certain survivor characteristics, then the syndrome may be diverted toward an atypical and pathological outcone. 
(b) Cognitive ModeI Explanation for Effects of Accidental Death

Despite the typical 'normality' of bereavement folloving un-contaminated accidental death, it is still necessary to show cognitive impact from which even these normal symptoms derive. The sudden disruption of a core cognitive dimension may be sufficient to cause mourning symptomology and the explanation for that effect has been given at great length in Part II. However, I believe that some notions about meaning are useful additions to the model's explanation of bereavement following an accidental death.

I have postulated that one of man's basic functions is to understand events and thus give meaning to experiences which he encounters. This serves adaptive/survival ends, as well as advancing the individual toward his valued goal objectives. Occasionally, an individual encounters an event which is beyond his cognitive capacity to comprehend. He has a sense of inadequacy until he is able, through changes in his framework, to conceptualize the experience and somehow incorporate the knowledge into his matrix. This is ordinarIIy a routine process of development associated with cognitive growth and advancement.

However, there occurs, rarely, an event in an individual's life for which meaning and explanation is virtually absent, an event for which rational comprehension is not possible because it does not exist in a manner consistent with the person's ordinary understanding of phenomena. Such 
an event is meaningless, purposeless and without rationale. I believe that accidental death is such an event and poses the dilemma of meaninglessness to the survivors. Not only is the loss untimely and therefore disruptive, it is also incomprehensible.

In addition to the damage to the cognitive matrix, there is the difficulty of conceptual incorporation with accidental death. There isn't any non-distorting way to make sense out of it. Intentionality is an important concept here, because it is a principle criteria by which we attribute and provide ourselves with understanding. In the case of suicidal. death, intentionality is one of the main meaning criteria that generates so much negative consequences. Yet, by definition, intentionality of victin, survivor or other is lacking when death is accidental. And without intentionality to an event, we can not readily assign meaning, purpose or responsibility. The questions "Why did this happen ...to the deceased...to the survivor?' is unanswerable and must basically remain unanswerable. The result is an experience of sustained shock and prolonged confusion; but particularly a reaction of lasting bewilderment and disillusionment. As grief proceeds, the mourner restructures his cognitive framework, but without the certainty of predictability that previously existed. Now he has encountered events which were not only un-predictable, but unjustified and inexplicable. Accidental death is not an error of the person's predictive practice; it is an error of assuming that all 
events - whether potentially predictable or not - somehow will manifest a rationale and justifiableress. When this assumption is disproved by the meaninglessness of an accidental death, with its senseless subsequent suffering, then disillusionment emerges and may pervade the cognitive matrix such that uncertaincy regarding the future acts to undermine the cognitive stability of the mournex. It has been my experience that survivors of uncontaminated accidental deaths are likely to proceed through a relatively normal acute grief syndrome and arrive at a healthy outcome. However, years later, they typically are still sensitive to unpredictability and injustice of events. Their cognitive reconstruction may be solid, but they remain wary, for they do not truly trust the future. They had been fooled by an expectation of meaningfullness to events (even painful ones) which the accidental death had proven illusionary.

\section{5 - Sudden Infant Death Syndrome}

(a) Introduction and Review of Literature

The Sudden Infant Death Syndrome (hereafter referred to as SIDS) or crib death involves the demise of a child whose health appears normal, and whose death occurs during sleep, without warning and without known etiology. The pattern is typically one in which the parents awaken in the morning and shockingly discover their infant dead in its crib. Though respiratory shut-down appears to be the physiologic dysfunction leading to the death, medical research into 
SIDS has rot yet plnpointed the causative agent, if any, for the shutdown. While SIDS falls within the general category of (intrasomatic) accidental death, there are unique qualities to this mode of death which make it worthwile to consider separately. One of these qualities is the nature of the relationship (i.e., parental loss of a child) which is an important determinant of the grief response and will be discussed as a general factor in the next chapter. Another quality relates more specifically to the mode of the death itself; namely, the realistic ambiguity of how death occurred. This ambiguity, which is absent in, for example, a child's death by auto accident, results in some idiosyncratic ief symptoms and a particular cognitive effect.

Several authors have written about the psychological effects of SIDS on the family members and even upon the physicians involved (Adelson \& Kinney,1956, Bergman et a1,1969, Halpern,1972; Salk et al,1971) Their views are generally consistent with Halpern (1972) who describes the immediate parental reaction to the discovery of the dead child as acute grief, including disbelief, a surge of rage and guilt, and intense fear and resentment over potential and actual allegations regarding the probability of child neglect or child abuse. This fear seems to account for the verbal and behavioral projection of blame onto older siblings of the deceased. Often an older sibling shares the discovery, yet may be immediately and persistently scapegoated for the mother's own sense of confusion, guilt and anxiety. There is 
prolonged obsessive rumination about the circumstances of the death, especially by the bereaved mothers. The mothers also develop an exaggerated pattern of overaprotection toward the other children in the family, despite the paradoxical projection of blame. Mothers become higinly concerned about their maternal. adequacy, while the fathers seen less self-doubtful. Some of these grief symptoms are common to parental survivors of child lass, as will be noted in the next chapter.However, the intensity and duration of the syndrome, along with the unusual rumination and projection of blame onto siblings, gives the SIDS a rather diatinct effect on bereavement that is different from other accidental deaths, even those involving children.

(b) Cognitive Model Explanation for Effects of Sudden Infant Death Syndrome

The cognitive bereavement effects following the death of a child frrom SIDS are similar to those of other abrupt modes, and also share the "role failure" and "planning discontinuance" effects associated with child deaths in general. These are discussed in the next chapter. Here, I wish to address the issue of ambiguity which surrounds SIDS, and to suggest how this ambiguity affects meaning attibution to the, death event by the mourning parents.

Recall that the distressing cognitive impact of suicidal death lay primarily in the imposed meanings of blame and accusation to the bereaved by the deceased through his selidestructive act. The survivors are virtually forced to under- 
stand or give meaning to the sulcidal death in terms of there own partial responsibillty for it. The narrow meanings attributable to a suicidal death result in an overwhelming and intolerable sense of role failure and, consequently, intense guilt. On the other: hand, accidental deaths generally lack meaningfulness and cause the mourner to experience disruption and suffering without rationale explanation. This leaves them bewildered and disillusioned. Cognitively, the SIDS combines the negative elements of both extremes of this continum between too much meaning (as occurs in suicide) and too little meaning (as occurs in accidents).

The ambiguity surrounding the circumstances of death are genuine, since no clear explanation for SIDS has been forthcoming. It is a meaningless event because it doesn't make any sense that a seemingly healthy infant should simply and inexplicably die during the night. The bereaved parents are realistically unable to give themselves explanation for their loss, over and above its injustice. The disillusiorment is intensified because the parents are not only unable to answer the self-posed question of Why?, but are also unable to provide a meaningful response to How? Their experience of loss is exacerbated by the combination of the abstract meaninglessnes that they share with other accident survivors plus the concrete meaninglessness of an unknown causation that is idiosyncratic to SIDS.

Yet the ambiguity involves a simultaneous and paradoxical pressure toward the other end of the meaning continuum, 
toward the possibility of parental responsibility for the death. The allegations of child neglect and abuse are not just externally generated; they derive aiso from the mourner's own sense of uncertainty regarding his role or role failure in causing the death. Lack of concrete explanation for the infant's demise provides a vacuum which the mourner nay fill with his own explanations, biased by self-doubt and self-blame. Unable to give abstract meaning to the loss, he attempts to at least provide himself with some concrete understanding of the trauma. The meaning imposed by such an organically inexplicable event tends to be one of parental inadequacy or irresponsibility. The parent so construing himself as the cause, however unintentional, of his infant's death is faced with such an alien cognition that he must deny, distort or project blame elsewhere. Hence, some of the sibling scapegoating reported by Halpern (1972).

\section{6 - Notes on Other Modes of Death}

The foregoing review and analysis of anticipatory dying, sudden death, suicide, accident and Sudden Infant Death Syndrome provided some demonstration of the explanatory powex of the cognitive model concerning the influence of the determinant, mode of death, upon bereavement. Some support for the importance of this general class of factors was 8 imutaneously presented by noting how different modes of death affect aspects of grief in different ways.

I believe that other circumstances of suciden death may 
have similarly idiosyncratic effects on the bereavement proces3. While it is beyond the scope of this treatise to explore the hypothetical ramifications of these additional circumstances, I offer them to the reader for his own pondering and speculation regarding the survivor's reactions: a) homocidal death (both the bereaved family and the perpertrator)b)multiple death (e.g., mother survives, rest of family perishes in auto accident); c) mass diaster, with many unrelated survivors who share the similarity of the loss (see Janis, 1954; Leighton, 1951, Lifton, 1963,1967, Lindemann, 1944, Tyhurst, 1950); d) sudden death occurring with versus without pain e) heroic deaths elther in wartime (Eliot,1946; Lindemann, 1944), or during non-war related rescue efforts; f) abortion versus spontaneous miscarriage (Cain et a1, 1964; Kaij et al, 1969), g) death from potentially lethal behaviors such as chronic self-abuse (e.g., alcohol related deaths) or high-risk occupations (construction workers); h) death from a hereditary disease which the survivors may be carrying (e.g., diabetes).

C - Relationship of Survivor to the Deceased

1. Introduction

There are numerous relationships which the deceased had with those in his interpersonal environment. And their are many variations within each relationship category. However, there does appear to be some commonalities of grief response according to the particular relationship class that the sur- 
vivor had vis-a-vis the deceased: In this section, the spouse and parent survivors will be reviewed and analyzed, followed by some brief notes on other relationships.

The influence of the relationship factor upon acute grief seems to be its impact upon cognitive disruption. In addition to the suddenness of the event causing a baseline disruption on the cognitive matrix, it appears that the particular relationship class of survivor to deceased will determine the extent or intensity of the disruption beyond the baseline. The degree of disturbance to cognitive stabil1ty will vary as a function of whether the survivor has suffered the loss of a spouse, child, parent or sibling. Each of these relationships offers a different degree of cognitive dependence upon the deceased and, therefore, variations of structural effect will occur.

2 - Spouse Survivor

(a) Introduction and Review of Literature

The narital relationship tends to be the primary dyadic bonding of adults in our society, with a somewhat lesser degree of adult's involvement with their parents or siblings. With regard to the spouses inter-dependence, Parkes(1972,p122) points out that "...husbands tend to occupy a greater proportion of the life of their wives than do wives of their husbands. The wife's roles, plans and problems tend to be husband oriented and she is reliant on him for money, status and company to a greater extent than he is on her. It comes as no surprise, therefore, to find that the loss of a husband 
is the commonest type of relacionship dissolution to give rise to psychological difficultiss." This is not to say that loss of a wire is un-disturbing for the surviving husband, as Parkes hinself has concluded elsewhere (Parkes et al,1969,Parkes \& Brown, 1972). Rather, the emphasis is upon the incerdependence of husband and wife in their dealing with the world at large. There is strain placed on either of the spouses' coping abilities after the death of their mate. Although the quality of the interdependence does have some effect on grief outcome (e.g., Parkes, 1971 reports greater guilt in widows who indicated greater pre-death quarrelling: see also Parkes,1965), even conflicted dyads are interdependent.

The general marital relationship has been considered the normative loss against which other intimate relationships have been compared because of the relative frequency of spouse death and the variance of symptomology. Both typical and atypical grief courses and symptons, as described in Part III, occur in spouse bereavement, regardless of which sex spoase survives (Baler \& Golde,1964; Berardo, 1968,1970; Clayton et al, 1971,1972, Friedman \& Zaris,1964; Fritz,1930; Fulcomer, 1942; Maddison \& Viola, 1968, Maddison \& Walker, 1967; Marris, 1958; Parkes,1954,1964a,1965,1971,1972, Parkes : Brown, 1972; Parkes et al, 1969, Silverman, 1966,1967,1970,1972). 
(b) Cognitive Modei Explanation for Effect of Spouse Survivor Relationship

The development of a marital relationship, as the paradigm of any intimate dyad, involves the increasing incorporation of the others viewpoints and perspectives into each spouse's cognitive framework. The individual must give thought to the spouse' $\varepsilon$ information input and the spouse's potential reaction to his behavior, decisions, ideas and emotional expressions. This occurs even in conflicted marriages, when the main purpose of considering the spouse's input may be in order to reject it. "What will my husband/wife think, do or feel about $x ?$ " is a routine question that married people ask themselves many times each day. The result is a cognitive matrix that includes a secondary, but integral, perspective that parallels one's own perspective and upon which much routine activity and decision-making is based.

Furthermore, there are numerous functional aspects of environmental interaction which are contingent on the spouse's sharing of the particular event. These include the phone call from the office concerning dinner time, or next summer's vacation plans, or their wedding anniversary, or parenting decisions, or sexual relations. In other words, the spouse relationship is the prime example of 'quantitative centrality'. A myriad of cognitive dimensions are linked to this core dimensional relationship. The individual's understanding of many events is typically related to or derived from or affiliated with this basic cognitive dimension. 
When a spouse dies, the survivor's cognitive matrix is, therefore, disrupted at many linkages and in many spheres. The disruptive ripples pervade the framework, as did the cognitive associations with the deceased prior to the death. Cognitive disarray is massive because so much of one's thoughts actions and feelings are contingent on or ac least indirectly related to the deceased spouse. And it must be noted, once again, that this extensive disruption occurs suddenly, making its overall effect that much more traumatic.

There is also an overload potential which should be considered. Most marital relationships evolve a separation of some functions (e.g., husband as breadwinner, wife as primary parent). When a spouse dies, the environmental demands (financial or parental) which the deceased had previously dealt with, must now be confronted by the survivor. At a time of cognitive inadequacy, the survivor must make new decisions. Since each spouse was likely to have depended on the other in meeting certain role-related demands, the survivor may not have developed sufficient cognitive capacity for dealing adequately with the necessary, but novel experiences. The large number of new demands under ordinary circumstances (e.g., a temporary separation) may well be stressful and overloading. During a state of cognitive disruption and inadequacy, they are almost certainly so. It is for this reason - partial protection from overload that social support is a vital intervention for both widows and widowers during bereavement, so that they can gradualize 
their cognitive adaptation to novel gemands.

\section{3 - Parent Survivor}

(a) Introduction and Review of literature

As indicated in an earlier section, the anticipated. death of a child offers the parents a greatly needed period of preparatory time for accepting the 10ss, and this helps to mitigate some of the impact and the symptomology of grief (Albin et al,1971; Binger et al, 1969, Bozenan et al,1955; Carpenter and Stewart,1962; Chodoff et a1,1964; Cobb,1956; Hamovitch, 1964,1965; Natterson \& Knudson, 1960). However, when a child's death occurs suddenly, there is no temporal cushion, and the impact on the surviving parents is typically devastating. I have already reviewed the pathological influence upon parental bereavement of a child's suicidal death (Cain, 1972, Herzog \& Resnik, 1968; Pretze1,1972; Whitis,1968) and the exaggerated effects of Sudden Infant Death Syndrome upon surviving parents (Adelson \& Kinney,1956; Bergman et al,1969; Halpern, 1972, Salk et al,1971). Other authors, writing of non-specific sudden child deaths similarly conclude that child loss generates extremely disturbing grief reactions in the surviving parents (Bibring,1970; Friedman et al;1963, Kennell et al,1970; Nolfi,1963; Orbach, 1959).

Cain \& Cain (1964) found that replacement of a child by conception shortly after the death is a relatively frequent attempt to undo the loss with a substitute, who in extreme instances are even given the same name as the dead 
child. The outcome of this sype of grief resolution is generaily pathological for the parents and psychonoxious for the replacement child. Wretmark (1959) found that a high proportion of bereaved psychiatric patients who were admitted to a Swedish mental hospital experienced cinild loss as a precipitating factor. Parkes(1972) and Lindemann (1944) note that the loss of a child is a unique situation that virtually always produces a state of alarm physlologically and has a poor bereavement prognosis. Gorer(1965) and Kalish (1968) both regard child loss as the nost distressing and persistent of all bereavements.

The thrust of the research on the aftermath of child , death is that such a loss is highly traumatic to the surviving parents, more so than any other relationship loss. Grief outcome is predicted to be poor, with bereavement symptomology typically intense, prolonged and often pathological.

(b) Cognitive Model Explanation for Effect of Parent Survivor

Death is something that happens to old people. At least that is one of our usual conceptions about death. "In a soclety in which the death of a child is statistically rare, we are particularly likely to be unprepared for those that do occur" (Parkes, 1972, p.123). "Also, the uniqueness of death between the ages of two months and 14 years intensifies its impact" (Kailsh,1969,p,102). Of all the varying confrontations with a death event, the loss of a child is typically the least frequent and least expected; hence, it is 
the most shocking, surprising and disruptive to the cognitive matrix of the surviving parent. The trauna of sudden deach is most severe in these instances. It rattles the predictive basis of the individual's understanding of the world.

Furthermore, the parent tends to attribute particularly negative meanings to the death of a child. A patent-child relationship is a dyad in which the major responsibility for survival, actually as well as conceptually, falls upon the adult member. We don't typically attribute a child's death to'his own fault' because he's usually not considered mature enough for behavior leading to death. Rather, a prime expectation by the parent of himself is care and protection for his offspring. Death destroys the relationship and grotesquely confronts the parent with his own sense of failure and inadequacy in fulfilling this self-imposed and fundamental expectation of parenthood ..... a reaction previously defined as guilt.

Children also have a positional centrality in the cognitive matrix of the parent. Whereas spouses may be viewed as construing their lives with their mate, parents often, subtlely conceptualize their world around their children; for example, getting them off to school, calling the baby-sitter, birthday parties, noisy houses, weekends with the family. Many activities, decisions and plans are indirectly influenced by their linkages to the children. The rupture of those linkages sends waves of disruption through the cognitive framework, and even into areas not 
thought to be related $\{.8 *$ nolse levels in the house; chores previously performed by the child and taken for granted).

Finally, the individual is postulated as being a predictor and planner of future events. He does this in order to increase his adaptive abilities and enhance his opporm tunities for goal attainment. Children are intimately related to parental future events, directly through parental plans (e.g., for summer camp, college studies and career goals) and indirectly as concrete links to an abstract future beyond the parent's own lifetime. A child's death shatters a parent's plans and predictions for the futire. He must re-construct an entire premise of his conceptual understanding of the world as it will be, shifting and de-limiting previous plans and expectations to accomodate the loss. When a child dies, the parent's construction: of the future is invalidated and his predictive security is undermined.

Thus, the cognitive effects of an especially unanticipated child's death its associated disruption throughout the cognitive framework, the meaning attributions attendant to the sense of failure, inadequacy and guilt at not meeting the self-imposed expectations of parenthood; plus the de-struction of predictions and plans for the future which must be re-construed .....combine to yield the highest potential for pathological bereavement and cognitive breakdown. 
4- Brief Nores on Othe - seiationships

(a) Adult Survivor of Parental Death

When the parent of an adult dies, there is usually min. imal disruption to the life and to the cognitive functioning of the survivor. This is apparently due to the partial anticipatory effect of the knowledge that the likelihood of death increase with age. This awareness reduces the initial impact of an elderly persons demise (Blauner, 1966; Fulton ; Fulton, 1971, Kalish, 1969). In this sense, death fufills rather. than contradicts expectation, so that even a sudden death is perhaps less conceptually abrupt for the survivor than it seems on the surface. It does not upset his framework's predictive base.

Furthermore, elderly parents tend to be peripheral rather than central to the adult's cognitive matrix, at least in contemporary American society (Blauner, 1966; Fulton \& Fulton, 1971, Kalish, 1969). The emphas is upon the nuclear family rather than the extended family, and the greater frequency of elderly death occurring in hospitals or homes for the aged both contribute to the distancing of the relationship between adult and his parent. When the parent dies, the cognitive effect is peripheral, does not affect major linkages or dimensions, and is minimally disorganizing and de-stabilizing to the structure.

The meaning attributed to death in later years also makes the event easier to cope with. since there is a sense of timeliness about such a death. This is not meant to imply 
callousness to the survivor, bit nerely an abllity to comprehend the event as relatively appropriate and tolerable. It is not necessary for the adult, confronted with the death of his parent, to deny or distort his understanding of the event. Such a death usually carries its own reasonable, nonaccusatory meaning (e.g., that the parent had lived a full Iife and died inevitably). This reduces the pathological potential of ambiguity,(SIDS), imposed negative meaning (suicide) or meaninglessness (accident).

The possibility of some exaggerated symptomology does occur when the survivor experiences a sense of failure with regard to the deceased parent. This may arise from the nature of the previous relationship (e.g.,a history of unresolved conflicts with the parent): or from the intentioned distancing and subtle rejection of nursing home placement as the parent grows older and more burdensome. If the adult survivor construes the death as a function of his failure or inadequacy as a son/daughter, then the self-imposed expectations of being a good or faithiul offspring will be unmet and guilt/self-blame will be felt. Generally, this negative meaning attributed to the death is, by itself, insufficient to produce a pathological grief syndrome. Most bereavements involving adults who have lost a parent are normal, mild and short-term.

(b) Child Survivor of Parental Death

Since this treatise is concerned with acute grief in adulthood, my remarks here and in the next section on sibling 
grief will be limited to a few commencs on the cognitive model's application to children, and then I'll refer the reader to other sources of information on childhood bereavement.

The proposed cognitive model of grief is a developmenttal model and,therefore, applicable to an analysis of childhood bereavement. It is likely that the extent of disruption will be substantially dependent on the age of the child and his level of cognitive development, While exceptional growth strides are possible, it is reasonable to assume that the differentiation, organization and integration of a child's matrix will be less advanced than most adults and, therefore, less capable of coping with all the ramifications of a death event. This is particularly true regarding parental death, because the parental relationship has greater centrality for the child than does any single relationship in the average adult. Again, this is basically a result of reduced differentiation, in this case, of the category of 'others'. Overal1, a parental death must be considered more disruptive and potentially more pathological for a child than for an adult, with an inverse relationship to age. Finally, the surviving parent can act as an added stressor to the child, and often does this when he (the parent) is having a difficult time dealing with his cwn spouseagrief. Cain \& Fast(1966) emphasize this latter problem, in very clear terms, regarding a surviving parent's pathological infuence on the surviving child's bereavement following a suicidal death. 
For a critical review of some of the contradictory literature on childhood grief and some of the methodological problems associated with this research the reader is referred to Markusen and Fulton (1971).

(c) Sibling Grief

In addition to the foregoing comments on childhood bereavement, the loss of a sibling may generate further disruption, if a dyadic relationship had begun to be formed. This might bear some similarity to the conjoint interdependence described under spouse bereavement, though of course of a different quality. Ease of identification with a sibling may also create the potential for negative meaning attributes to the death, such as 'Why him and not me?' with Intensification of guilt; or 'If hin, then possibly me too! ' with intensification of fear and anxiety.

As with parental death (but in this case both parents are involved) the surviving parents may add stress to the child as a result of their own bereavement difficulties. This was discussed earlier with reference to Halpern's(1972) study of SIDS in which the mother's sense of blame was explicitly projected onto the surviving sibling.

Others who have investigated sibling grief includes Blum and Rosenweig (1944) and Rosenweig (1943) noting a higher incidence of later schizophrenia; Cain et al (1964, 1964a) lcoking at the effects of miscarriage; Holland et al (1971) on the death of an identical twin; Swanson (1960) on an identical twins suicide; Weston\& Irwin(1963) respreschool. 


\section{(d) General}

Viewing the family as a nulti-member unit, whose interaction and roie relationsizips shift and re-adjust dramatlcally when one of its members dies, provides a systems analysis of bereavement. This approach has been taken by Eliot $(1932,1935,1946,1955)$, Goldberg and Mudd(1968), Jensen and Wallace(1967), Kalish(1969), Orbach (1959). Vollnan et al (1971) has offered an insightful description of family patterns and their reactions to sudden death, their need for and receptivity of crisis counseling intervention, the variants of family structure that help or hinder bereavement and the importance of role functions of the deceased in grief outcome.

The medical and nursing professions have a unique and significant relationship with both the deceased and the survivors, which is subject to both criticism and advice by Autton (1962), Binger et al(1961),Bonine(1967), Feifel and Fulton(1966), Fulton and Fulton(1971), Natterson and Knudson(1960) and Schoenberg et al (1969).

Some investigators have reported, as well, on the grief response - often paradoxical - of patients in psychotherapy (Kirtley \& Sacks,1369; Light,1972; Litman,1964; Rosenthal,1947, Young,1960). And others have observed that the death of an important social leader - such as President Roosevelt or Kennedy. - can disrupt the individual to the point of bereavement, as well as disrupt the equilibrium of tine community, despite the absence of a formal relationsinip with the deceased (Blauner,1966; Greenstein,1965;Heckel, 1964; 
Johannsen, 1946; Nemtzow \& Lesser, 1954; Orlansky,1947; O'Toole,1966, Wolfenstein \& Kinan,1965; Wolff, 1947)

D - Characteristics of the Survivor

1. Age

In the last chapter, I noted that the degree of disruption in children appears to be related inversely to age on the basis of his advancement in cognitive development. There are also differences reported in cognitive and other grief symptoms in adults of different age brackets, However, the results are generally not consistent across studies. In addition, the cognitive explanation for the age differences that are found is not strong. It appears that while age may be a factor in determining the intensity of the grief, the relationship between age and pathology in adults is not clear.

For example, Clayton et al (1968) found no significant differences in the symptoms of bereaved widows of different ages. However, in a later study (Clayton et a1,1970), they did find that younger women experienced more guilt in association with their grief. Comparing a group of London widows under age-65 with a group over age-65, Parkes (1971) found the younger women more likely to consult their physiclans during the first six nontins after the death than did the older women. The younger widows also increased their sedative intake seven-fold during this period, while the death preclpitated no such change in the older group. His 
findings were confirmed by Maddson \& Walker (1967) in studying American widows between ages 45 and 60 . They found that the younger widows had a higher illness score than had older wdows, on a questionnaire about their physical health and mental health. But as $I$ mentioned, the studies are not really consistent, for when Maddison \& Viola (1968) replicated the study in Australia, the finding was not confirmed, They offer no explanation.

Contradictory results are drawn from bereavement studies of elderly as well as young widows. Stern et al (1951) described the grief reactions of 25 mourners between ages 53 and 70 years old, and found a notable absence of overt mental disorders. However, Kay et al(1955) investigated about 200 psychiatric patients over the age of 60 who were diagnosed with affective disorders (depression or mania). He found that the incidence of bereavement as a precipitant was greater in those whose first attack occurred after age 60, than in those who had initial attacks at earlier ages. He attributes this to the vulnerability of the aged to bereavement as a trigger for emotional disturbances. Bereavement and mental illness was examined by Parkes (1965) who studied the relationship between three different age groups of adults and the psychiatric diagnosis or major presenting symptoms. He found no significant differences,but Stern \& Susser (1969) found differences at all age groups amongst those seeking psychiatric help for the first time, with the 20-29 age range being disproportionately high. 
Other studies have reported on select age groups such as the elderly (Bellun,1958; Berardo, 1940, Kastenbaum, 1969) and the adolescent (Laufer,1906). Most investigations of the age variable are, nonetheless, limited in their findings and there does not seem to be any consistent theme or explanation for the distinct conclusions. For example, Kraus and Lilienfeld(1959) report an outstanding excess of mortality among the young (uncer 35 years) widowed. Rees (1970) finds hallucinations, sense of presence and illusions of presence more frequent in those mourners over age 40 . And Loveland (1968) concluded that young widows experience a greater religious change after a loss than do older widows,

While these findings may be of some esoteric interest when examined in isolation, as a composite, they appear inconclusive and unrelated. The age factor does not offer sufficient explanation for such diverse and inconsistent results. It seems that the variable of age, unlike its effect in childhood bereavement, is not a significant factor, by itself, as a determinant of grief course or outcome.

\section{(b) Sex of Survivor}

Comparisons of grief reactions betwen the sexes are more consistent than findings reported for age differences. The view that emerges from these studies is that women, overall, have a more difficult bereavement period with more frequent and more intense symptomology than men. The males, however, tend to mask their grlef, and this may explain some of the disproportion between the sexes. 
In both atudies, clayton et al $(1968,1970)$ reporter a significantly higher incidence of symptoms in women, including Insomnia, crying ano consumption of sedatives and tranquilizers. Similar results are found by Kraus \& Lilienfeld (1959), Kutscher (1969), Marris(1958), Parkes(19720, Parkes \& Brown(1972) and Wretmark (1959). The particular trauma of child loss seems to impact more severely upon the mothers than the fathers. Halpern (1972) found that mothers bereaved by SIDS were more disturbed than the fathers, manifested by more intense and extreme symptoms. This was attributed to the fathers' lower vulnerability to self-doubts regarding parenting, whereas mothers felt largely responsible for the child's death. Lindemann (1944) and Wretmark (1959) provide similar conclusions regarding the greater disruptive effect on the female parent following child loss. However, when the cause of a child's death is suicide, several authors have found a reversal of the relationship between mother and pathological mourning (Cain, 1972; Herzog \& Resnik, 1968). In these instances, the father experiences intensified denial, guilt anger and depression for proionged periods. As Parkes(1972) has pointed out in explaining the grief proneness of wives over husbands, the fenale in contemporary society has a greater involvement and comitment to family members than do their male marital partners. Much of her functioning is routineiy and directly involved in dealing with the world of, and in interaction with, these others. Her husband, however tends to diffuse his involve- 
ment beyond the immediate family (e.g., to his job). While the femaleb plans, problems and daily coping issues tend to center on the farily, the male's life space is usually more expanded.

Translating these ideas into the cognitive model, the woman's cognitive (and derivative emotional and behaviora1) functioning is quantitatively centralized around the core family dimensions. Her perspectives of the world and her cognitive stance vis-a-vis the environment are primari1y influenced through these dimensions. Consequently, her cognitive abilities are highly developed in these areas of mothering and marriage. Moreover, she is 1 ikely to identitfy herself along these dimensionsal relationships. When a sudden death occurs to a familial member, the woman's cognitive matrix is especially disrupted because it had been more reliant on these core dimensions for its stability than had been her husband's cognitive structure. The cognitive disruption is more severe, therefore, because the damage occurs to a structural component which is of greater critical importance to her overall cognitive integrity than is the same component in her spousés framework. Similarly, there is greater identity disruption for women than for men, since she had more firmly based her knowledge of herself on her relationships with these particular family others. When death involves a child, the pathological grief experienced by mothers appears related to the above factors. Also important regarding bereavement for a child, however, is the unique 
negative meanings that such a death imposes upon the aother. Care and protection of offspring are typical self-imposed expectations of both parents. However, fathers appear to conceptualize this role expectation at a more abstract and generalized level (e.g., earning a ilving influencing major decisions affecting the fanily). Mothers, on the other hand, construe and function whin the care and protection role expectation at a concrete level of routine functioning and interaction with the children (e.8., feeding,bathing, nursing their 1linesses). When a child dies suddenly, a concrete event, the woman experiences this as meaning that she has been an inadequate protector; she has a sense of failure in her concrete role expectations of motherhood. This generates intense guilt feelings.

In sum, there are differences in the male and fenale response to sudden death, with women apparently more prone to both normal and pathological mourning. Ihis is partially due to her cognitive matrix' greater structural reliance upon core familial dimensions than is her husband's frameork. Hence, she experiences a heightened disruption when death damages one of these dimensions.

\section{Other Characteristics}

There are numerous other individual characteristics which gan potentially influence bereavement following sudden death. However, little research has been done in an attempt to correlate these characteristics with either specific symptoms or the normal/patiological course of bereavement. 
Lindemann(1944) has suggested that certain personality types are more likely to suffer pathological mourning, such as the obsessive or depressive. He feels, however, that a history of neurotic symptom reactions were not that important in determining atypical reactions. However, this is contradicted by Bergler(i948) who reports a greater incidence of psychopathology and prolonged grief in neurotically diagnosed individuals. Parkes (1972) believes that some people are 'grief-prone' and react excessively to a loss. He suggests that previous excessive guilt and depression may prognosticate a poor mourning outcome. Nonetheless, Parkes does emphasize that cultural and incidentai factors may also play a role in determining the particular form a reaction will take. In addition to pre-grief mental states, other personal variables which ma affect the bereavement process include other recent losses or stress (Parkes,1972); religious beliefs and attitudes (Adlerstein, 1958, Alexander \& Adlerstein, 1959); socioeconomic class (Birtchne11,1972), history of childhood bereavement (Archibald et al,1972; Birtchne11,1969, Bowlby,1960,1963; Hilgard \& Newnan,1961,1963; Hil1,1967,1969, 1970,1972; Markusen \&Fulton, 1971); and the quality of the relationship prior to the death (Hinton, 1967; Parkes,1972).

The determinants of grief symptomology discussed in this section have, by necessity of presentation, been artificially delineated. I wish to emphasize in closing this section that individuals suffering from the abrupt loss of 
a significant other person in their ifvesare affected. by many influences simutaneously. There is considerable interaction between the specific variables and general factor groups I've outlined. A sudden death leaves behind mourners who must experience the loss due to a specific mode of death, who are of varied ages, either sex, with a particular relationship to the deceased, each having their own personalicy characteristics and histories with which they confront the traumatic event. They also understand the experience with their own unique cognitive matrix. While the scientist or theorist, for his purposes, may hypothetically dissect these variables to note their particular influences, it must be emphasized that the mourner himself is the reality composite who is currently experiencing whatever influences these variables impose. 


\section{Closine vote}

The foregoing cognitive model of acute grief, along with the supportive sections which applied the model to actual grief symptonology and determinant factors, has been developed and presented with a clinical purpose in mind. It is my belief that these ideas can serve the grief counselor by allowing hin to conceptualize the bereavement problem from the most functional perspective. In that way, he may use those techniques which will be most functional, effective and appropriate.

The evolvement of a cognitive clinical approach has already been accomplished by others (see Parad,1965,1969) In the field of 'cris is intervention' methodology. Indeed, this methodology has been used by the helping professions in alding the bereaved toward healthy grief resolution. However, the application of crisis intervention techniques to the problems of grief have been globally justified on the basis of the 'crisis' nature of a death event. It is my contention that such a global rationale is a weak and insufficient reason for a clinician to intervene with specific techniques. Rather, clinical intervention should be selectively applied in ways which match a particular technique to a particular problem, in which botk problem (as it is conceived) and technique share basic assumptions about man.

While crisis intervention (a cognitive approach) has been demonstrated to be a highly successful approach to the treatment of grief problems, grief itself had not been 
analyzed froin a cognitive standpoint. Therefore, an underlying purpose of this dissertation has been to provide such an analysis. In this way, it is intended to clarify and oblidify the linkage between the problem (bereavement) and its preferred mode of solution (crisis intervention). Furthermore, the analysis offers some novel perspectives on the cognitive aspects of the grief process which will permit the cognitively oriented crisis counselor to incisively rather than globally, apply his available techniques. 


\section{REFERENCES}

Abely, $x$. \& Leconte, $M$. Attempt at interpreting tanic reactions following sorrow. American Journal of Hedical Fsy= cholopy, $1938,46,232-240$.

Ablin,A.R., Binger, C.M., Stein, R.C., Kushner, J.H., Zoger, S. \& Mikkelson, C. A conference with the family of a laukemic child. American Journal of Diseases of Children, 1971, 122, 362-364.

Ablon. J. Bereavement in a Samoan community. British Journa1 of Medical Psycholosy, 1971, 44, 329-337.

Adelson, L. \& Kinney, E.R. Sudden and unexpected deatk in infancy and childhood. Pediatrics. 1956, 17, 663-697.

Adlerstein, A.M. The relationship between religious belief and death affect. Doctora Dissertation.Princeton, N.J.: Princeton University, 1958.

Aginsky, B.W. The socic-psychological significance of death among the Pomo Indians. Arertcan Inago, 1940, 1, 1-11.

Alexander, I.E. \& Adlerstein, A.M. Death and religion. In H. Feifel (ed.), Meaning of Death. New York: McGraw-Hil, 1959.

Alexander, I.E. \& Adlerstein. A.M., Affective response to the concept of death in a population of children and early adolescents. Journal of Genetic Psychology, 1958,43,167-177.

Alexander, I.E. \& Adlerstein, A.M. Studies in the psychology of death. In H.P. David \& J.C. Brenglemann (eds.), Perspectives in Personality Research, liew York, Springer, 1560.

Alexander, I.E., Colley, R.S, \& Adlerstein, A.M. Is death a matter of indifference? Iournal of Psychology, 1957,43, $277-283$.

Almy, T.P. Experimental studies on the irritable colon. American Iournal of Medicine, 1951,10,60-67.

Anderson, C. Aspects of pathological grief and mourning. International Journal of Psychoanalys is, 1949, 30, 48.55.

Archibald, H.C., Bell, D., Miller, Co\& Tuddenhan, R.D. Bereavement in children and adult p3ychiatric disturbance. Psychosomatic Medicine, 1962, 24, 343-351.

Arthur, B. \& Kemme, M.L. Bereavement in children. Journal of Chilehood Psycholosy and Psychiocis, 1954, 20, 167-171. 
Augenbara, B. \& Neuringer, C. Heipting survivors with the imparz of sulctue. In A.C. Cain (ed.), Survivors of

Sulcide. Springiteld, I11. Charles C. Thomas, 1972

Autton, N. A study of bereavenent. Nursing Times, 1962,58, $1551-1552$.

Baler, L.A. \& Golde, P.J. Conjugal bereavenent, A strategic ares of research in preventive psychlatry. Working Papers In Community Menta1 Health. Volume II. Eambridge: Harvard School of Public Health, Spring, $196 \overline{6}^{\circ}$.

Barnacle, C.H. Grief reactions and their treatment. Biseases of the Nervous Systen, 1949, 10, 173-176,

Barry, H. Orphanhood as a factor in psychos1s. Journal of Abnorinal and Soclal Esychology, 1936, 30,431-433.

Barry, H. A study of bereavement, An approach to the problems of tental disease. American Journal of Orthopsychiatry, 19.39. 9, 355-359.

Barry, H. Significance of maternal berezvenent before the age af eight in psychiatric patients. Archives of Neurology and Psychlatry, 1949, 62, 630-667.

Barry, E.Jr: Barry, H.III, \& Lindemann, E, Depenciency in adule patcerns following eavly maternal bereavenent. Journal of Mervous and Mental Diseases, 1965, 140, 196-206.

Barry, H. $\varepsilon_{6}$ Lindemann, E. Critical ages for maternal bereavement in psychoneurosis. Psychosonat ic Medicine, 1960, 22, $166-181$.

Beck, A.T. Depression: Causes and Treatment. Philadelphia: University of Fenn. Press, 1967.

Beck, A.T., Sethi, B.B. \& Tuthil1, R.W. Childhood bereavement and adult depression. Archives of General Psychiatry, 1963, 9, 295-302.

Becker, $E$. Toward a comprehenstye theory of depression, A cross-disciplinary appraisal of oujects, gates and meanings. Journar of Nervous and Nienta1 Diseases, 1962, 135, 26-35.

Becker, H. Some forms of sympathy. Journal of Abnormal and Soclal Psychology, 1931, 26, 56-58.

Becker. H. The sorrow of bereavement. Journal of Abnormal and Social Psychology, 1933, 27, 391-340.

Becker, H. \& Bruner, D.K. Attitudes toward death and the dead and sone possible causes of ghost fear. Mental Hygiene. 1931, 15, 828-837. 
Becker, D. \& Margolin. F. How surviving parents handle their young children's adaptation to a crisis of loss. American Journal of Orthopsychiatry, 1967, 37, 753-757.

Bellum, S.S. \& Hardt, R.H. Mental status and mental disorders anong the aged. American Sociological Review, 1958, 23, 155-162.

Bendann, E. Death Customs: An Analytio Study of Burial Rites. New York: Alfred A. Knop i, 1930.

Berardo, F.M. Widowhood status in the U.S.I Perspective on a neglected aspect of the family iffe-cycle. Fanily Coordinator, 1968, 17, 191-203.

Berardo, F.M. Survivorship and social isolation: The case of the aged widower. Family Coord nator, 1970, 19, 11-25.

Bergler, E. Psychopathology and duration of mourning in neurotics. Journal of Clinical Psythopachology, 1948, 3, $478-482$.

Bergman, A.B., Pomeroy, M.A. \& Beckwith, J.B. The psychlatric tol1 of Sudden Infane Death Syndrone. G.P., 1969,40, 99-105.

Berkenkamp, C. Parental suicide as a source of resistance to marriage. International Journal of Group Psychotherapy, 1961, 11, 204-208.

Bibring, G.L. The death of an infant A psychiatric study. New England Journal of Medicine, 1970, 283, 370-371.

Binger, C.M., Albin, A.R., Feurstein, R.C., Kushner, J.H., Zoger, S. \& Mikkelson, C. Childhood leukenias Enotional impact on patient and family. New England Journal of Medicine, 1969, 280, 414-418.

Birk, A. The bereaved child. Mental Health, 1966, 25, 9-11.

Birtchnel1, J. The possible consequences of early parental death. Exitish Journal of Medical Psycholosy, 1969, 42,1-12.

Birtchneil, J. Recent parental death and tiental 111ness. British Journal of Psychiatry, 1970, 116, 289-297.

Birtchnell, J. Depression in relation to early and recent parental death. British Journal of Esychlatry, 1970a, 116, 299-306.

Birtchnel1, J. The relationship between attempted suicide, depression and parental death. British Journal of Psychtatry, 1970b, 116, 307-313. 
Birtchne11, J. The interrelationship between social class, early parental death and mental illness. Psycholosical Medicine, 1972, 2, 166-175.

Blauner, R. Death and social structure, Psychiatry, 1966, 25. 378-394.

Blum, G.S. \& Rosenwelg, S. The incidence of 8 lbling and parental death in the anarnesis of female schizophrenics. Journal of Genetic Psjahology, 1944, 31, 3-13.

Bonine, G.N. Student's reactions to children's death. American Journal of Nursing, 1967, 67, 1439-1440.

Bowlby, J. Seperation anxiety. International Journal of Psychoanalysis, $1961,41,89-113$.

Bowlby, J. Grief and nourning in infancy and early childhood. Psychoanalytic Study of the Child, 1960a, 15, 9-52.

Bowlby, J. Seperation anxiety: A critical review of the 1it. erature. Journal of Child Psychology and Psychiatry, I(19601961), 251-269.

Bowlby, J. Processes of mourning. International Journal of Psychoanalysis, $1961,42,31 \%-340$.

Bowlby, J. Childhood mourning and tts implications for.psychi :... atry. American Journal of Psychiatry, 1961a, 118, 481-498.

Bowlby, J. Pathological mourning and childhood mourning. Journal of American Psychoanalytic Assaciation, 1963, 11, $500-541$.

Boyd, T.A.S. \& McLeod, L.E. Circardian rythyms of plasma corticoid levels. Annals of the New York Acadeny of Science. 1964, 116, 990-1017.

Bozeman, M.E., Orbacin, C.E. \& Sutheriand, A.M. P3ychological impact of cancer and its treatment: III. The acaptation of mothers to threatened loss of their children through leukenia: Part I. Cancer, 1955, 8, 1-19.

Brewster, H:H. Speration reactinn in psychosomatic disease and neurosis. Human Organization, 1950, 9, 19-22.

Brill, N. Liston, E. Parental loss in adults with emotional disorders. Archives of General Psychiatry, 1966, 14, 307-314.

Brim, O.G., Freeman, H.E., Levine, S. \& Scotch, N.A. The Dying Patient. New York: RusseiI Sage Foundation, 1970. 
Briner, J.S. On perceptual readines3. Esychological Review, 1957, 64, 123-157.

Brown, $F$. Depression and childhoco bereavenent. Journal of Mental Science, 1961, 107, 754-758.

Brown, $F_{6}$ Chilahood bereavement and subsequent psychiatric disorder $:$ British Journal of Psychiatryi, 1966, 112, 1035-104l.

Bruhn, J.G., Thurman, A.E., Chandler, E.C. \& Bruce, T.A. Patients reactions to death in a coronary care unit. Journal of Psychosomatic Medicine, 1970, 14, 65-70.

Bunch, J. Recent bereavement in relation to suicide. Journal of Psychosomatic Research, 1972, 16, 361-366.

Burgert, Es. Jr. Emotional Impact of childhood acute leukemia. Mayo Clinic Proceedings, 1972, 47, 273-277.

Buss, A.H. Psychopathology. New Yorks John Wiley, 1966.

Buxbaum, R.E. Grief begins not with death, but with knowing it is near. Texas Medicine, 1966, 62, 44-45.

Cain, A.C. Survivors of Suiclde. Springfleld, I11.: Charles C. Thomas, 1972 .

Cain, A.C. \& Cain, B.S. On replacing a child. Journal of the American Academy of Child Psychiatry, 1964, 3, 443-456.

Cain, A.C., Erickson, M.E., Fast, I. \& Vaughan, R. Children's disturbed reactions to their mother's miscarriage. Psychosomatic Medicine, $1964,26,58-66$.

Cain, A.C. \& Fast, I. Children's disturbed reactions to parent suicide. Arerican Journal of Orthopsychiatry,.1966, 36, 873-880.

Cain, A.C. \& Fast, I. The legacy of suicide, Observations on the pathogenic impact of suicide upon marital partners. Psychiatry, 1966a, 29, 406-411.

Cain, A.C. \& Fast, I. Parent suicide and suicide prevention.

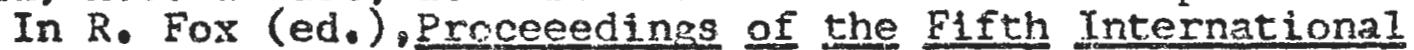
Conference for Suicide Prevention. viennas International Association for Suicide Prevention, 1970.

Cain, A.C. Fast, I. \& Erickson, M.E. Children's disturbed reactions to the death of a sibling. Amertcan Journal of Orthopsychiatry, 1954a, 34, 741-752.

Cameron, No Reasoning, regression and communication in schizophrenics. Psychological Monographs, 1938, 50, 1. 
Cameron, N. Fersonality Devalopment and Psychopathology: A Dynainic Apreadch. Bostong Houghton, Miffin, 1963.

Cannon, W.B. Bodily Changes in Pain. Hunger. Fear and Rage. New York, Applecon, 1929

Caplan, G. Principles of Preventive Psychiatry. New Yorks Basic Books, 1954

Caplan, G. An Approach to Community Mental Health: London: Tavistock, 1961.

Caplan, M.G. \& Douglas, V.I. Incidence of parental loss in children with depressed mood. Journal of Child Pswchiatry and Psychology and Allied Professions, 1959, 10, 225-232.

Carpenter, E.S. Eternal life and self definition among the Aivilik Eskimos. American Journal of pgychiacry, 1954, 60,

Carpenter, K.M. \& Stewart, J.M. Parents take heart at the City of Hope. American Journal of Nursing, 1962, 62, 82-85.

Carstairs, G.M. Attitude to death and suicide in an Indian cultural setting. International Journal of Social Psychiatry, $1955,1,33-41$.

Cattell, J.P. Psychiatric implications of bereavement. In A.H. Kutscher (ed.), Death and Bereavement. Springfield, I11. Charles C. Thomas, 1969.

Chesser, E. Living with Suicide. London: Hutchinson, 1967.

Chodoff, P. Stress, defenses and coping behaviors Observations in parents of children with malignant diseses. American Journal of Psychiatry, 1964, 120,743-

Choron, J. Modern Man and Mortality. New York: Macmillan, 1964.

C1ayton, P.J., Desmarais, L. \& Winokur, G. A study of normal bereaverent. American Journal of Fsychiatry, 1968, 125, $168-178$.

Clayton, R.J. inalikas, J.A. \& Maurice, W.L. The depression of widowhood. British Journal of Psychiatry, 1972, 120,71-77.

Clayton, P.J. Hallkas, J.A. \& Maurice, W.L. The bereavenent of the widowed. Diseases of the Nervous System, 1971, 32 , $597-604$.

Cobb, B. Psychological impact of long lliness and death of a child on the family circle. Journal of Pediatrics, 1956. $49,746-751$. 
Cobb, S. \& Lindemann, E. Sympositm on management of Cocoanut Grove burns at Massachusetts General Hospital: Neuropsychiatric observations. Annele of Surgery, 1943, 117, 814-824.

Cobb, S. \& Lindemann, E. Enviromental factors in rheumatoid arthritis. Journai of the American Medical Association, $1939,113,568-670$.

Cohen, M. \& Lipton, L.M. Spontaneous Remission of schizophrenic psychosis following maternal death. Psychiatric Quarterly, 1950, 24, 716-725.

Cox, P.R. \& Ford, J.R. The mortality of widows shortly after widowhood, iancet, $1964,1,163$.

Crisp, A.H. \& Priest, R.G. Psychoneurotic states during the year following bereavement. Journal of Psychosomatic Research. $1972,16,351-355$.

Cumming, J. \& Cumming, E. Ego and Milieu: Theory and Practice of Enviromental Therapy. New York: Atherton, 1962.

Cutter, F. Some Fsychological problems in hemodyalys is. Omega, $1970,1,37-47$.

Dabrowski, k. Positive Disintegration. Bostons Little, Brown, 1964.

Dennehy, C.M. Childhood bereavement and psychiatric iliness. British Journal of Psychiatry, 1966, 112, 1049-1069.

Deutsch, H. Absence of grief. Psychoanalytic Duarterly, 1937, $9,12-22$.

Devereux, G. Primitive psychiatry, funerals, suicide and Mohave social structure. Bulletin of the History of Medicine, 1942 $11,522-542$.

Diagnostic and Statistical Manual of Mental Disorders, 2nd Ed.. (ESM-II). Washington: American Psychiatric Association, 1968.

Douglas, J.D. The Social Meanings of Suicide. Princeton, N.J.: Princeton University Press, 1967.

Edelson, S.R. \& Warren, P.H. Catatonic schizophrenia as a mourning process. Diseases of the Nervous System, 1963, $24,2-8$.

Eisendrath, R.M. Role of grief and fear of death of kidney transplant patients. American Journal of Psychiatry, 1969, $126,381-387$.

Eliot, T.D. The adjustment behavior of bereaved families: A new field of research. Social Forces, 1930, 8, 543-549. 
Eliot, T.D. The bereaved fanily. Annals of the American Acadeiny of Political and Social Sciences, 1.932, $160, \frac{184-190}{18}$

Eliot, T.D. War bereavement and their recovery. Marriage and Family Living, 1946, 8, 1-6.

Ellard, J. Emotional reactions associated with death. Medical Journal of Lustralia, 1968, 1, 979-983.

Engel, G.L. Is grief a disease? Psychosomatic Medicine, 1961, $23,18$.

Engel, G.L. Psychological Development in Health and Disease. Philadelphia: Saunders, 1962

Engel, G.L. Grief and grieving. American Journal of Nursing, $1964,64,93-98$.

Farberow, N. (ed.) Proceedings of the 4 th International Conference for suicide Prevention. Los Angelos: Delmar, 1968.

Farberow, N. Bibliography on Suicide and Suicide Prevention. Rockville, Md.: N.I.M.H. Publications, 1972

Farberow, N. \& Shneidman, E.S. The Cry for Help. New York: McGraw-Hi11, 1961.

Feifel, H. The Meaning of Death. New York: McGraw-Hill, 1959.

Feifel, H. Functions and attitudes toward death. Journal of the Long Is land Consultation Center, 1967, 5, 26-32.

Feifel, H. Attitudes toward death: A psychological perspective. Journal of Consulting and Clinical Psychology, 1969, 33, 292-295.

Feinberg,.D. Preventive therapy with siblings of a dying child. Journal of American Academy of Child Psvchiatry. $1970,94,644-668$.

Fenichel, 0 . The Psychoanalytic Theory of Neurosis. New York: Norton, 1945.

Festinger, L. Conflict, Decision and Dissonance. Stanford, Ca1.: Stanford University Press, 1964

Flave11, J.H. The Developmental Psychology of Jean Piaget. New York, Van Nostrand, 1963.

Foster, L.E., Lindemann, E. \& Fairbanks, R.J. Grief, Pastoral Counseling, 1950, 1, 28-30. 
Frawley, T.F. Use of hydrocortisone in acute hypoglycemia. Annals of the New York Acadeny of Science, 1955, 61, 464-470.

Frederick, J. Physiological reactions induced by grief. Omega, 1971, 2, 71-76.

Freud, S. Mourning and Melancholia. In Complete Psychological Works of Sigmund Freud. London: Hogarth, 1917, 152-170.

Friedman J. \& Zaris, D. Paradoxical response to the death of a spouse. Disesses of the Nervous System, 1964, 25,480-483.

Friedman, S.B., Chodoff, P., Mason, J.W. \& Hamburg, D.A. Parents and the death of a child. Pediatrics, 1963, 32, $610-625$.

Fritz, M.A. A study of widowhood. Sociology and Social Research, 1930, 14, 553-559.

Fulcomer, D.M. The adjustment behavior of some recently bereaved spouses. Ph.D. Dissertation, Northwesteen University, 1942

Fulton, R.L. Death and Identity. New York: John Wiley \& Sons, 1965.

Fulton, R.L. Death, grief and social recuperation. @mega, 1970, $2,22-28$.

Fulton, R.L. Contemporary funeral practices. In H.C. Raether (ed.) Modern Euneral Service. New York: Prentice-Ha11, 1971.

Fulton, R.L. Editorial comment. Omega, 1971, 2, 62-63.

Fulton, R.L. The clergyman and the funeral director: A study in role conflict. Social Forces, 1961, 39, 317-323.

Fulton, R.L. \& Fulton, J. A psychosocial aspect of terminal care: Anticipatory grief. Omega, 1971, 2, 91-100.

Gaylin, W. The Meaning of Despair. New York: Science House, 1968.

Geis, G. \& Fulton, R.L. Death and social values. Indian Journal of Social Research, 1962, 3, 7-14.

Gerber, I. Bereavement and the acceptance of professionaI service. Community Mental Health Journal, 1969, 5, 487-495.

Ginsburg. G.P. Public conceptions and attitudes about suicide. Journal of Health and Social Behavior,.1971, 12, 200-207.

Goldberg, M. \& Mudd, E.H. The effects of suicidal behavior upon marriage and the family. In H.L.P. Resnick (ed.) Suicidal Behavior: Diagnosis and Management. Boston: Little, Brown \& Co., 1968. 
Goldfogel, L. Working with the parent of a dying child. American Journal of Nursing, $1970,70,1675-1679$.

Gorer, G. Death, Grief and Momming. New Yorks Doubleday, 1967.

Granville, L. \& Grossman, R. Early bereavement and schizophrenia. British Journal of Psychiatry, 1966, 112, 1027-1034.

Greene, W.A. The psychological setting of the development of leukemia and lymphoma. Annals of the New York Academy of Science, $1966,125,794-801$.

Greenstein, F.I. Young, men and the death of a young president. In M. Wolfenstein and G. G. Kliman (eds.), Children and the Death of a President. New York: Doubleday, 1965 .

Greer, S. The relationship between parental loss and attempted suicide. British Journal of Psychiatry, 1964, 110, 698-704.

Gregory, I. Studies of parental deprivation in psychiatric patients. American Journal of Psychiatry, 1958, 115, 423-442.

Gregory, I. Anterospective data concerning loss of a parent. 1. Delinquency and High School drop-out. Archives of General Psychiatry, 1965, 13, 99-1.09.

Grollman, E.A. Explaining Death to Children. Boston: Beacon Press, 1967.

Guyton, A.C. Function of the Human Body. Philadelphia: Saunders, 1969.

Habenstein, R.W. \& Lamers, W.M. Funeral Customs Around the if World. Milwaukee: Bulfin, 1961.

Hallett, J.W., Leopold, I.H. \& Vogel, A.W. Treatment of experimental herpes simplex keratitis in the rabbit. AMA Archives of Ophthalmology, 1951,46, 33-41.

Halpern, W.I. Some psychiatric sequelae to crib death. American Iournal of Psychiatry, $1972,129,398-402$.

Hamovitch, M.B. The Parent and the Fatally I11 Child. Los Angelos: Delmar, 1964.

Harvey, O.J., Hunt, D.E. \& Schroeder, H.M, Conceptual Systems and Personality Organization. New York: Wiley, 1961.

Heckel, R.V. The day the president was assassinated: Patients reactions in one mental hospital. Mental Hospital, 1964, $15,48-50$.

Heider, F. The Psychology of Interpersonal Relations. New York : Wiley, 1958 . 
Helvic, c.o. An epidernic of hysteria in a high school. Journal of Schocl Health, 1968, 33, 505-509.

Henslin, J.M. Guilt and guilt neutralization: Response and adjustment to suicide. In 3.D. Douglas (ed.) Deviance and Respectability: The Social Constriction of Moral Meaning. New York: Basic Books, 1970.

Herzog, A. \& Resnick, H.L.P. A clinical study of parental response to adolescent suicide with recommendations for approaching the survivors. In N.L. Farberow (ed.) Proceedings of the 4th International Conference for Suicide Prevention. Los Angelos: Delmar, 1958.

Hilgard, J.R. Early parental deprivation in schizophrenia and alcohol ism. American Journal of Orthopsychiatry, 1963, 3, 409-420.

Hilgard, J.R. \& Newman, M.F. Anniversaries in mental illness. Psychiatry, 1959, 113-123.

Hilgard, J.R. \& Newman, M.F. Evidence for functional genes is in mental illness: Schizophrenia, depressive psychosis and psychneurosis. Journal of Nervous and Mental Disease, 1961, $82,3-16$.

Hilgard, J.R. \& Newman, M.F. Parental loss by death in childhood as an etiological factor among schizophrenic and alcoholic patients compared with a non-patient community sample. Journal of Nervous and Mental Disease, 1963, 87, 14-28.

Hill, O.W. The association of childhood bereavement with suicidal attempts in depressive illness. British Journal of Pŝychiatry, 1969, 115, 301-304.

Hill, 0.W. Some psychiatric non-sequelae of childhooh bereavement, British Journal of Psychiatry, 1970, 116, 679-680.

Hinton, J. Dying - London: Penguin, 1967.

Hobson, C.J. Widows of Blackton. New Society, 1964, 13-19.

Holland, J., Harris, S. \& Holmes, J. Psychological response to death of an icientical twin by the surviving twin with the same disease: Concurrent malignant melanoma in identical twins of triplets. Omega, 1971, 2, 160-167.

Hopkinson, G. \& Reed, G. Bereavement in childhood and depressive psychosis. British Journal of Psychiatry, 1966, 112, 459-463.

Howells, J.G. Theory and Practice of Family Psychiatry, New York: Brunner/Mazel, 1971. 
Irion, P. The Funeral and the Mcurners. New York: Abigcion, 1954.

Jackson, E,N. Telling a Child About Death, Now York : Channel Press, 1965

Jackson, E.N. Understanding Grief. Nashville: Abingdon, 1957.

Jackson, E.N. Grief and religion. In H.Feifel (ed.) The Meaning of Death. New York: McGraw-Hi11, 1960.

Jacobs, J. Adolescent Suicide. New York: Wiley Interscience, 1971.

Jacobson, E. Depressinn: Comparative Studies of Normal, Neurotic and Psychotic Conditions. New York: International Univers $i=$ ties Press, 1971 .

Jakab, I. \& Howard, M.C. Art therapy with a 12-year old girl who witnessed a suicide and developed school phobia. Psychotherapy and Psychosomatics, 1969, 17, 309-310.

Janis, I.L. Problems of theory in the analys is of stress behavior. Journal of Social Issues, 1954, 10, 12-25.

Janis, I.L. Psychological stress: Psychoanalytic and behavioral studies of surgical patients. London: Chapman \& Hail, 1958 .

Jensen, G.D. \& Wallace, J.G. Family mourning process. Family Process, $1967,6,56-66$.

Johannsen, D.E. Reactions to the death of President Roosevelt. Journal of Abnormal and Social Psychology, 1946, 41, 218-222.

Kaij, L. Malinguist, A. \& Nilsson, A. Psychiatric aspects of spontaneous abortion: II. The importance of bereavement, attachment and neurosis in early life. Journal of Psychosomatic Diseases, 1969, 13, 53-59.

Kalish, R.A. An approach to the study of death attitudes. American Behavioral Scientist, 1963, 6, 68-70.

Kalish, R.A. Dealing with the grieving family. RN, 1963, 26, $81-84$.

Kalish, R.A. Some vaiables in death attitudes. Journal of Social Psychology, 1963, 59, 137-145.

Kalish, R.A. Death and bereavement: A bibliography. Journal of Human Relations, 1965, 13, 118-141.

Kalish, R.A. Social distance and the dying. Community Mental Health Journal, 1966, 2, 152-155. 
Kalish, R.A. Effects of death uoon the family. In L. Pearson(ed), Death and Dying: Current Issues in the Ireatment of the Dying Person. Cleveland: Case Western Reserve Press, 1969.

Kastenbaum, R. \& Aisenberg, R.B. The Psychology of Death. New York; Springer, 1972.

Kay, D.W., Roth, M. \& Hopkjns, B. Etiological Eactors in the causations of affective disorders in old age. Journal of Mental Science, 1955, 101, 302-

Kelly, G.A. A Theory of Personality: The Psychology of Fersonal Constructs. New York: Norton, 1963.

Kennard, E.A. Hopi reactions to death. American Anthropolagical Review, 1950, 15, 635-643.

Kenne11, J.H., Slyter, H. \& Klaus, M.H. The mourning response of parents to the death of a newborn infant. New England Journal of Medicine, 1970, 283, 344-349.

Kephart, W.M. Status after death. American Sociological Review, $1950,15,635-643$.

Kirkpatrick, J., Samuels, S., Jones, H. Zweibelson, I. Bereavement and school adjustment. Journal of School Psychology, 1965, $3,58-63$.

Kirtley, D.D. \& Sacks, J.M. Reactions of a psychotherapy group to ambiguous circumstances surrounding the death of a group member. Journal of Consulting and Clinical Psychology, 1969, 33, 195-199.

Klein, M. Mourning and its relation to manic-depressive states. International Joirnal of Psychoanalysis, $1940,21,125-143$.

Kligfeld, B. \& Krupp, G. Sexual adjustment of widows. Sexology, 1966, November, 230-233.

Knight, J.A. \& Herter, F. Anticipatory grief. In A.H. Kutscher, (ed.) Death and Bereavement. Springfield, I11.: Charles C. Thomas, 1969.

Koranyi, E.K. Psychodynamic theories of the 'Survivor Syndrome'. Canadian Psychiatric Association Journal, 1969, 14, 165-174.

Knudson, A.G. \& Natterson, J.M. Practice of pediatrics - Participation of parents in the hospital care of fatally ill children. Pediatrics, $1960,26,482-$

Kraus, A.S. \& Lilienfeld, A.M. Some epidemiological aspects of the high mortality rate in the young widowed group. Journal of Chronic Diseases, 1959, 10, 207- 
Krupp, G.R. The bereaved reaction: A special case of separation anxiety - sociccultural considerations. Fsychoanalytic Study of Society, $1.962,2,42-74$.

Krupp, G.R. Identification as a defense against anxiety in coping with loss. International Journal of Psvchoanalysis. $1965,46,303-314$.

Kubler-Ross, E. On Death and Dying. London: Collier Macmillan, 1969.

Krupp, G.R. \& Kligfeld, B. Bereavement reaction: A crosscultural evaluation. Jounnal of Religion and Health, 1962 , 1. $222-246$.

Kutscher, A.H. Death and Bereavement. Springfield, I1l: Charles C. Thomas, 1969

Kutscher, A.H. \& Kutscher, L.G. For the Bereaved. New York: Frederick Fell, Inc., 1971.

Kutscher, A.H., Schoenberg, B. \& Carr, A.C. Thanatology as related to dentistry. Journal of the American Dental Association, $1970,81,1373-137 \%$.

Lamers, W.M. Colloquium on "Grief and Mourning". San Mateo County, California, Division of Mental Health Services, December, 1972.

Langer, M. Learning to Live as a Widow. New York: J. Messmer,1957.

Laufer, M. Object loss and mourning during adolescence. Psychoanalytic Study of the Child, 1966, 21, 269-293.

Lehrman, S.R. Reactions to untimely death. Psychiatric Quarterly, 1956, 30, 564-578.

Leighton, A. Psychological factors in major disasters. Medical Progress Reports, University of Rochester, 1951.

Lester, G. \& Lester, D. Suicide: The Gamble with Death. Englewood Cliffs, N.J.: Prentice-Hal1, 1971.

Lester, D. \& Kan, E.G. Effect of a friend dying on attitudes toward death. Journal of Social Psychology, 1971, 83, 249-150.

Levinson, B.M. The pet and the child's bereavement. Mental Hygiene, 1967, 51, 197-200.

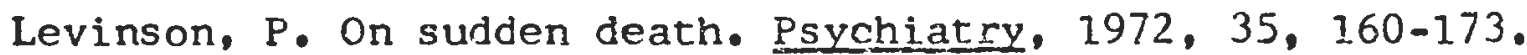

Lifton, R.J. Psychological effects of the atomic bomb in Hiroshima: The theme of death. Daedalus, 1963,92, 462-497. 
Lifton, R.J. Boundaries: Psychological Man in Revolution. New York: Vintage Books, 1967.

Lifton, R.J. Death in Life: Survivors of Hiroshima. New York: Random House, 1967.

Light, D.W., Jr. Psychiatry and suicides Management of a mistake. American Journal of Sociology, 2972, 5, 77-87.

Lindemann, E. Symptomology and management of acute grief. American Journal of Psvchiatry, 1944, 101

Lindemann, E. Psychiatric problems in the conservative treatment of ulcerative colitis. AMA Archives of Neurology and Psychia try, $1.945,53,322-3 \overline{24}$.

Lindemann, E. Modifications in the course of ulcerative colitis in relation to changes in life situations and reaction patterns. Proceedings of the Association for Research in Nervous and Mental Diseases, 1950, 2, 699.

Lindemann, E. Psychological factors as stressor agents. In J.M. Tanner (ed.) Stress and Psychiatric Disorders: Mental Health Research Fund Proceedings. Oxford: Blackwel1, 1960.

Lindemann, E, \& Greer, I.M. A study of grief: Emotional response to suicide. Pastoral Esychology, 1953, 4, 9-13.

Lipson, C. Derial and mourning. International Journal of Psychoanalysis, $1963,44,104-107$.

Litman, R.E. When patients commit suicide. American Journal of Psychotherapy, 1964, 19, 570-576.

Loeb, A, Feshbach, S, Beck, A.T. \& Wolf, A. Some effects of reward upon the social perception and motivation of psychiatric patients varying in depression, Journal of Abnormal and Social Psychology, 1964, 68, 609-616.

Louria, D.B. Experience with a diagnosis of a disease due to opportunistic fungi. Annals of the New York Academy of Science, $19062,98,617-627$.

Loveland, G.G. The effects of bereavement on certain religious attitudes and behavior. Sociological Symposiums, Fall 1968, $1,17-27$.

Maddison, D. \& Viola, A. The health of widows in the year following bereavement. Journal of Psychosomatic Research, $1968,12,297-306$.

Maddison, D. \& Walker, W.L. Factors affecting the outcome of conjugal bereavement. British Journal of Psychiatry, 1967. 113, $1057-1067$. 
Mandler, G. The intermption of nehavinr. Nebraska Symposium on Motivation, i964, 12, 163-219.

Markusen, E. E Fulton, R. Childhood bereavenent and behavior disorders: A critical review. Omesa, 1971, 2, 101-106.

Marris, : P. Widows and Their Families. London: Routledge, 1958.

Masserman, J.H. Emotional reactions to death and suicide. American Practitioner, 1954, 5, 41-46.

Matchett, W.F. Repeated hallucinatory experiences as part of the mourning process among the Hopi indian female. Psychiatry, 1972, 35, 185-194.

McLean, R. The role of adrenocorticotrophic and adrenocorticosteroid hormones in the treatment of tuberculosis. Annals of the New York Academy of Science, 1963, 106, 130-147.

McConville, B.J., Boag, L.C. \& Purokit, A.P. Mourning processes in children of varying ages. Canadian Psychiatric Association Journal, $1970,15,253-255$.

McDermott, N.T. \& Cobb, S. Psychiatric survey of 50 cases of brinchial asthma. Journal of Psychosomatic Medicine, 1939, 1. 203-244.

Mehrabian, A. An Analysis of Personality Theories. Englewood Cliffs, N.J.: Prentice-Hali, 1968.

Miller, G.A., Galanter, E., \& Pribam, K.A. Plans and the Structure of Behavior. New York: Holt, Rinehart \& Winston, 1960.

Moreno, J.L. The social atom and death. Sociometry, 1947, $84,80-84$.

Moritz, A.R. \& Zamchick, N. Sudden and unexpected death of young soldiers. Archives of Pathology, 1946, 42, 459-494.

Morse, T.S. On talking to bereaved burned children. Journal of Irauma, 1971, 11, 894-895.

Moss, L.M. \& Hamilton, D.M. Psychotherapy of the suicidal patient. American Journal of Psychiatry, 1956, 113, 814-820.

Munro, A. Childhood parent loss in a psychiatriccally normal population. British Journal of Preventive and Social Medicine, $1965, \frac{19,69}{190}$

Munro, A. Parental deprivation in depressive patients. British Journal of Psychiatry, 1966, 112, 443-457. 
Muslin, H.Y., Gyartas, $K, \&$ Pieper, H. Separation experience and cancer of the breast. Annals of the New York Academy of Science, $1960,125,802-506$.

Natterson, J.M. \& Knudson, A.G. Observations concerning the fear of death in fatally ill children and their mothers. Psychosomatic Medicine, 1960, 22, 456-463.

Nemtzow, J. \& Lesser, S.R. Reactions of children and parents to the death of President Kennedy. American Journal of Orthopsychiatry, $1964,34,280-281$.

Newcomb, T.M. Personality and Social Change. New York: Holt-Rinehart, 1943

Nolfi, M. Families in grief: The question of casework intervention. Social Work, 1967, 12, 40-46.

Opler, M.E. The reactions to death among Mescalero Apaches. Southuest Journa1 of Anthropology, 1946,2,454-467

Orbach, C.E. The multiple meanings of the loss of a child. American Journal of Psychotherapy, 1959, 13, 906-913.

Orbach, C.E., Sutherland, A.M. \& Bozeman, M.E. Psychological impact of cancer and its treatment: The adaptation of mothers to the threatened loss of their children through leukemia: Part II. Cancer, 1955, 8, 20-33.

Orlansky, H. Reactions to the death of President Roosevelt. Journal of Social Psychology, 1947, 26, 235-266.

Ormsby, H.L., Dempster, G. \& Van Rooyer, C.E. Effect of cortisone on experimentally induced herpetic keraritis in the rabbit. American Journal of Ophthalmology, 1951, 34, $60-68$.

Osgood, C.E. \& Tannenbaum, P.H. The principle of congruity in the prediction of attitude change. Psychological Review, $1955,62,42-55$.

o'Toole, J.K. Mourning a:president: The reactions of a group of emotionally disturbed adolescent girls to the assassination. Psychiatric Quarterly, 1966, 40, 737-755.

Parad, H.J. Crisis Intervention: Selected Readings. New York: Family Service Association of America, 1965.

Parad, H.J. Selected Bibliography: Crisis-oriented Short-term Therapy. Berkeley, Calif.: School of Social Welfare, 1969.

Parkes, C.M. Effects of bereavement on physical and mental health - A study of the medical records of widows. British Journal of Medicine, 1964, 2, 274-279. 
Parkes, C.M. Recent bereavenent as a cause of mental illness. British Journal of Psychiarry, 1964(a), 110, 198-204.

Parkes, C.M. Grief as an illness, New Society, 1964(b), 3, 11.

Parkes, C.M. Bereavement and mental illness. British Journal of Medical Psychologi, 1965, 38, 1-12.

Parkes, C.M. The psychopathology of grief. British Journal of Medical Psycholozy, 1965a,38, 25-26.

Parkes, C.M. The psychosomatic effects of bereavement. In o.W. Hill (ed.) Modern Trends in Psuchosomatic Medicine. London, Butterworth, 1970 .

Parkes, C.M. "Seeking" and "finding" a lost object: evidence from recent studies of the reaction to bereavenent. Social Science and Medicine, 1970(a), 4, 187-201.

Parkes, C.M. The 1st year of bereavement: A longitudinal study of the reaction of Londion widows to the death of their husbands. Psychiatry, 1971, 33, 444-467.

Parkes, C.M. Determination of outcome of bereavement. Proceedings of Research in the Sociology of Medicine. 1971(a), $64,279$.

Parkes, C.M. Bereavement: Studies of Grief in Adult Life. New York: International Universities Press, 1972.

Parkes, C.M. \& Brown, R.J. Health after bereavement: A controlled stüdy of young Boston widows and widowers. Psychosomatic Medicine, $1972,34,449-461$.

Parkes, C.M., Benjamin, B. \& Fitzgerald, G. Broken heart: A statistical study of increased mortality among widowers. British Medical Journal, 1969, 1, 740-743.

Paul, L. Crisis intervention. Mental Hygiene, 1966, 50, 141-145.

Paul, N.L. The use of empathy in the resolution of grief. Perspectives in Biology and Medicine, 1967, 11, 153-168.

Paul, N.L. \& Grosser, G.H. Operational mourning and its role in conjoint family therapy. Community Mental Health Journal. $1965,1,339-345$.

Piaget, J. The Psychology of Intelligence. Patterson, N.J.: Littlefield-Adams, 1960.

Pollock, G.H. Mourning and adaptation. International Journal of Psychoanalys is, $1961,42,347-361$. 
Pretzel, P. Understanding and Counseling the Suicidal Person. New York: Abingdon, 1972 .

Racy, J. Death in an arab culture. Annals of the New York Academy of Science, 1969, 164,877-380.

Random House Dictionary of the English Language: The Unabridged Edition. New York: Random House, 1967.

Rees, W.D. The hallucinatory and paranormal reactions of bereavement. M.D. Thesis, Oxford, London, 1970.

Rees, W.D. \& Lutkins, S.G. The mortality of the bereaved . British Medical Journal, 1967, 4, 13-16.

Resnick, H.L.P. Psychological re-synthes is: A clinical approach to the survivors of a death by suicide. International Psychiatry Clinics, $1969,6,213-224$.

Resnick, H.L.P. Suicidal Behaviors: Diagnosis and Management. Boston: Little, Brown \& Co., 1968.

Rochlin, G. Loss and restitution. Psychoanalytic Study of the Child, 1953, 8, 288-309.

Rochlin, G. Griefs and Discontents: The Eorces of Change. Boston: Little, Brown \& Co., 1965.

Rogers, C.R. Client Centered Therapy. Boston: Houghton-Mifflin, 1951.

Rogers, C.R. \& Dymond, R.F. (eds.) Psychotherapy and Personality Change. Chicago: University of Chicago Press, 1954.

Rosenbaum, M. Emotional aspects of wartime separation. Family, $1944,24,337-341$.

Rosenthal, P. The death of the leader in group psychother\&py. American Journa? of OEthopsychiatry, 1947, 17, 266-277.

Rosenweig, S. Sibling death as a psychological experience with special reference to schizophrenia. Psychoanalytic Review, $1943,30,177-186$

Rosenweig, S. \& Bray, D. Sibling death in the anamneses of schizophrenic patients. AMA Archives of Neurology and Psychiatry, $1943,49,71-92$.

Rosner, A.A. Mourning before the fact. Journal of the American Psychoanalytic Association, 1962, 10, 564-570. 
Ruitenbeek, H.M. Death Interpretations. New York: De11, 1969.

Salk, L., Finch, S.M. \& Belmon, H.S. Sudden Infant Deatin: Impact on family and physician. Clinical Pediatrics, 1971, $10,248-250$.

Salter, A. The Case Against Psychoanalysis. New York: Citadel Press. $1 \overline{963}$.

Saucier. J.F. Anthropology and psychodynamics of mourning. Canadian Psychiatric Association Journal, 1967, 12, 477-496.

Schacter, S. \& Singer, J.E. Cognitive, social and physiological determinants of emotional states. Psychological Review, $1962,69,379-399$.

Schlesinger, B. \& Macrae, A. The widow and widower and remarriage: Selected findings. Omega, $1971,2,10-18$.

Schmale, A.H.J. \& Iker, H.P. The affect of helplessness and the development of cancer. I. Identification of uterine cervical cancer in women of atypical cytology. Psychosomatic Medicine, 1966, 28, 714-721.

Schoenberg. B. A survey of advice of physicians for the bereaved. General Practice, 1969, 40, 105-110.

Schoenberg, B, Carr, A.C., Peretz, D. \& Kutscher, A.H. Physicians and grief. General Practice, 1969, 40, 115-118.

Schoenberg, B., Carr, A.C., Peretz, D. \& Kutscher, A,H. Loss and Grief: Psychological Management in Medical Practice. New York: Columbia University Press, 1970.

Scott, W.C. Mania and mourning. International Journal of Psychoanalys is, $1964,45,373-379$.

Shapiro. D. Neurotic Styles. New York: Basic Books, 1965.

Shneidman, E.S. Essays in Self-Destruction. New York:

Science House, 1967

Shneidman, E.S. Classification of suicidal phenomena. Bulletin of Suicidology, July, 1968, 1-10.

Shneidman, E.S. The Psvchology of Suicide. New York: Science House, 1970 .

Shneidman, E.S, and Farberow, N.L. Clues To Suicide. New York: McGraw-Hil1, 1957. 
Shneidman, E.S., Farbero, N.L. \& Litnan, R.E. A taxonomy of death: A psychological poirt of view. In N.L. Farberow and F.S. Shneidman (eds.), The Cry for Help. New York: McGraw-Hi11, 1961.

Shoor, M. \& Speed, M.H. Death, delinquency and the mourning process. Psychiatric Quarterly, 1963, 37,,540-548.

Siggins, L.D. Mourning: A critical survey of the literature. International Journal of Psychiatry, 1967, 3, 418-438.

Silveztnan, P.R. Services to the widowed, lst step in a program of preventive intervention. Community Mental Health Journal, $1967,3,37-44$.

Silverman, P.R. The widow as a caregiver in a program of preventive intervention with other widows. Mental Hygiene, $1970,54,540-547$.

Solnit, A.J. \& Green, M. Psychological considerations in the management of deaths on pediatric hospital services Part I: The doctor and the child's family. Pediatrics, 1959, $24,1.06-112$.

Stein, Z. \& Susser, M.W. Widowhood and mental illness, British Journal of Preventive and Social Medicine, 1969, 23, $106-108$.

Stengel, E. Further studies on pathological wandering. Journal of Mental Science, 1943, 89, 224 -

Stenge1, E. Studies on the psychopathology of compulsive wandering. British Journal of Medical Psychology, 1939, $18,250-$

Stern, K. \& Lariviere, A. Observations psychiatrique sur de deul. Un Medical Canada, 1957, 86, 1082.

Stern, K., Williams, G.M. \& Prados, M. Grief reactions in later 1ife. American Journal of of Psychiatry, 1951, 108, 289-294.

Stone, H.W. The grief reactions of middle-aged spouses: Suicide and non-suicide compared. Ph.D. Dissertation, School of Theology, Claremont, Calif., 1971.

Sugar, M. Normal adolescent mourning. American Journal of Psychotherady, 1968, 22, 258-269.

Sullivan, H.S. The Interpersonal Theory of Psychiatry. New York: Norton, 1953 .

Swanson, D.W. Suicide in identical twins. American Journal of Psychiatry, 1960, 116, 934-935. 
Symposium Report on Bereavement. British Medical Journal, $1967,3,232$.

Talcaferro, W.H. Modification of the immune response by radiation and cortisone. Annals of the New Yorik Academy of Science, $1957,69,745-755$.

Toffler, A. Future Shock. New York: Random House, 1970.

Toynbee, A. Man's Concern with Death. New York: Mcgraw-Hi11,1969.

Tyhurst, J.S. Individual reactions to community disaster: The natural history of psychiatric phenomena. American Journal of Psychiatry, L950, 107, 764-769.

Volkan, V.D. Normal and pathological grief reactions: A guide for the family physician. Virginia Medical Monthly, $1966,93,651-666$.

Volkan, V.D. Typical findings in pathological grief. Psychiatric Quarterly, 1970, 44, 231-250.

Volkan, V.D. A study of patient's "Re-grief Work" - through dreams, psychological tests and psychoanalysis. Psvchiatric Quarterly, 1971, 45, 255-273.

Volkan, V.D. The linking objects of pathological mourners. Archives of General Psychiatry, 1972, 27, 215-221.

Volkart, E.H. \& Michael, S.T. Bereavement and mental health. In A.H. Leighton, J.A. Clausen \& R.N. Wilson (eds.)

Explorations in Social Psychiatry. New York: Basic Books, 1957.

Völlman, R.R., Ganzert, A., Picher, L. \& Williams, W.V. Reactions of family systems to sudden and unexpected death. Omega, 1971, 2, 101-106.

Wah1, C.i. The differential diagnosis of normal and neurotic grief following bereavement. Psychosomatics, 1970, 11, $104-106$.

Waller, W. The Family: A Dynamic Interpretation. New York: Dreyden, 1951.

Werner, H. Comparative Asvchology of Mental Development.

New York: International Universities Press, 1957.

Werner, $\mathrm{H}$. The concept of development from a comparartive and organismic view. In D.B. Harris (ed.) The Concept of Development. Minneapolis: University of Minnesota Press, $1951 \mathrm{a}$

Westberg, G.E. Minister and Doctor Meet. New York: Harper, 1962. 
Weston, D.L. \& Irwin, R.C. Preschool child's response to the death of infant sibling. American Journal of Diseases of Children, $1963,106,564-567$.

Whitis, P.R. The legacy of a child's suicide. Family Process, $1968,7,159-169$.

Wolff, H.G. Stress and Disease. Springfield, Ill.: Charles C. Thomas, 1953 .

Wolfenstein, M. \& Kliman, G. Children and the Death of a President: Multidisciplinary Studies, Garden City, $\mathrm{N} . \bar{Y}_{0}$ : Doubleday, 1965 .

Wolff, K.H. A partial analysis of student reaction to president Roosevelt's death. Journal of Social Psychology, 1947, $26,35-53$.

Woodburne, L.S. The Neural Basis of Behavior. Columbus: Merril1, 1967.

Wretmark, G. A study in grief reactions. Acta Psychiatrica et Neurologique Scandanavia Supplement, $1 \overline{959}, 136,292$.

Yamamoto, J., Okonogi, K., Iwasaki, I. \& Yoshimura, S. Mourning in Japan. Anerican Journal of Psychiatry, 1969, $125,1660-1665$.

Young, W.H. Death of a patient during psychotherapy. Psychiatry, $1960,23,103-108$

Young, M., Benjamin, B., \& Wallis, C. The mortality of widows. Lancet, 1963, 2 454-456. 